\title{
THERMOLYSIS OF POLYSTYRENE
}

\author{
by \\ Yan Simard, B. Eng. \\ Department of Chemical Engineering \\ McGill University \\ Montreal
}

May, 1994

A Thesis submitted to the Factulty of Gaduate

Studies and Research in partial fulfillment of the Requirements for the degree of Master of Engineering

(c) Yan Simard, 1994 


\begin{abstract}
Styrene was recovered from polysityrene (rrolecular weight of 138002 ) by thermolysis in a nitıcgen atmosphere at temperatures between $368^{\circ} \mathrm{C}$ and $407^{\circ} \mathrm{C}$. The results were independent of the initial weight of polystyrene which was varied between 30 and 480 grarns. Up to $70 \%$ of the polystyrene was converted to styrene. The styrene yield increased with temperature. At higher temperatures, the residue left in the: reactor consisted mainly of styrene monomer, dimer and trimer ( $\mathrm{MW}$ of 190). The maximum rate constant of volatile production was found to fit a first order model. The activation energy obtained was $166.5 \mathrm{~kJ} / \mathrm{mol}$, which is in accordanco with literature values.
\end{abstract}




\section{RÉSUMÉ}

Le styrène a été récupéré du polystyrène (poids moléculaire de 139000) par thermolyse dans une atmosphère d'azote à une température entre $368^{\circ} \mathrm{C}$ et $407^{\circ} \mathrm{C}$. Les résultats étaient indépendants du chargement initial de polystyrène, ce chargement a été varié entre 30 et 480 grammes. Jusqu'à $70 \%$ de polystyrène à été transformé en styrène. La production de styrène augmente avec la température. Aux températures élevées, le résidu restant dans le réacteur était composé principalement de monomère, dimère et trimère du styrène (poids moléc. de 190). Le taux maximum de production de matières volatiles obtenues correspondait à une réaction du premier ordre. L.'énergie d'activation obtenue est de $166.5 \mathrm{~kJ} / \mathrm{mol}$, ce qui est an accord avec les valeurs dans la littérature. 


\section{ACKNOWLEDGEMENTS}

I would like to thank my research supervisors, Dr. D.G. Cooper and Dr. M.R. Kamal for their continuous guidance and support.

I greatly appreciated the time spent in the lab with my fellow co-workers, Bill McCaffrey, Mike Brues, John Campanelli and Paul Lageraaen. I also want to thank my friends from the Falcon Research Group, Mike Zenaitis, Steve Wenthworth, Scot Hughes, Benjy Wentcure, Jeff Barriga and Dave Quesnel and my T-H comrades, Tony Pillo and John Keleris for their encouragement.

From the our department, I wish to thank Jean Dumont, Anne Prihoda and Pat Fong for giving me assistance throughout my stay.

From the department of chemistry here at McGill, thanks to Françoise Sauriol for the NMR analysis.

This work was supported by the Fonds pour la Formation de Chercheurs at l'Aide à la Recherche, the National Science and Engineering Reseach Council and by Martinex Science, Inc.

Finally, I wish to express my gratitude to my mother, Diane Lafond, my father, Michel and my brother, Patrick, for being very supportive and encouraging. 


\section{TABLE OF CONTENTS}

1. INTRODUCTION ................................................................

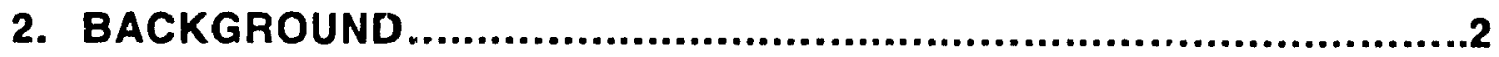

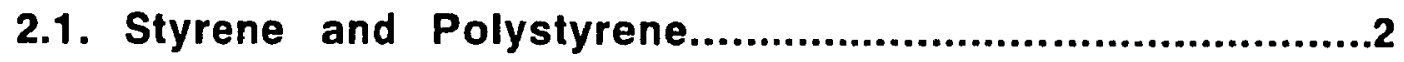

2.2. Degradation of Polyiner ..............................................6

2.3. Mechanism of Thermolysis of Polystyrene.....................6

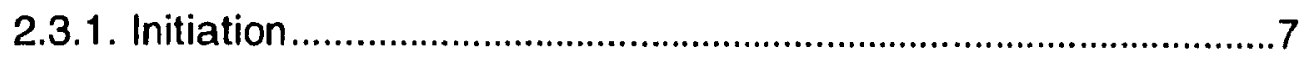

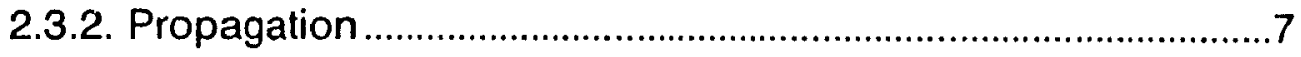

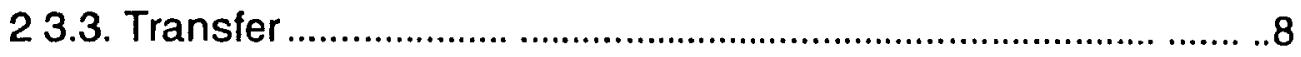

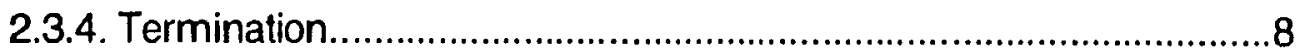

2.4. Results of Previous Studies......................................8

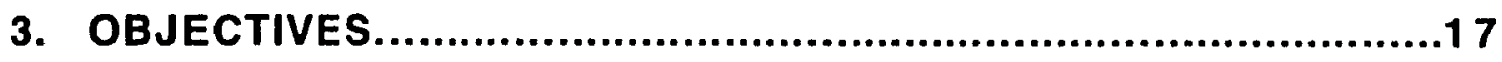

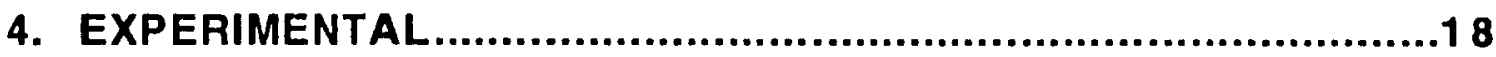

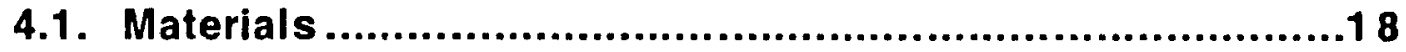

4.2. Apparatus.......................................................... 8

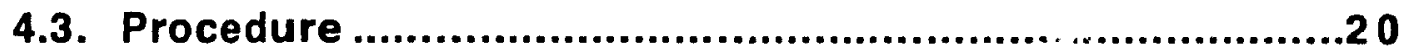

4.4. Analytical techniques..............................................22

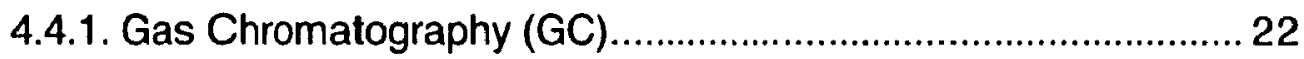

4.4.2. Gas Chromatography-Mass Spectroscopy (GC-MS)............. 25

4.4.3. Nuclear Magnetic Resonance (NMR) ...................................... 25

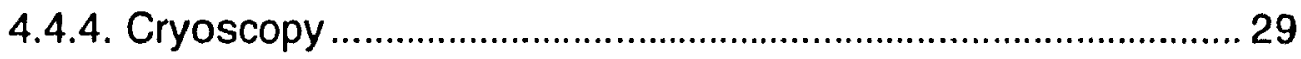

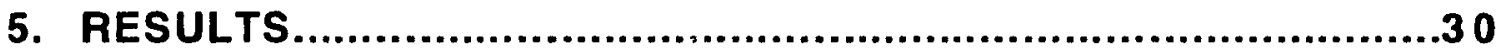

5.1. Mass Balances.......................................................30

5.2. Yield of Volatile Product............................................3 2

5.3. Composition of Volatile Product ...................................32

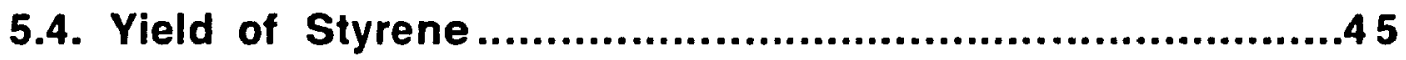

5.5. Yield of Dimer .........................................................45

5.6.Yield of Toluene.........................................................46

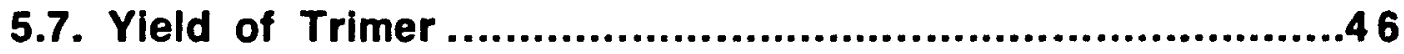




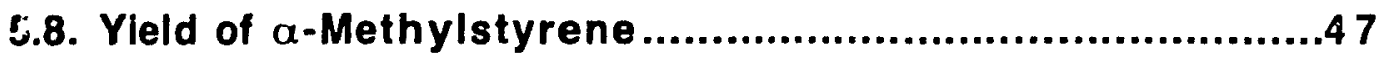

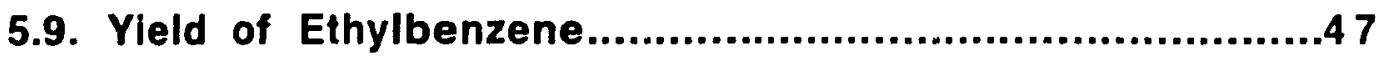

5.10. Yield of 1,3-Diphenylpropane...................................48

5.11. Amount of Residue................................................6 3

5.12. Residue composition...........................................6 3

6. DISCUSSION.............................................................67

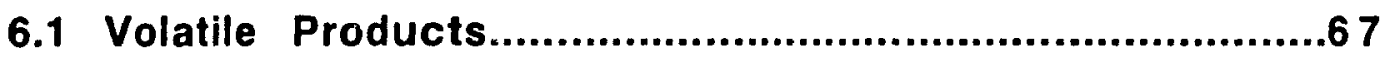

6.2. Residue.............................................................. 4

6.3. Kinetics ................................................................... 7

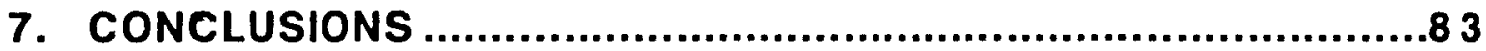

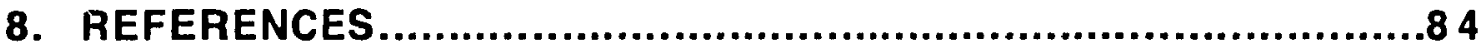




\section{LIST OF TABLES}

Table 2.1, Characteristic of Radical Chain Scission Degradation Process

Table 2.2, Past Work in Polystyrene Degradation .............................................. 16

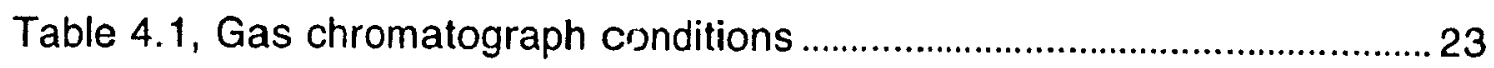

Table 5.1. Mass Balance for Experiments .........................................................

Table 5.2, Data of Integration of ${ }^{1} \mathrm{H}$ NMR for Experiments..............................66

Table: 6.1, Rate Constants for Experiments................................................ 81

Table 6.2, Comparison of activation energies for polystyrene thermal degradation. 


\section{LIST OF FIGURES}

Figure 21 , Structures of styrene monomer, dimer, trimer and polymer..............4

Figure 2.2, Addition polymerization of polystyrene ...........................................5

Figure 2.3, Alkylation of benzene with ethylene to form ethylbenzene, followed by dehydrogenation. ................................................................5

Figure 2.4: Reaction (1), initiation mechanism ................................................. 13

Figure 2.5: Reaction (1), intramolecular hydrogen transfer.............................. 14

Figure 2 6: Reaction (1), formation of tolyl and phenylethyl radicals................ 15

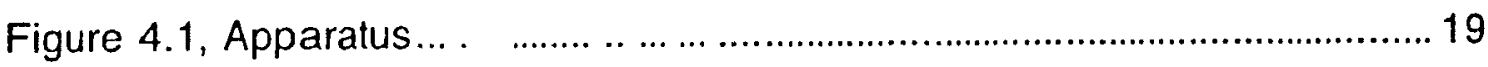

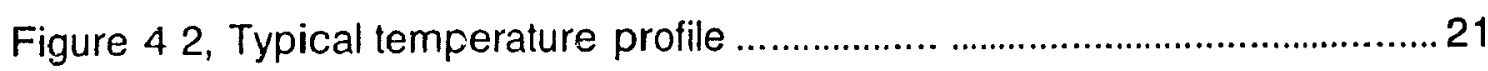

Figure 4.3, Gas chromatogram of the ninth volatile fraction of the experiment run at $390^{\circ} \mathrm{C}$ for 32 minutes........................................ 24

Figure 4.4, Mass spectrum of peak 16.56 of gas chromatogram of Figure

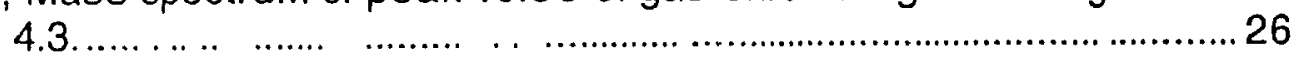

Figure 4 5, NMR of startıng material (polystyrene) ......................................... 27

Figure 4.6, NMR of residue, Polystyrene thermolysed for 33 minutes at

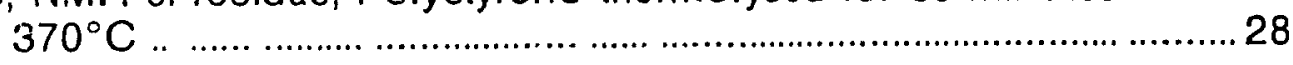

Figure 5.1, Volatile yield as a function of time for different temperatures......... 33

Figure 52 , Volatıle yicld as a function of temperature for 30 minutes reaction time.

Figure 5.3, Volatile composition as a function of time at different temperatures.....

Figure 5.4, Volatile composition as a function of time at different temperatures..

Figure 5.5, Volatile composition as a function of time at different temperatures................................................................................. 38

Figure 5.6, Volatile composition as a function temperature ................................ 41

Figure 5.7, Volatile composition as a function temperature ................................ 42

Figure 5.8 , Volatile composition as a function temperature ............................... 43 
Figure 5.9, Volatile composition as a function temperature.

Figure 5.10, Styrene proauction as a function of time for different temperature.

Figure 5.11, Styrene yie!ds as a function of temperature for 30 minutes reaction and for different charges

Figure 5.12, Dimer production as a function of time for different temperature.

Figure 5.13, Dimer yield as a function of temperature for 30 minutes reaction and for different charges...

Figure 5.14, Toluene production as a function of time for different temperature. ... .... . .............................................

Figure 5.15, Toluene yields as a function of temperature for 30 minutes reaction and for differeni charges ........................... . . . ... ... 54

Figure 5.16, Trimer production as a function of time for difierent temperature

Figure 5.17, Trimer yield as a function of temperature for 30 minutes reaction and for different charges

Figure 5.18, a-Methylstyrene production as a function of time for different temperature

Figure 5.19, a-Methylstyrene yield as a function of temperature for 30 minutes reaction and for different charges.

Figure 5.20, Ethylbenzene production as a function of time for different temperature.

Figure 521 , Ethylbenzene yield as a function of temperature for 30 minutes reaction and for different charges ............... . . .60

Figure 5.22, 1,3-diphenylpropane production as a function of time for different temperature.

Figure 5.23, 1,3-Diphenylpropane yield as a function of temperature for 30 minutes reaction and for different charges

Figure 5.24, Residue yields as a function of temperature for 30 minutes reaction and for different charges

Figure 5.25, Cryoscopic molecular weight of residue as a function of volatile yield

Figure 6.1, Overall rate of volatile production as a function of 
temperature from different sources.

.70

Figure 6.2, Styrene concentration as a function of temperature from different sources.

Figure 6.3, Summation of monomer, dimer and trimer concentration of styrene as a function of reaction time at different temperatures.

Figure 6.4, Summation of monomer, dimer and trimer concentration of styrene as a function of temperature with different initial charges.

Figure 6.5, Average molecular weight of residue as a function of volatile yield

Figure 6.6, First order model, $\ln (1-\mathrm{X})$ versus reaction time, at $\mathrm{T}=368^{\circ} \mathrm{C}$, initial charge of 120 grams

Figure 6.7, First order model, $\ln (1-X)$ versus reaction time, at $T=396^{\circ} \mathrm{C}$, initial charge of $\mathbf{4 8 0}$ grams.

Figure 6.8, Arrhenius plot for volatile yield with melt temperatures and different charge 


\section{INTRODUCTION}

About 160 million tons of municipal solids waste (MSW) is being sent to landfill sites in the U.S. each year. This amounts to about $1.8 \mathrm{~kg}$ per person per day. In Quebec, 2.2 million tonnes of municipal solid waste (MSW), or $0.9 \mathrm{~kg}$ per person per day, were generated in 1988 [1]. The major component of the MSW is paper and paperboard, namely, $36 \%$ by weight [2]. Plastics constitute only 7 to $8 \%$ on a weight basis or 14 to $22 \%$ on a volume basis [3]. Even with this low fraction of the total MSW, the public views plastic as the main source of the problem in the present solid waste crisis. This poor reputation is due to the longevity and visiblity of plastics in the environment [4], and because plastics are assume to be non-recyclable.

The three basic methods of MSW management are: land filling, incineration, and recycling. The most common solution of land filling is becoming too expensive and is the least favoured method. The destruction of wastes by incineration is becoming more important although this process is often also expensive and can create problems with unwanted emissions if not properly controlled. The third alternative of recycling is becoming increasingly favoured. The particular components of the MSW stream are recycled at different rates. Aluminum is recycled at a $25 \%$ rate, and paper has a $22 \%$ recycling rate. Plastics have the lowest recycling rate, namely, 1\%. The recycling of plastics is in its infancy. By the year 2000, the recycling rate of plastics is expected to reach $6 \%$ [5]. Recycling can be subdivided into two parts: chemical recycling and mechanical recycling. Processing post-consumer plastics into the same product or another product is mechanical recycling. Treating post-consumer plastics with heat and/or chemicals to recover materials 
with added value is chemical recycling.

\section{BACKGROUND}

\subsection{Styrene and Polystyrene}

Figure 2.1 shows the structures and the molecular weights (MW) of styrene monomer, dimer (2,4-diphenylbutene), trimer (2,4,6-triphenylhexene) and polymer:

Polystyrene is a commodity thermoplastic; this means that polystyrene is produced in large quantity at low cost. It represented $11.2 \%$ of the plastic produced in the U.S. in 1991 [5]. The most important characteristic of general purpose polystyrene is a glasslike solid (i.e. transparent) below $100^{\circ} \mathrm{C}$. Other importani qualities are ease of processing, rigidity and low moisture absorption [6a]. Since polystyrene is nonpolar, chemically inert, resistant to water and easy to fabricate, it is the product of choice for electronic, medical, food packaging, optical, appliance, and automotive applications [6a].

The formation of polystyrene from styrene is an addition polymerization (Figure 2.2) that can involve either a free radical, anionic, or cationic mechanismı. Addition polymerization is favoured because the aromatic ring is able to stabilize the propagating specias. This polymerization can be initiated, in an oxygen-free atmosphere, by either heat or with the addition of an appropriate initiator.

The discovery of styrene monomer is credited to Newman [6a] who, in the 1780 's, isolated it by steam distillation from liquid ambar, a solid resin obtained from a family of trees or shrubs native to the Far East and California. E. Simon was credited with the first polymerization of styrene in 1839 [6a]. He named the 
prodsict, obtained by steam distillation from a resinous gum, styrol. In 1938, The Dow Chemical Company became the first company in the United States to commercialize polystyrene successfully [6a]. The first commercialisation was with bulk polimerization using the "can" process [7].

Today, most general purpose polystyrene is produced by solution polymerization in a continuous process. In general, free radical initiation is the most important industrial method of synthesizing polystyrene. Polystyrene produced by free radical polymerization is less thermally stable then anionic polymerized polystyrene [B]. Today, commercial production of styrene is usually achieved by direct alkylation of benzene with ethylene to form ethylbenzene, followed by dehydrogenation (Figure 2.3) [9]. The product from this reaction typically contains (in \% weight): $35-40 \%$ styrene, $59-61 \%$ ethylbenzene, $1-2 \%$ toluene, $0.5-2 \%$ benzene, and $0.2-0.5 \%$ tars [10]. Styrene is recovered by vacuum distillation using specially designed columns and suitable inhibitors of styrene polymerization. An inhibitor and antioxidant for the storage of styrene is p-tert-butylcatechol (TBC). 


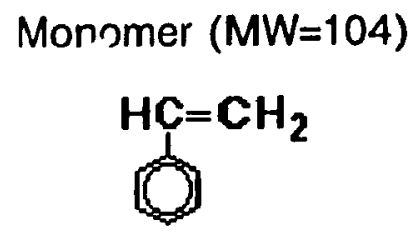

Dimer ( $M W=208)$

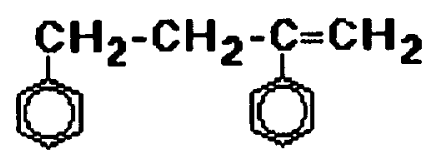

Trimer $(\mathrm{MW}=312)$<smiles>C=C(CC(CCCc1ccccc1)c1ccccc1)c1ccccc1</smiles>

Polymer<smiles>C=C(CC(CCCc1ccccc1)c1ccccc1)c1ccccc1</smiles>

Figure 2.1, Structures of styrene monomer, dimer, trimer and polymer. 


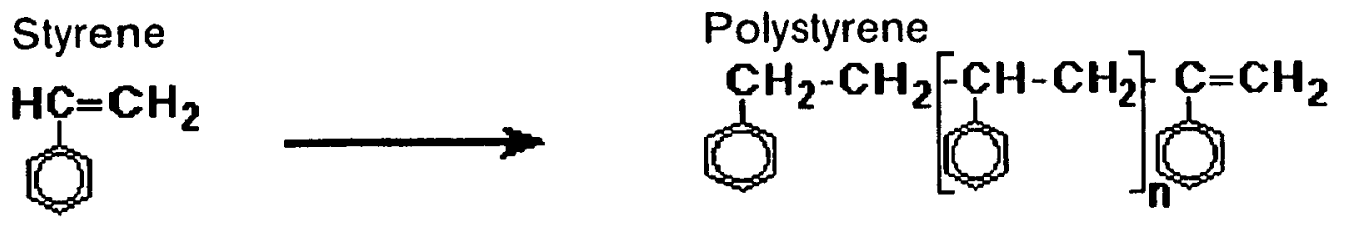

Figure 2.2, Addition polymerization of polystyrene

$Q+\mathrm{CH}_{2}=\mathrm{CH}_{2}$ catalyst $\mathrm{CH}_{2}-\mathrm{CH}_{3} \frac{600-650^{\circ} \mathrm{C}}{\text { oxide catalysts }} \mathrm{HC}=\mathrm{CH}_{2}+\mathrm{H}_{2}$

Figure 2.3, Alkylation of benzene with ethylene to form ethylbenzene, followed by dehydrogenation. 


\subsection{Degradation of Polymer}

Degradation, for a polymer, is usually associated with chain cleavage and a reduction in molecular weight. Generally, degradation involves the chemical modification of the polymer by its environment. There are many modes of degradation. Oxidative, mechanical, catalysed and thermal degradations are some of them. They can occur separately or simultaneously. When degradation occurs, the properties of the polymeric material change. The earliest work on degradation was actually carried out to maintain polymer stability or minimize the effects of degradation. Recently, researchers are more concerned with polymer degradation as a technique to convert waste polymers into high value chemicals. Thermolysis is one of these techniques.

Thermolysis or thermal degradation of polymers is the degradation by addition of energy in the form of heat without the presence of another component [11]. Thermolysis can occur in two ways, either chain scission or depolymerization. However, both mechanisins can be operative in a reaction at the same time.

Chain scission can occur at weak points or randomly along the polymeric chain. It results in a rapid decrease in molecular weight and very little monomer being formed. Depolymerization, on the other hand, occurs at the end of the polymer chain to yield an appreciable amount of monomer and a very slow decrease in molecular weight of the rest of the polymer chain.

\subsection{Mechanism of Thermolysis of Polystyrene}

There have been many studies examining the mechanisms of thermal degradatin of polystyrene. However, unsolved problems remain and conflicting 
views are still not fully resolved $[8,12-26]$. Degradation of polystyrene is an endothermic reaction. Many competitive elementary reactions and side reactions can occur. Raising the reaction temperature increases the complexity of the already complicated reaction. The breakdown of the polymer chains is a free radical chain reaction involving four sieps: initiation, propagation, transfer and termination. The basic characteristics of each step are shown in Table 2.1.

\subsubsection{Initiation}

The initiation reaction is associated with the different an ounts of irregular structures (weak points) in the polymer [8]. The identities of these points have not yet been established [27] but structures suggested include chain branches, unsaturations, head-to-head links, and initiator residues. Nor are the positions of these weak points in the polymer chain established. Some researchers beleive them to be randomly distributed along the polymer chain $[8,14,28-30]$, while others suggest that they are at the chain ends [31-33]. The inituation step occurs by carbon-carbon bond scission at weak points, chain ends and/or randomly to produce free radicals [6b]. Two types of radicals are formed when a chain is broken: the primary macroradical or methylene end group radical $\left(R_{1}\right)$, and the secondary macroradical or normal polystyryl radical $\left(R_{2}\right)$. This is illustrated in Figure 2.4, Reaction (1).

\subsubsection{Propagation}

The propagation step occurs by B-scission. When it involves the chain end radical $\left(R_{1}\right.$ or $\left.R_{2}\right)$, depolymerization to styrene occurs with the production of the same starting chain end radical with one unit less, as shown in Figure 2.4, Reaction (2) for the $R_{2}$ radical. 
In addition, B-scission can involve an internal radical (produced after a transier step) where chain scission occurs. This leads to a molecular weight decrease, and, as shown below, the production of a $R_{2}$ radical and an unsaturated chain end which is a weak structure at which may later be an initiation site. This is illustrated in Figure 2.4, Reaclion (3).

\subsubsection{Transfer}

The transfer step involves either intramolecular (back biting), e.g., 1,5transfer, or intermolecular hydrogen abstraction, as shown in Figure 2.5, Reactions (1) and (2) respectively. As the names imply, a hydrogen atom is transferred within a molecule (intramolecular) or between two molecules (intermolecular) iesulting in a new chain radical.

\subsubsection{Termination}

The termination step can be either the coupling of two radicals or a disproportionation. If the radicals couple, they recombine to give a long polymer chain and there is increase in molecular weight. But if disproportionation occurs, two chain ends are formed: a saturated benzylic chain end and an unsaturated thermally unstable chain end. This is shown in Figure 2.5, Reaction (3).

\subsection{Results of Previous Studies}

Between $280^{\circ} \mathrm{C}$ and $300^{\circ} \mathrm{C}$, the molecular weight of polystyrene decreases but no volatile products are evolved. Initiation and termination are the main mechanism of degradation of polystyrene at these low temperatures. Free radicals produced by carbon-carbon scission (Figure 2.4, Reaction (1)) immediately terminate by disproportionation or by coupling (Figure 2.5, 
Reaction (3)).

The unsaturated chain ends are believed to be the primary initiation sites for thermal degradation, above $300^{\circ} \mathrm{C}$ [24]. The formation of volatile products is observed when polystyrene is heated above $300^{\circ} \mathrm{C}[12]$. These volatile products consist mainly of styrene monomer, dimer, and trimer, and smaller amounts of toluene and $\alpha$-methylstyrene [27].

Between about $330^{\circ} \mathrm{C}$ and $450^{\circ} \mathrm{C}$, the primary sites for radical generation are the chain ends [27]. Initiation at a benzyl group chain end produces either a tolyl radical and a methylene end group radical $\left(R_{1}\right)$ or a phenylethyl radical and a normal polystyryl radical $\left(R_{2}\right)$ (Figure 2.6, Reaction (1)). With initiation at an unsaturated end group, $\alpha$-methylstyryl radical and a normal polystyryl radical are formed (Figure 2.6, Reaction (2)). Coupling of the tolyl, phenylethyl and $\alpha$ methylstyryl radicals with hydrogen yields toluene, ethylbenzene and $\alpha$ methylstyrene.

The chief mechanism of styrene formation is via the $\beta$-scission of the $R_{2}$ radical (Figure 2.4, Reaction (2)). An intramolecular 1,3-transfer from the $R_{2}$ radical (similar to Figure 2.5, Reaction (1)) followed by a $\beta$-scission results in the formation of either the tolyl radical and the unsaturated chain end or the dimer and the $R_{2}$ radical which is two units shorter (Figure 2.4, Reaction (3), with $R$ replaced by $H$ ). An intramolecular 1,5-transfer from $R_{2}$ radical (Figure 2.5, Reaction (1)) followed by a $\beta$-scission gives the formation of either the 1,3 diphenylpropyl radical and the unsaturated chain end or the trimer and the $R_{2}$ radical which is three units shorter (Figure 2.4, Reaction (3), with $R$ replaced by a styrene unit). 1,3-diphenylpropane is formed by disproportionation of the 1,3diphenylpropyl radical. In summary, the normal chain or secondary radical $\left(R_{2}\right)$ 
forms the following compounds: styrene, dimer (2,4-diphenylbutene), trimer (2,4,6-triphenylhexene), toluene and 1,3-diphenylpropane.

Styrene is also formed by depolymerization of the methylene end group or the primary radical by $\beta$-scission. Benzene can also be produced, by $\beta$-scission followed by disproportionation or $\mathrm{H}$ abstraction, along with a propene end chain. The hydrogen intramolecular 1,2 transfer occurs because it leads to the formation of the more stable tertiary radical. $\alpha$-methylstyrene is produced by $\beta$ scission along with the shorter radical $R_{2}$. The intramolecular hydrogen 1,3transfer would yield a dimer (1,3 diphenylbutene) after $\beta$-scission of the $R_{1}$ radial. The hydrogen intramolecular 1,4-transfer would yield ethylbenzene after $\beta$-scission and termination of the $R_{1}$ radial. Therefore, starting with the methylene end group or primary radical $\left(R_{1}\right)$ the compounds that can be formed are: styrene, $\alpha$-methylstyrene, ethylbenzene, dimer and benzene.

As examined above, $\beta$-scission, mainly involving the normal chain end radical, is the most frequent of al! reactions in polystyrene degradation [18]. This explains why styrene is by far the most important volatile product.

An alternative mechanism for the formation of oligomers has been proposed by Dean et al. [8]. They obtained evidence to suggest that dimers and trimers are possibly formed by monomer recombination, occurring within the molten polystyrene and in the vapour phase above it. In support of this, Ostani et al. [34] have shown that the hydrogen 1,3-transfer of the normal polystyryl radical $\left(R_{2}\right)$ followed by $\beta$-scission is not the main pathway to the dimers.

Thermal degradation of polystyrene has been summarised previously [18, $35]$ and studied by many researchers [10-13, 22, 27, 36-42]. Several different 
conditions and approaches have been used. It is possible to operate at atmospheric pressure or under vacuum with or without the addition of a catalyst. Different temperatures, reaction times and initial charges have been used. This has led to a range of yields and product qualities. For example, carrying out the reaction under vacuum generated large amounts of dimer and trimer in the volatile fraction $[37,40,43-45]$. Tha addition of catalysts increased the variety of products obtained. Many of these were present in low concentrations, but there was an overall decrease in molecular weight $[22,30,46]$. In all the studies, both higher temperatures and longer reaction times resulted in an increase of the amount of the volatile fraction $[22,30,37,40,44-47]$ and a decrease in the molecular weight of the residue $[22,37,44-45]$. Many of these experiments were done with very small samples and none of them had an initial charge larger than 20 grams. Table 2.2 summarizes the work that has been done on thermal degradation of polystyrene at temperatures between $310^{\circ} \mathrm{C}$ and $450^{\circ} \mathrm{C}$. 


\section{Table 2.1, Characteristic of Radical Chain Scission}

Degradation Process [18]

\begin{tabular}{c|c|c}
$\begin{array}{c}\text { Chain Reaction } \\
\text { Step }\end{array}$ & $\begin{array}{c}\text { Elementary } \\
\text { Reaction }\end{array}$ & Mode \\
\hline Initiation & C-C scission & $\begin{array}{c}\text { Weak points } \\
\text { Chain end } \\
\text { Random }\end{array}$ \\
\hline Propagation & B-Scission & $\begin{array}{c}\text { Depolymerization } \\
\text { Chain scission }\end{array}$ \\
\hline Transfer & $\begin{array}{c}\text { Hydrogen } \\
\text { abstraction }\end{array}$ & $\begin{array}{c}\text { Intramolecular } \\
\text { Intermolecular }\end{array}$ \\
\hline Termination & Mutual destruction & $\begin{array}{c}\text { Coupling } \\
\text { Disproportionation }\end{array}$
\end{tabular}




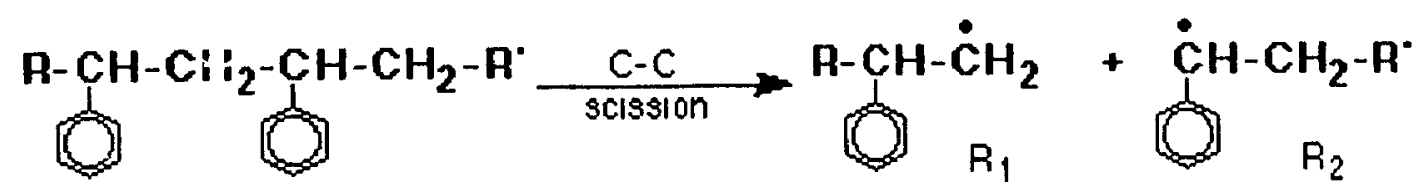

Reaction (1)

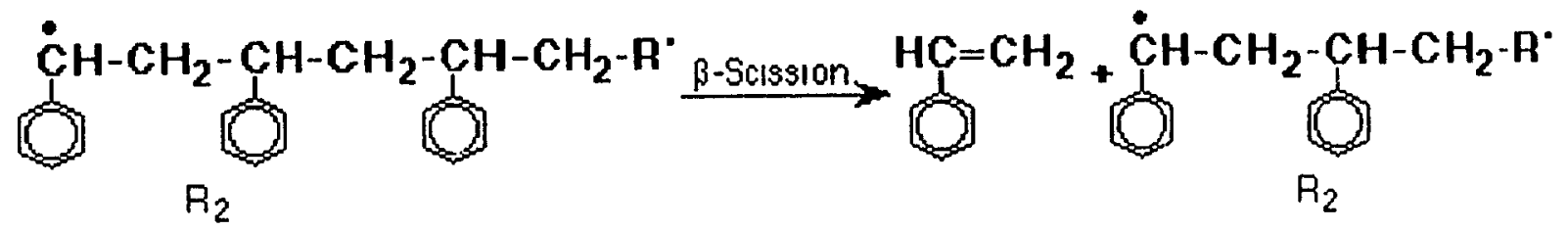

Reaction (2)

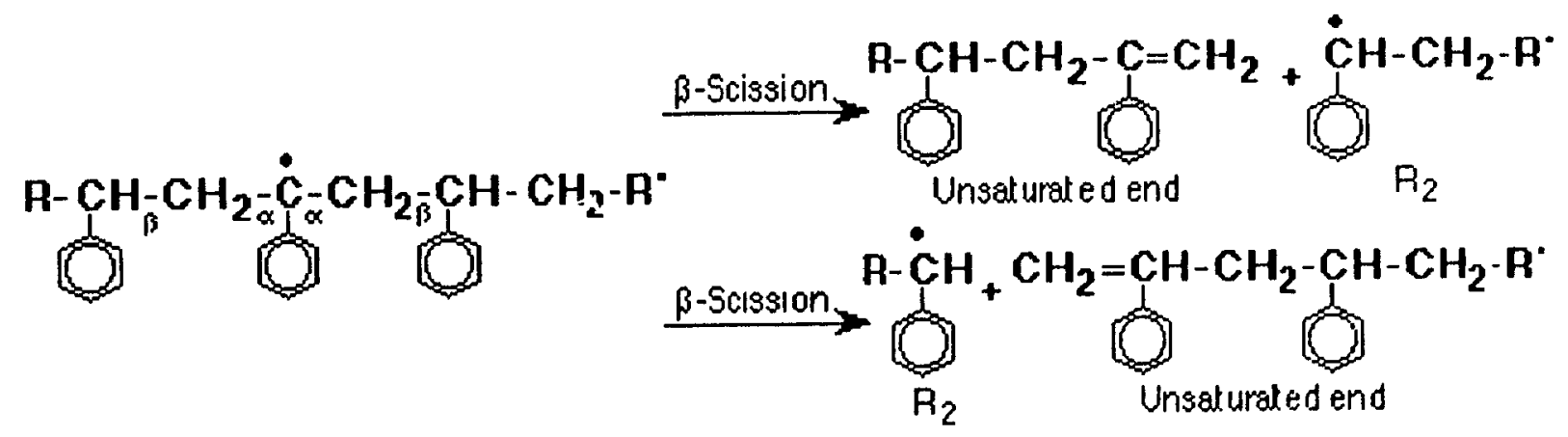

Reaction (3)

Figure 2.4: Reaction (1), initiation mechanism; Reaction (2), depolimerization; Reaction (3), chain scission. 


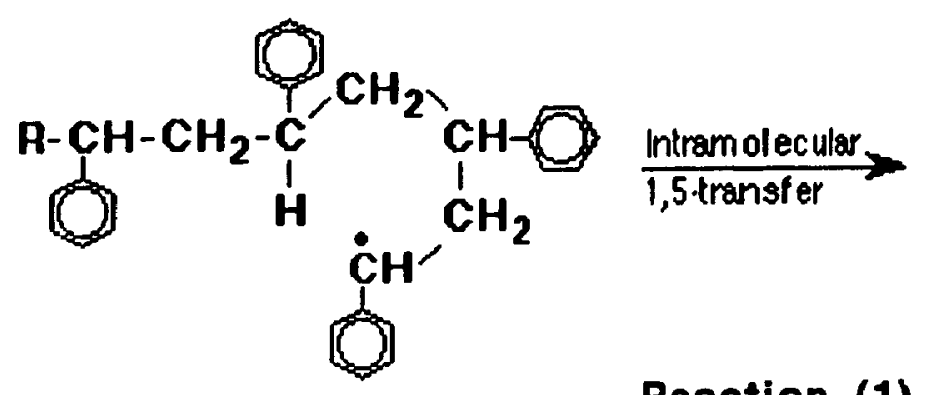<smiles>[R]C(CC(C)c1ccccc1CC(CCCCc1ccccc1)c1ccccc1)c1ccccc1</smiles>

Reaction (1)<smiles></smiles><smiles>BrC(CC(CC(Br)c1ccccc1)c1ccccc1)c1ccccc1</smiles>

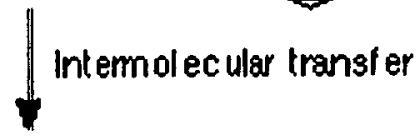<smiles>[R]C(CCc1ccccc1)c1ccccc1</smiles>

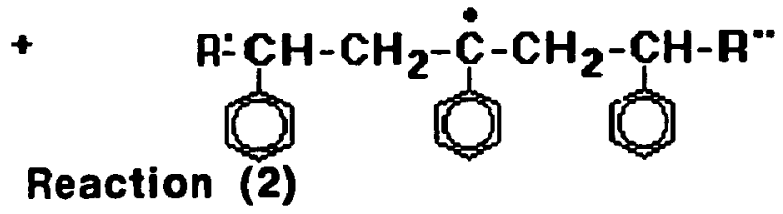

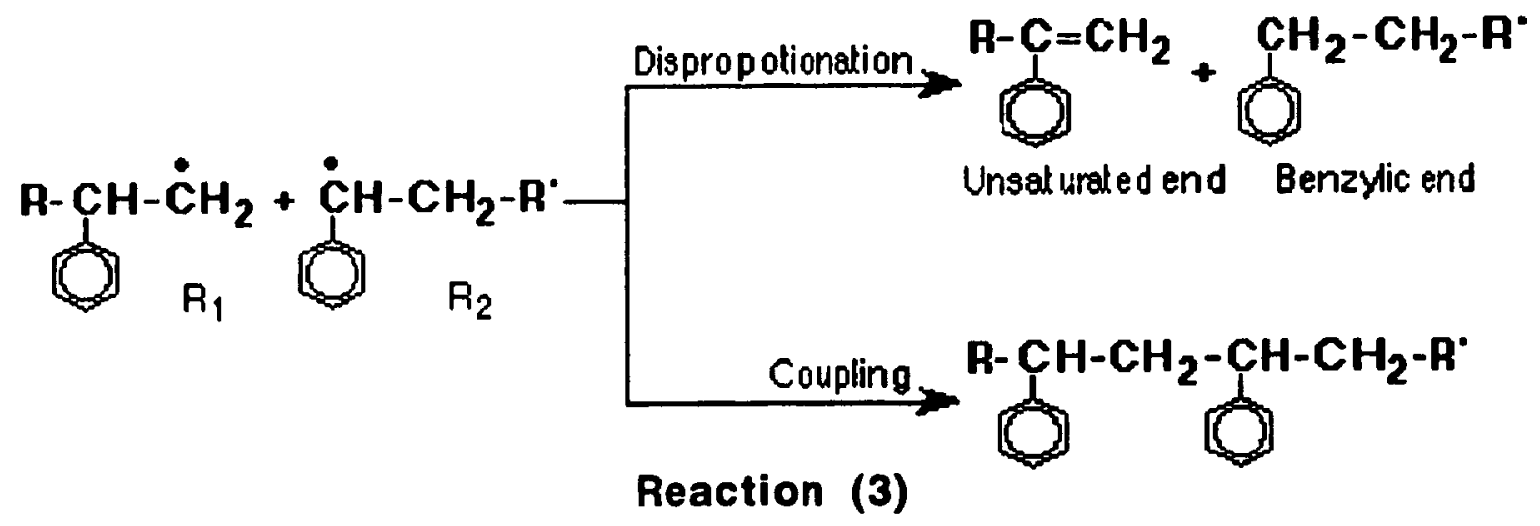

Figure 2.5: Reaction (1), intramolecular hydrogen transfer; Reaction (2), intermolecular hydrogen transfer; Reaction (3), termination. 


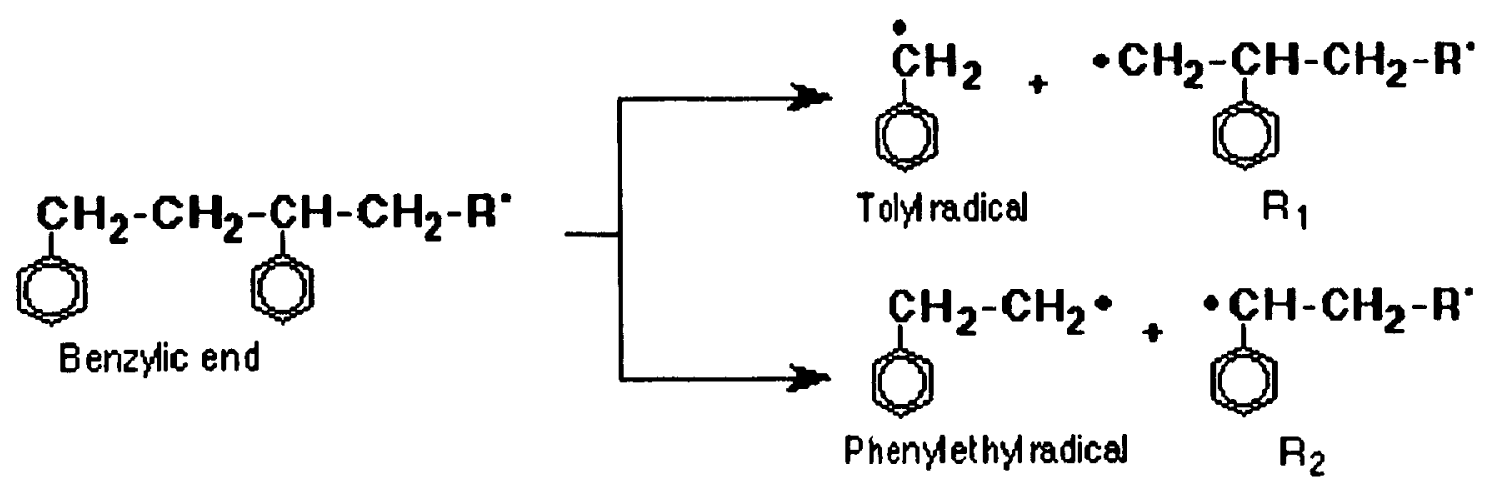

Reaction (1)

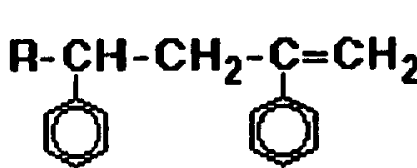

Unsal uraled end

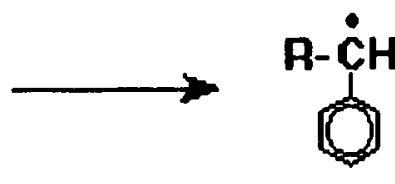

$\mathrm{A}_{2}$

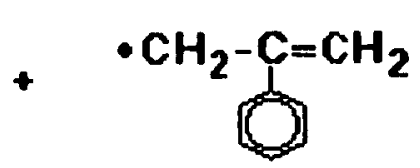

$\alpha$-methylstyryl radical

Reaction (2)

Figure 2.6: Reaction (1), formation of tolyl and phenylethyl radicals; Reaction (2), formation of $\alpha$ methylstyryl radical 
Table 2.2, Past Work in Polystyrene Degradation

\begin{tabular}{|c|c|c|c|c|c|c|}
\hline Authors & Set-Up & $\begin{array}{c}\text { Tempe- } \\
\text { rature } \\
\left({ }^{\circ} \mathrm{C}\right)\end{array}$ & $\underset{(h r)}{\operatorname{Time}}$ & $\begin{array}{r}\text { Sampl } \\
\text { e size }\end{array}$ & $\begin{array}{l}\text { Volatil } \\
\text { e Yield } \\
\text { (\% wt. } \\
\text { of PS) }\end{array}$ & $\begin{array}{c}\text { Styren } \\
\text { e Yie!d } \\
\text { (\% wt. } \\
\text { of } \\
\text { volatile } \\
\text { ) }\end{array}$ \\
\hline $\begin{array}{c}\text { Costa et al. } \\
{[36]}\end{array}$ & $\mathrm{N}_{2} \mathrm{~atm}$. & 348 & 0.5 & $5 \mathrm{mg}$ & 40 & 36 \\
\hline $\begin{array}{l}\text { Madorsky et } \\
\text { al. }[26,37]\end{array}$ & vacuum & $350-420$ & $0.5-4$ & $\begin{array}{c}25-50 \\
\mathrm{mg}\end{array}$ & $3.6-99.9$ & $4.8-96.4$ \\
\hline $\begin{array}{c}\text { Lehrle et al. } \\
\text { [11] }\end{array}$ & $\begin{array}{c}\text { N2 atm. } \\
\text { flash } \\
\text { pyrolysis }\end{array}$ & $450-480$ & flash & $<0.1 \mathrm{mg}$ & $\cdots$ & 100 \\
\hline $\begin{array}{l}\text { Staudinger } \\
\text { et al. }[40]\end{array}$ & $\begin{array}{l}\text { N2 atm. } \\
\text { vacuum }\end{array}$ & $\begin{array}{l}310-350 \\
290-320\end{array}$ & $\begin{array}{c}6 \\
12 \\
\end{array}$ & $\cdots$ & $\begin{array}{l}85 \\
84 \\
\end{array}$ & $\begin{array}{l}72.9 \\
45.2 \\
\end{array}$ \\
\hline Ide et al. [31] & N2 atm. & 420 & 2.4 & $20 \mathrm{~g}$ & 90.2 & 69.2 \\
\hline Ide et al. [46] & $\mathrm{N}_{2} \mathrm{~atm}$. & $\begin{array}{l}350 \\
400 \\
450 \\
\end{array}$ & $\begin{array}{c}1.08 \\
1.2 \\
1.2 \\
\end{array}$ & $\begin{array}{l}17.6 \mathrm{~g} \\
16.6 \mathrm{~g} \\
16.6 \mathrm{~g}\end{array}$ & $\begin{array}{l}72.6 \\
77.8 \\
79.8 \\
\end{array}$ & $\begin{array}{l}48.8 \\
64.4 \\
73.3 \\
\end{array}$ \\
\hline Marc [35] & $\mathrm{N}_{2} \mathrm{~atm}$ & $330-410$ & $0.5-1$ & $3 g$ & $5.9-75.9$ & 97 \\
\hline $\begin{array}{c}\text { Lageraaen } \\
\text { [42] }\end{array}$ & $\mathrm{N}_{2} \mathrm{~atm}$. & $\begin{array}{l}350 \\
420\end{array}$ & 0.5 & $4 \mathrm{~g}$ & $\begin{array}{l}72 \\
78\end{array}$ & $\begin{array}{l}84.4 \\
90.6\end{array}$ \\
\hline
\end{tabular}




\section{OBJECTIVES}

The goal of the research was to develop a practical process to convert waste polystyrene into high yields of styrene monomer. The first step was to scale-up from the microgram and milligram experiments reported in the literature. At the same time, it would be advantageous to eliminate expensive factors such as the need for vacuum ano catalysts. Finally, the emphasis has been on the use of moderate temperatures.

This work is part of a more general program in chemical recycling. The objective of this chemical recycling research at McGill is to develop a technology, usable in industry, to recover useful chemical products from plastics waste under mild thermal conditions.

The specific objectives of this Master's project were as follows:

1. To design and construct a large scale apparatus, 30 to $500 \mathrm{~g}$ capacity, to thermally depolymerize polystyrene under nitrogen atmosphere.

2. To recover and identify the condensate and residue fraction from the polystyrene thermolysis.

3. To investigate the effect of varying the starting amount of polystyrene on the production rate and nature of the recovered products.

4. To investigate the effect of varying the reaction temperature and the reaction time on the production rate and nature of the recovered products.

5. To investigate the kinetics of polystyrene thermolysis. 


\section{EXPERIMENTAL}

\subsection{Materials}

The polystyrene used was STYRON 688 in powder form produced by free radical polymerisation by Dow Chemical Canada Inc. The number average molecular weight $\left(\overline{\mathrm{M}}_{i}\right)$ and polydispersity inciex $\left(\overline{\mathrm{M}}_{N_{N}} / \overline{\mathrm{M}}_{1:}\right)$ were 138000 and 2.6, respectively. A sample of consumer polystyrene was also utilized in the form of a clear polystyrene cup.

\subsection{Apparatus}

Two experimental set-ups were used, differing only in the capacity of the reactor vessels (Figure 4.1). The small set-up (samples weighing 30 to 120 grams) was a $500 \mathrm{ml}$ flat bottom reactor covered with four-necked lid under a nitrogen atmosphere and mixed by a paddle connected to a motorised shaft. Heating was provided by a flat flask heating mantle (Series STM) from Glas-Col with a controller (Model BS5001J1) from Omega Engineering Inc. Thermocouples, type J, also from Omega Engineering Inc. were used to monitor the melt and still temperatures. The volatiles were condensed and collected in a roiating vessel with six 50 or $100 \mathrm{ml}$ receiving flasks. Ten volatile fractions were obtained by rotating the receiving flasks during the experiment. This allowed the collection of sequential samples of the liquid during a reaction.

The large set-up is the same as the small one except that the reactor and heating mantle have a capacity of 2 litres, allowing a charge between 120 and 480 grams of polystyrene, and longer condensers and still. 


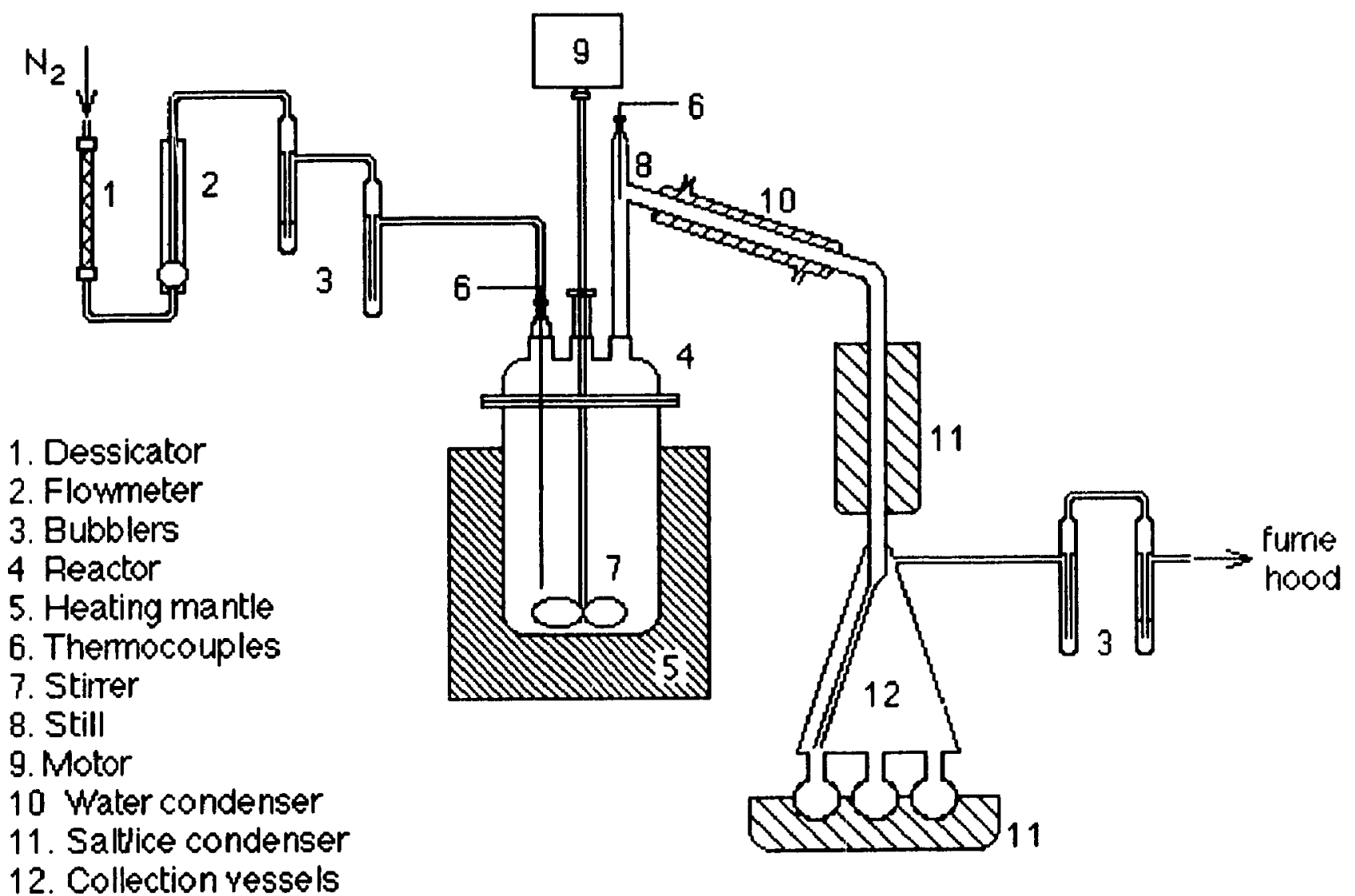

Figure 4.1, Apparatus 


\subsection{Procedure}

The apparatus consisted of two main parts: The reaction vessel and the rotating receiving vessel. The experiments were conducted isothermally under a nitrogen atmosphere, in order to avoid the thermal oxidation of the polymer. When an experiment is started, the first step is to weigh each part of the apparatus. The experiment is set-up in the fume hood. The reaction vessel is charged with a specified amount of polystyrene. After, the apparatus is purged with nitrogen for at least 15 minutes, ice is placed around the condenser and in the receiving vessel ice bath. The heating mantle is started and controlled at the set temperature. The reaction proceeds for the set time, with a constant nitrogen flow rate of $5 \mathrm{ml} / \mathrm{min}$. and the temperature is recorded. When the experiment is completed, all parts are weighed again and the yields of residue and volatiles are calculated. The residue and volatiles are stored in a refrigerator under a nitrogen atmosphere for further analysis.

A typical temperature profile from an experimental run is shown in Figure 4.2. Two temperature curves are shown, one for the melt and one for the still. It can be seen that 10 to 20 minutes were needed for the polymer to reach the desired temperature. An average reaction (melt) temperature was calculated for the constant region of the temperature profile. In this case (initial polystyrene charge of 120 grams and small set up), the reaction or melt temperature was $393^{\circ} \mathrm{C}$. An average standard deviation of $5^{\circ} \mathrm{C}$ in the reaction temperature was observed for all experiments. The reaction time refers to the length of the experiment starting after the still temperature reaches the high value. In this study, the reaction temperature range considered was $370-420^{\circ} \mathrm{C}$, the maximum reaction time was 45 minutes and the initial polystyrene charges varied from 30 to $480 \mathrm{~g}$. 


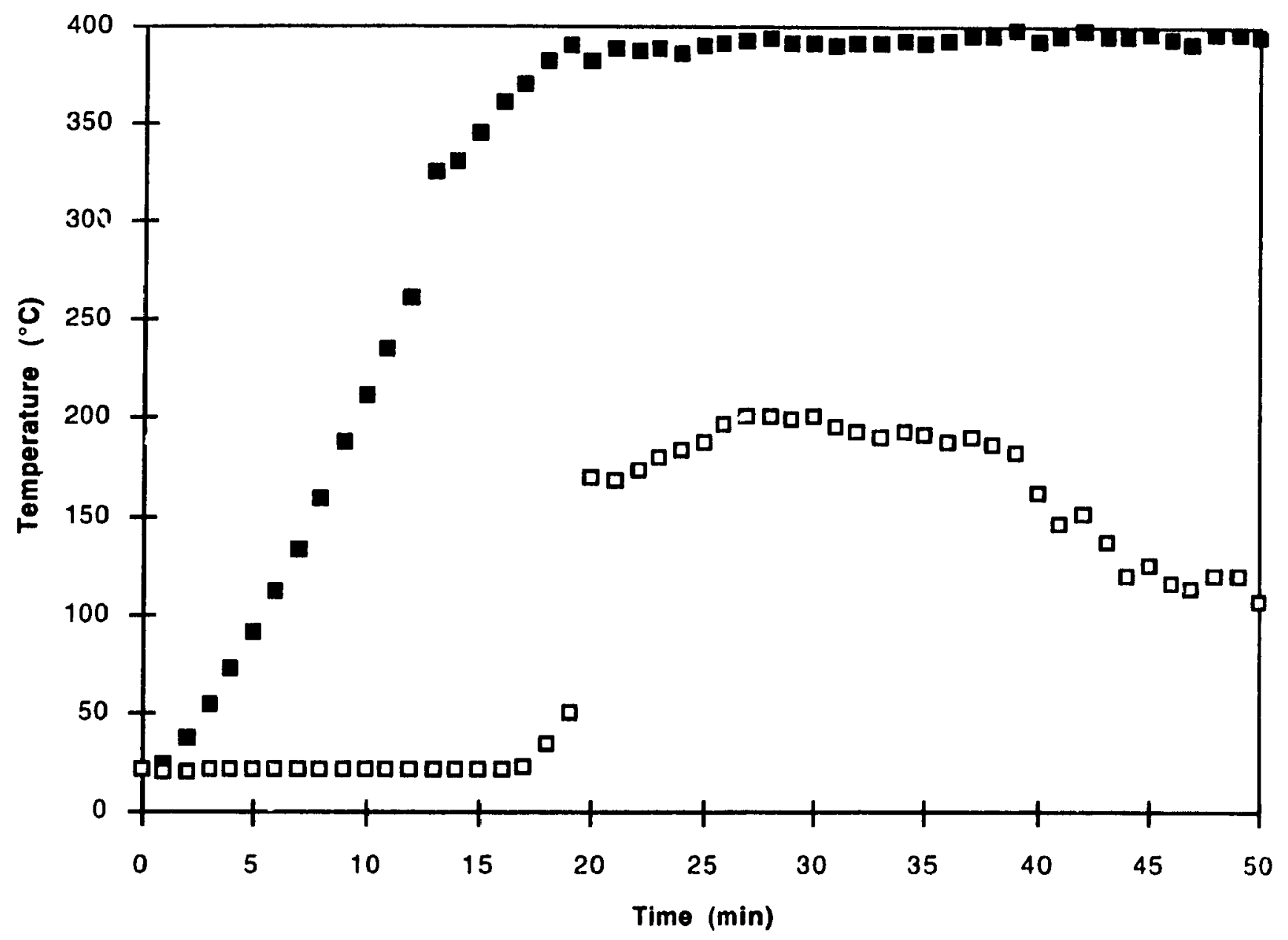

Figure 4.2, Typical temperature profile: $\square$ Melt temperature; $\Xi$ Still temperature. 


\subsection{Analytical techniques}

\subsubsection{Gas Chromatography (GC)}

The condensed volatile fractions obtained in the collection flasks were analysed by gas chromatography (GC). The gas chromatograph used was a Hewlett Packard 5890A with a flame ionization detector. The column used was selected for its ability to detect aromatic compounds and small hydrocarbons. The operating conditions are listed in Table 4.1.

Samples from the volatile products were injected to determine the component distributions and concentrations. For the quantitative results, it was assumed that the area under each peak, calculated by the GC integrator, was directly proportional to the corresponding amount of the component on a mass basis. This was justified by injecting a standard test mixture with known concentrations.

Standards were injected in the gas chromatograph and their peak retention times were compared to the retention time of different volatile product peaks. By this method, it was possible to account for over $70 \%$ of the components in the volatile products. A typical gas chromatogram of the ninth volatile fraction of the experiment run at $390^{\circ} \mathrm{C}$ for 32 minutes is shown in Figure 4.3 


\begin{tabular}{l|l} 
Chromatograph & Hewlett Packard 5890A \\
\hline Detector & Flame ionization \\
\hline Column & $6^{\prime} \times 1 / 8^{\prime \prime}$ stainless steel \\
\hline Packing & $\begin{array}{l}3 \% \text { OV-101 on chromosorb W } \\
\text { HP } 100 / 120 \text { mesh }\end{array}$ \\
\hline Initial oven temperature & $60^{\circ} \mathrm{C}$ \\
\hline Initial time & $8 \mathrm{minutes}$ \\
\hline Rate & $15^{\circ} \mathrm{C} / \mathrm{min}$ \\
\hline Final oven temperature & $275^{\circ} \mathrm{C}$ \\
\hline Final time & $2 \mathrm{minutes}$ \\
\hline Injector temperature & $280^{\circ} \mathrm{C}$ \\
\hline Detector temperature & $300^{\circ} \mathrm{C}$ \\
\hline Helium flow & $30 \mathrm{ml} / \mathrm{min}$ \\
\hline Hydrogen flow & $30 \mathrm{ml} / \mathrm{min}$ \\
\hline Air flow & $300 \mathrm{ml} / \mathrm{min}$ \\
\hline Sample size & $0.05 \mu l$
\end{tabular}




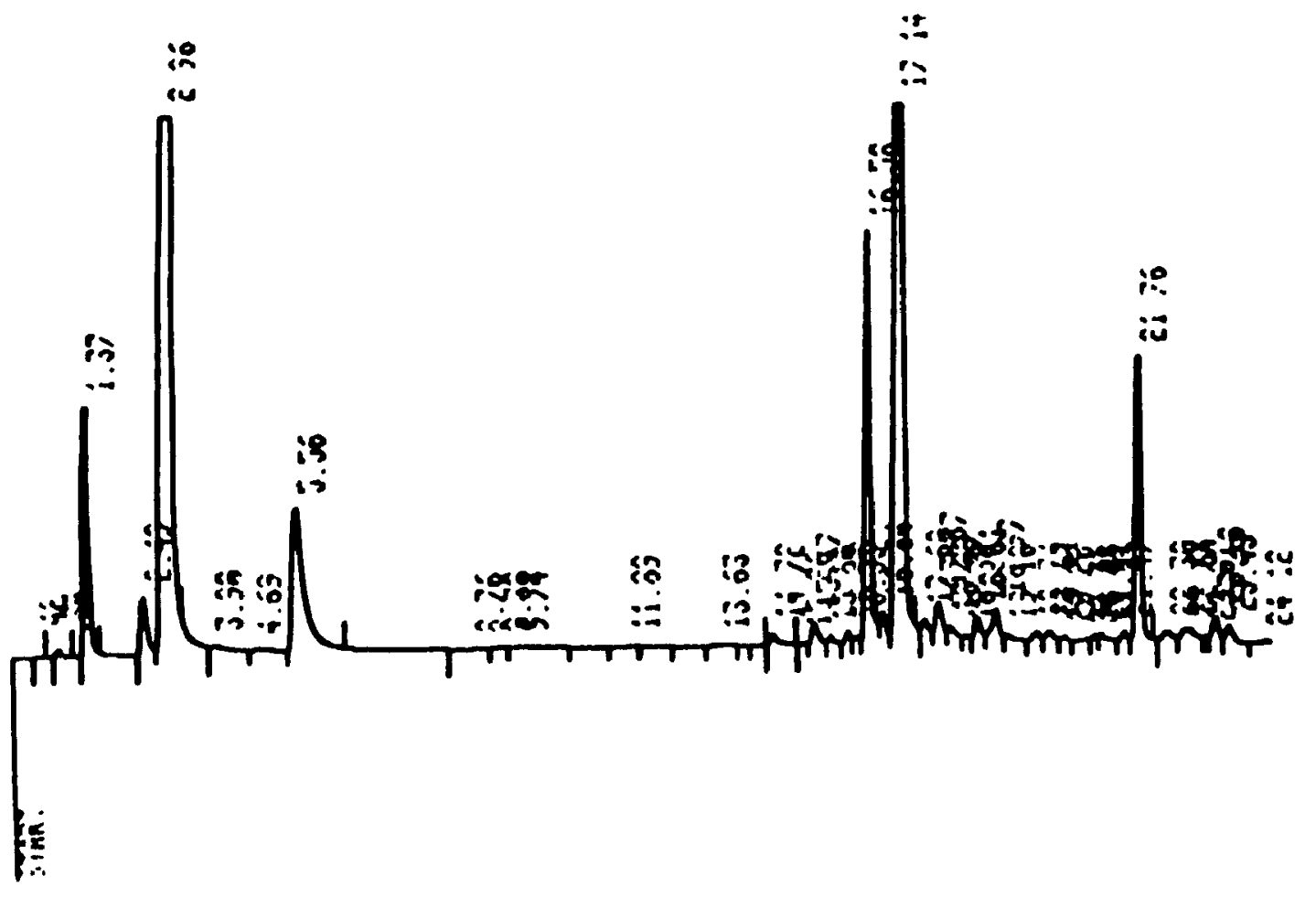

Figure 4.3, Gas chromatogram of the ninth volatile fraction of the experiment run at $390^{\circ} \mathrm{C}$ for 32 minutes: Identification of peaks: 0.42.Benzene, 1.37.Toluene, 2.42.Ethylbenzene, 2.96.Styrene, 5.56. $\alpha$-Methylstyrene. 


\subsubsection{Gas Chromatography-Mass Spectroscopy (GC-MS)}

GC-MS was used to identify large peaks where no standard was found with the same retention time. For example, on the gas chromatogram shown in Figure 4.3, these peaks are at retention time $16.56,17.14$ and 21.76 minutes. Figure 4.4 shows the spectrum of the 16.56 minutes peak. Mass spectroscopy gives the molecular weight and the decomposition products of the compound being scanned. This information facilitates identifying the molecular formulae of the compounds. Combining this method with gas chromatography, it was possible to account for over $90 \%$ of the components in the volatile products.

\subsubsection{Nuclear Niagnetic Resonance (NMR)}

NMR is used in this project to provide some information regarding the composition of the residue. With this method of analysis, it is possible to make a distinction between aromatic, olefinic, vinylic and aliphatic protons. If a comparison is made between polystyrene before and after thermolysis, the decrease of the quantity of one structure relative to another can be known. Using the appropriate ratios, the molecular weight of the residue can be calculated. The NMR analysis was performed in the Department of Chemistry at McGill University using a Varian XL-300 NMR Spectrometer. Figure 4.5 shows a NMR spectrum of polystyrene along with its molecular formula to show the correspondence between the peaks and the protons. Figure 4.6 shows a typical NMR spectrum of residue and its formula of probable termination. 


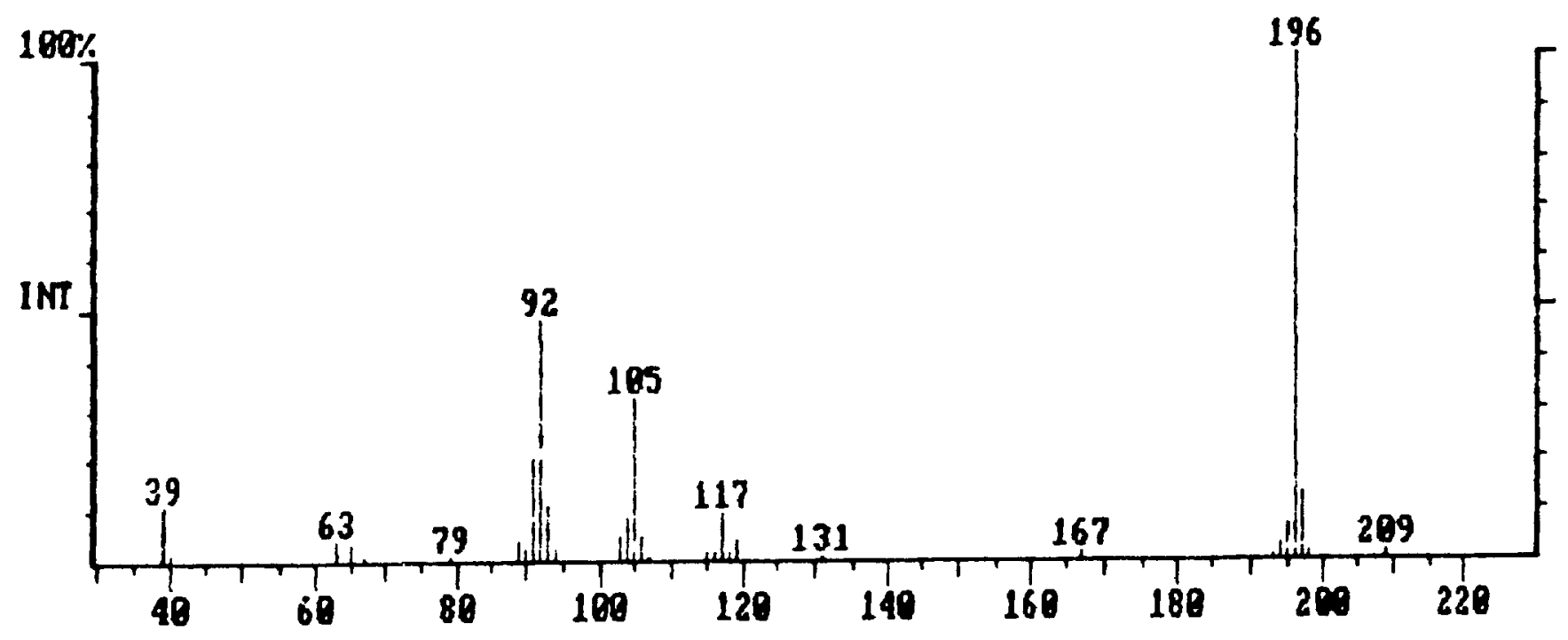

Figure 4.4, Mass spectrum of peak 16.56 of gas chromatogram of Figure 4.3. 

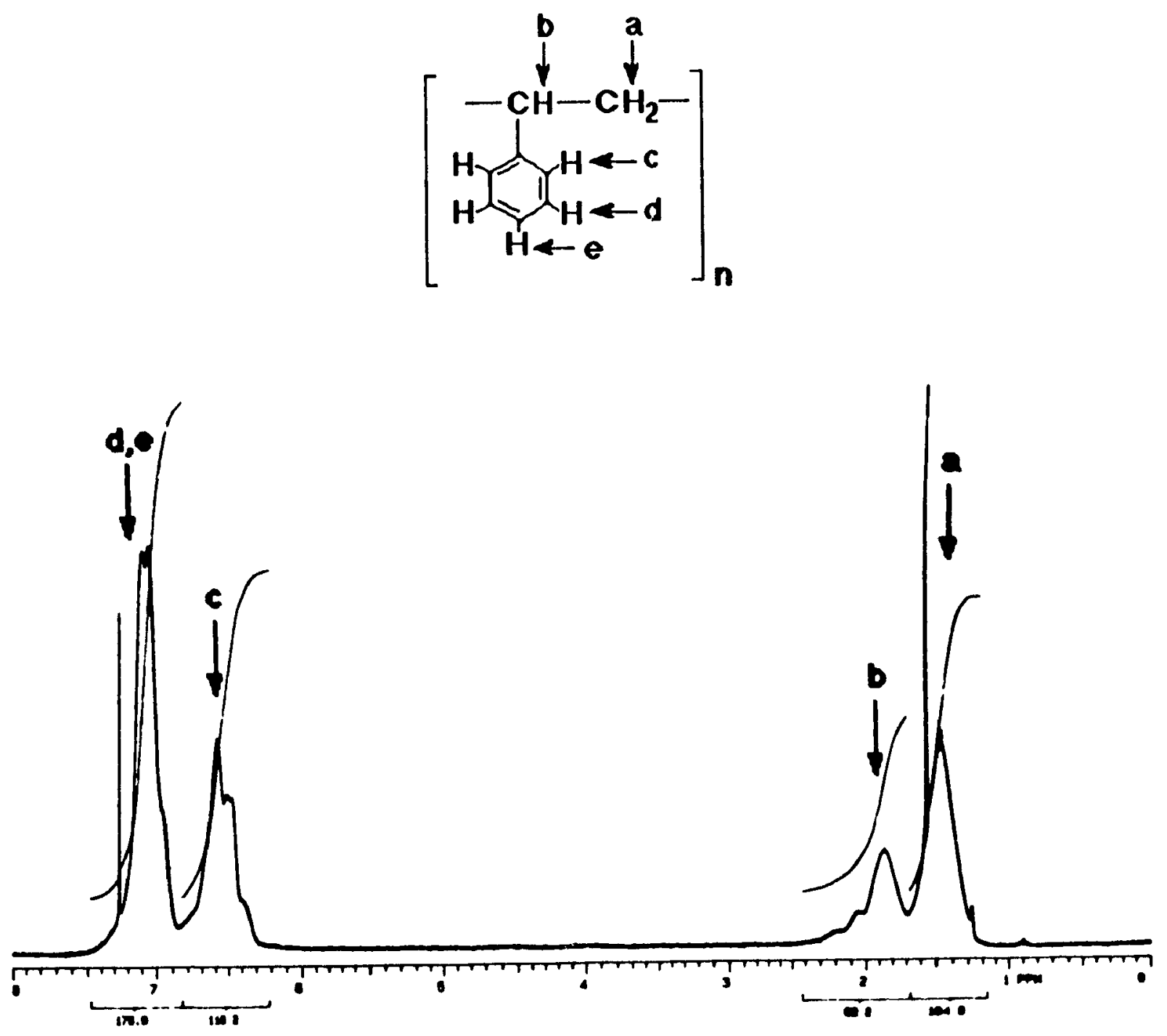

Figure 4.5, NMR of starting material (polystyrene): Identification of peaks: a.Methylene, b.Methine, c.Aromatic,ortho, d.Aromatic, meta, e.Aromatic,para. 

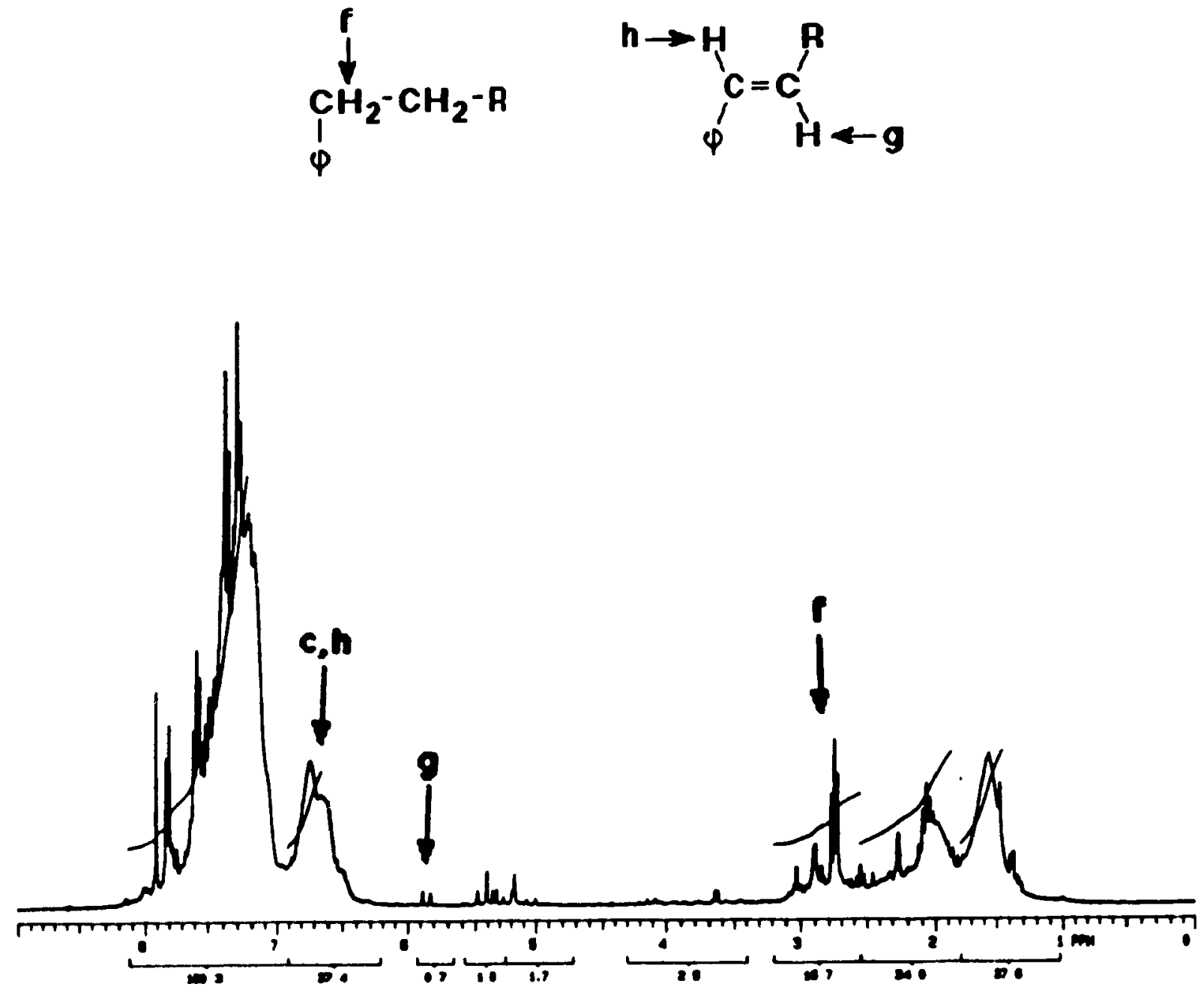

Figure 4.6, NMR of residue, Polystyrene thermolysed for 33 minutes at $370^{\circ} \mathrm{C}$ : Identification of peaks: f.Terminal methylene, g.Terminal double bond,cis-proton with phenyl group, h.Terminal double bond conjugated with phenyl group. 


\subsubsection{Cryoscopy}

Cryoscopy was used to determine the average molecular weight of the residue. A cryoscope is an instrument to measure freezing point depression. Since the freezing point depression of a solution is a colligative property, the average molecular weight of a solute weighed into a known weight of solvent can be determine by cryoscopy. Equation (4.1) is used to find the average molecular weight of the solute $\left(M_{2}\right)$ when the solution is very dilute.

$$
\Delta T=\frac{R T^{2} V_{1}}{\Delta H_{1}} \frac{c_{2}}{M_{2}}
$$

Equation (4.1)

Where $\Delta T$ is the freezing point depression, $R$ is the gas law constant, $T$ is the freezing temperature of the pure solvent, $V_{1}$ is the volume of solvent, $\Delta H_{1}$ is the latent heat of vaporisation and $c_{2}$ is the solute concentration (mass per unit volume solution) [48].

Rearranging Equation (4.1) gives Equation (4.2) to find the average molecular weight (M.W.)

$$
M . W .=\frac{1000 K_{1} m_{2}}{\Delta T m_{1}} \quad \text { Equation }
$$

Where $K_{f}$ is the molal freezing point depression constant of the solvent, $\mathrm{m} 1$ and $\mathrm{m} 2$ are the weights of solvent and solute, respectively, in grams and $\Delta \mathrm{T}$ is the observed lowering of the freezing point (Cryette reading). In this project, bromoform was chosen to be the solvent $\left(K_{1}=14.4\right)[55]$. 


\section{RESULTS}

\subsection{Mass Balances}

Two types of products were measured by weight after each experiment. These were the condensed volatile fraction in the collection flasks and the residue in the reaction vessel. Mass balances are shown in Table 5.1. It can be seen that the losses are negligible and consistent between experiments. On average, the relative losses were equal to $3.7 \%$ for experiments with an initial charge of 30 grams, $1.6 \%$ for a charge of 60 grams, $0.9 \%$ for 120 grams and $0.11 \%$ for an initial charge of 480 grams of PS. The average absolute loss is equal to 0.93 grams with a standard deviation of 0.73 grams. 
Table 5.1. Mass Balance for Experiments

\begin{tabular}{c|c|c|c|c|c|c}
$\begin{array}{c}\text { React. } \\
\text { time } \\
\text { (min) }\end{array}$ & Temp. & Charge & \multicolumn{2}{|c|}{ Yields (\% wt of PS) } & \multicolumn{2}{|c}{ Losses } \\
\hline 30 & 371 & 30 & 68 & 30 & 0.71 & 2.4 \\
\hline 30 & 373 & 30 & 55 & 42 & 0.72 & 2.4 \\
\hline 30 & 371 & 60 & 66 & 32 & 1.31 & 2.2 \\
\hline 12 & 388 & 60 & 42 & 57 & 0.25 & 0.4 \\
\hline 31 & 391 & 60 & 17 & 82 & 0.95 & 1.6 \\
\hline 30 & 391 & 60 & 15 & 83 & 1.23 & 2.0 \\
\hline 30 & 407 & 60 & 15 & 84 & 0.98 & 1.6 \\
\hline 12 & 368 & 120 & 87 & 12 & 0.97 & 0.8 \\
\hline 34 & 368 & 120 & 48 & 51 & 1.08 & 0.9 \\
\hline 20 & 378 & 120 & 43 & 56 & 0.83 & 0.7 \\
\hline 9 & 382 & 120 & 66 & 33 & 1.02 & 0.9 \\
\hline 23 & 384 & 120 & 36 & 64 & 0.00 & 0.0 \\
\hline 33 & 388 & 120 & 29 & 70 & 1.02 & 0.9 \\
\hline 40 & 394 & 120 & 13 & 86 & 0.72 & 0.6 \\
\hline 28 & 395 & 120 & 19 & 80 & 1.18 & 1.0 \\
\hline 21 & 401 & 120 & 7 & 92 & 1.22 & 1.0 \\
\hline 33 & 373 & 480 & 60 & 40 & 1.20 & 0.2 \\
\hline 31 & 381 & 480 & 49 & 51 & 1.06 & 0.2 \\
\hline 32 & 390 & 480 & 27 & 73 & 0.00 & 0.0 \\
\hline 34 & 395 & 480 & 11 & 89 & 0.00 & 0.0 \\
\hline
\end{tabular}




\subsection{Yield of Volatlle Product}

The total volatile yield from all the collection flasks is included in Table 5.1. It can be seen in Figure 5.1 that the volatile yield increases with longer time and with higher melt temperature. Figure $\mathbf{5 . 2}$ shows the volatile yield as a function of the melt temperature and initial charge of polystyrene for a reaction time around 30 minutes. This demonstrates the increase in volatile yield with increasing temperature more clearly than Figure 5.1. However, the initial charge of polystyrene has no significant effect on the volatile yield.

\subsection{Composition of Volatile Product}

Figure 4.3 shows a typical gas chromatogram of the volatile fraction. The main components are: styrene, dimer (2,4-diphenylbutene), $\alpha$-methylstyrene, 1,3-diphenylpropane, trimer (2,4,6-triphenylhexene), toluene and ethylbenzene. Trace amount of benzene and oligomers are present. Peak with retention time of approximatly $16.56,17.14$ and 21.76 minutes were identified by GC-MS as shown in Figure 4.4, which is the spectrum of peak 16.56 minutes. The parent peak with a molecular weight of 196 and the decomposition peaks at 92 (toluene) and 105 (radical of $\alpha$-methylstyrene) indicates that the compound is 1,3-diphenylpropane. 


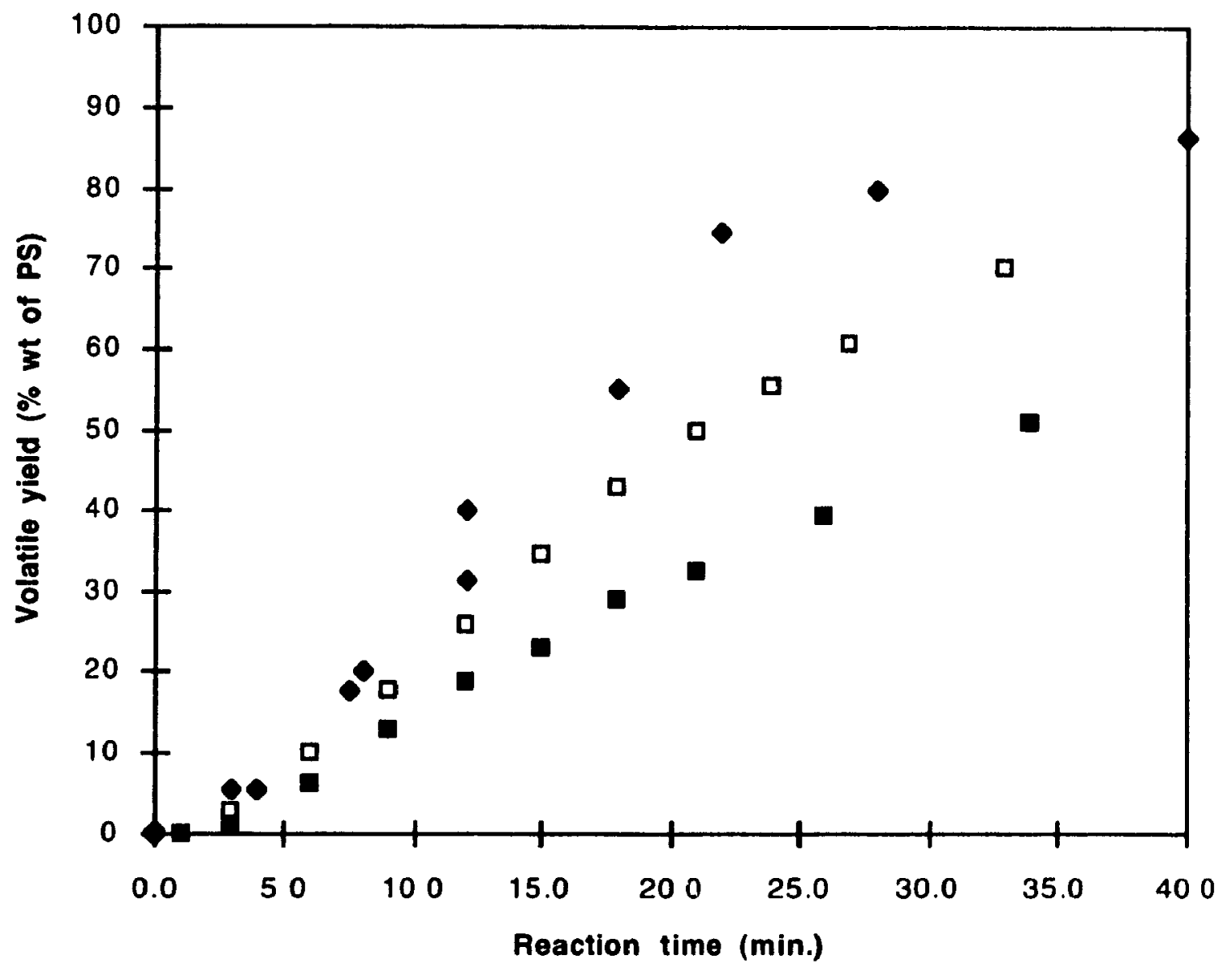

Figure 5.1, Volatile yield as a function of time for different temperatures: $\square 368^{\circ} \mathrm{C}$; $387^{\circ} \mathrm{C}$; $394^{\circ} \mathrm{C}$. 


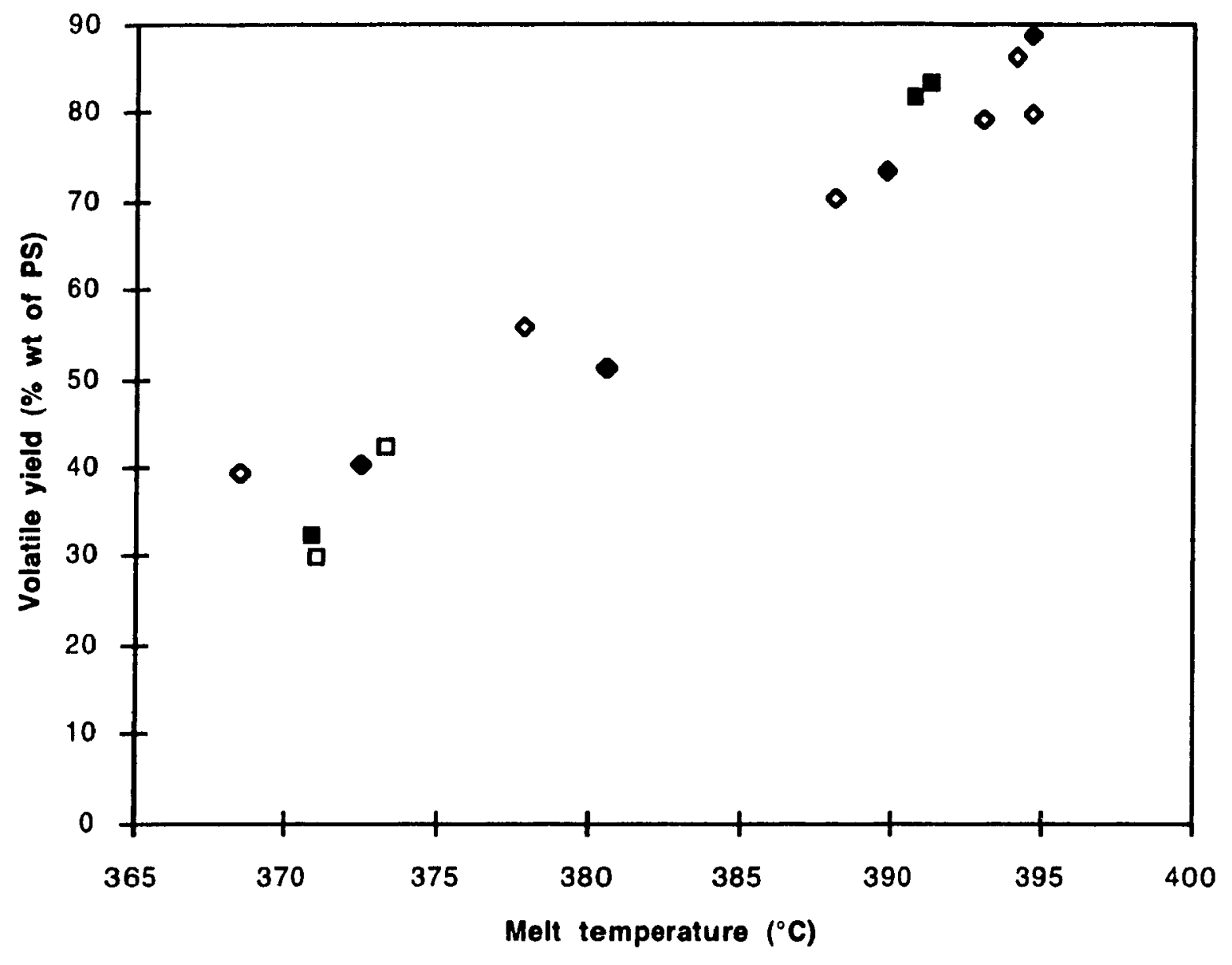

Figure 5.2, Volatile yield as a function of temperature for 30 minutes reaction time: $\square 30$ grams; $\square 60 \mathrm{~g} ; \diamond 120 \mathrm{~g} ; \diamond 480 \mathrm{~g}$. 
Figures 5.3, 5.4 and 5.5 show the change in composition of the volatile fraction as a function of the reaction time at two temperatures $\left(381^{\circ} \mathrm{C}\right.$ and $395^{\circ} \mathrm{C}$ ). The components monitored were styrene and styrene dimer (Figure 5.3), toluene and styrene trimer (Figure 5.4) and $\alpha$-methylstyrene, ethylbenzene and 1,3-diphenylpropane (Figure 5.5). The composition in each case is the fraction of the component of the total volatile collected at a particular time. As these are all the major compounds present ( $>94 \mathrm{~mol} \%$ of each volatile fraction), combined they represent a complete picture of the change of volatile evolution with time.

In Figure 5.3 there is a slight decrease in styrene concentration and a slight increase in dimer concentration as the reaction proceeds. The lowest styrene concentration obtained was about $70 \%$ (wt of styrene / wt of volatile). It can also be seen that the styrene concentration is lower and the dimer concentration is higher with higher temperature.

In Figure 5.4, the plots of concentration of toluene vs. time at both reaction temperatures are essentially the same and are constant at $2.0 \%$ (wt of toluene I $w t$ of volatile). The trimer concentration increases slightly with time for the higher temperature and decreases for the lower temperature. The overall trimer concentration is higher for the higher temperature.

Figure 5.5 demonstrates a dramatic increase in $\alpha$-methylstyrene and 1,3diphenylpropane concentration, but only a slight increase in ethylbenzene concentration, as the reaction proceeds. The size of the increase in c $\alpha$ methylstyrene concentration is larger for the lower temperature, from $0.2 \%$ to $3.8 \%$ (wt of $\alpha$-methylstyrene / wt of volatile), than the higher temperature, from $0.3 \%$ to $2.2 \%$. Conversely, the lower reaction temperature results in more ethylbenzene than the higher temperature. Both curves of the 1,3diphenylpropane concentration are similar in magnitude but the higher temperature curve seems to level off. 


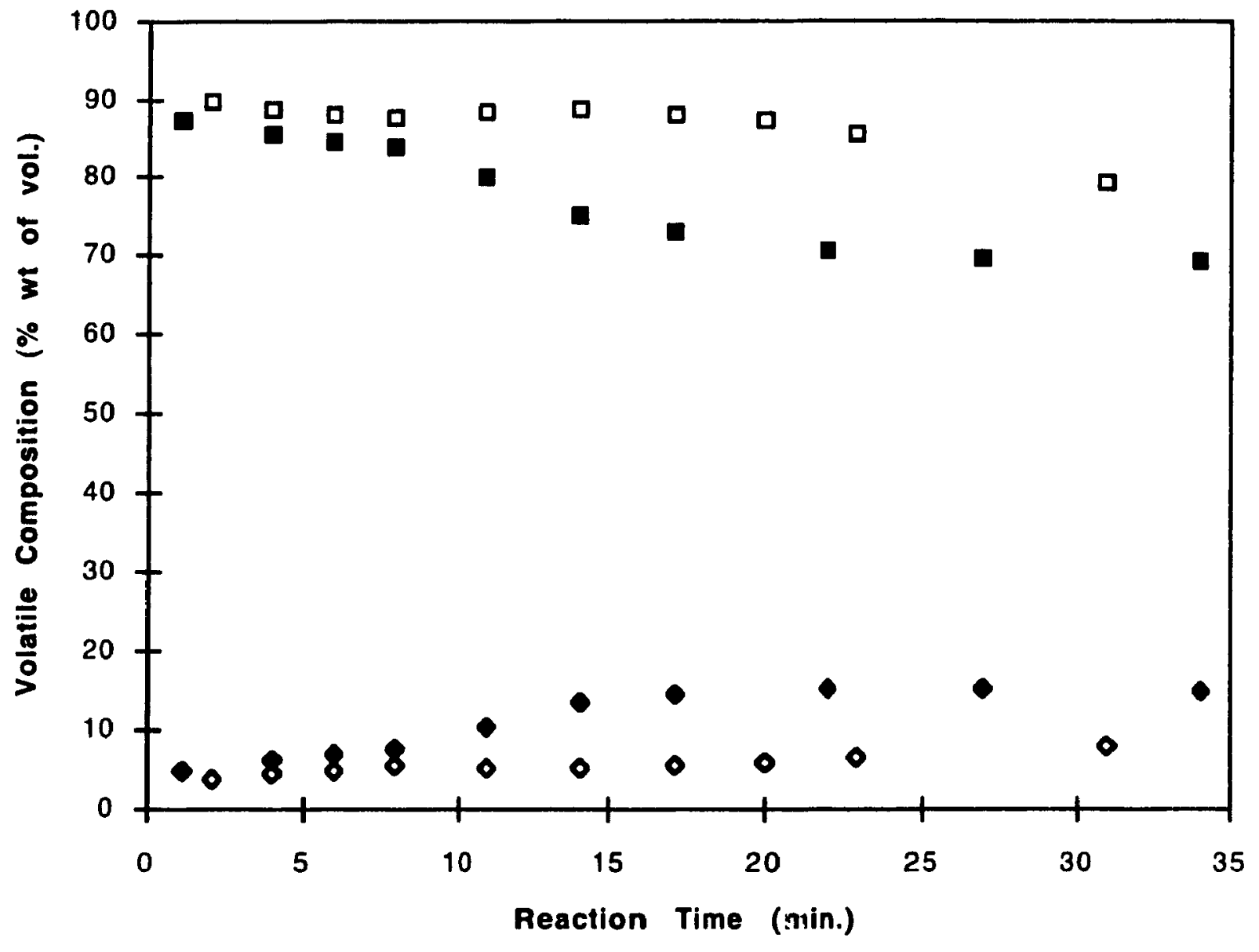

Figure 5.3, Volatile composition as a function of time at different temperatures: $\square$ Styrene at $381^{\circ} \mathrm{C}$; - Styrene at $395^{\circ} \mathrm{C}$; $\diamond$ Dimer at $381^{\circ} \mathrm{C}$; $\diamond$ Dimer at $395^{\circ} \mathrm{C}$. 


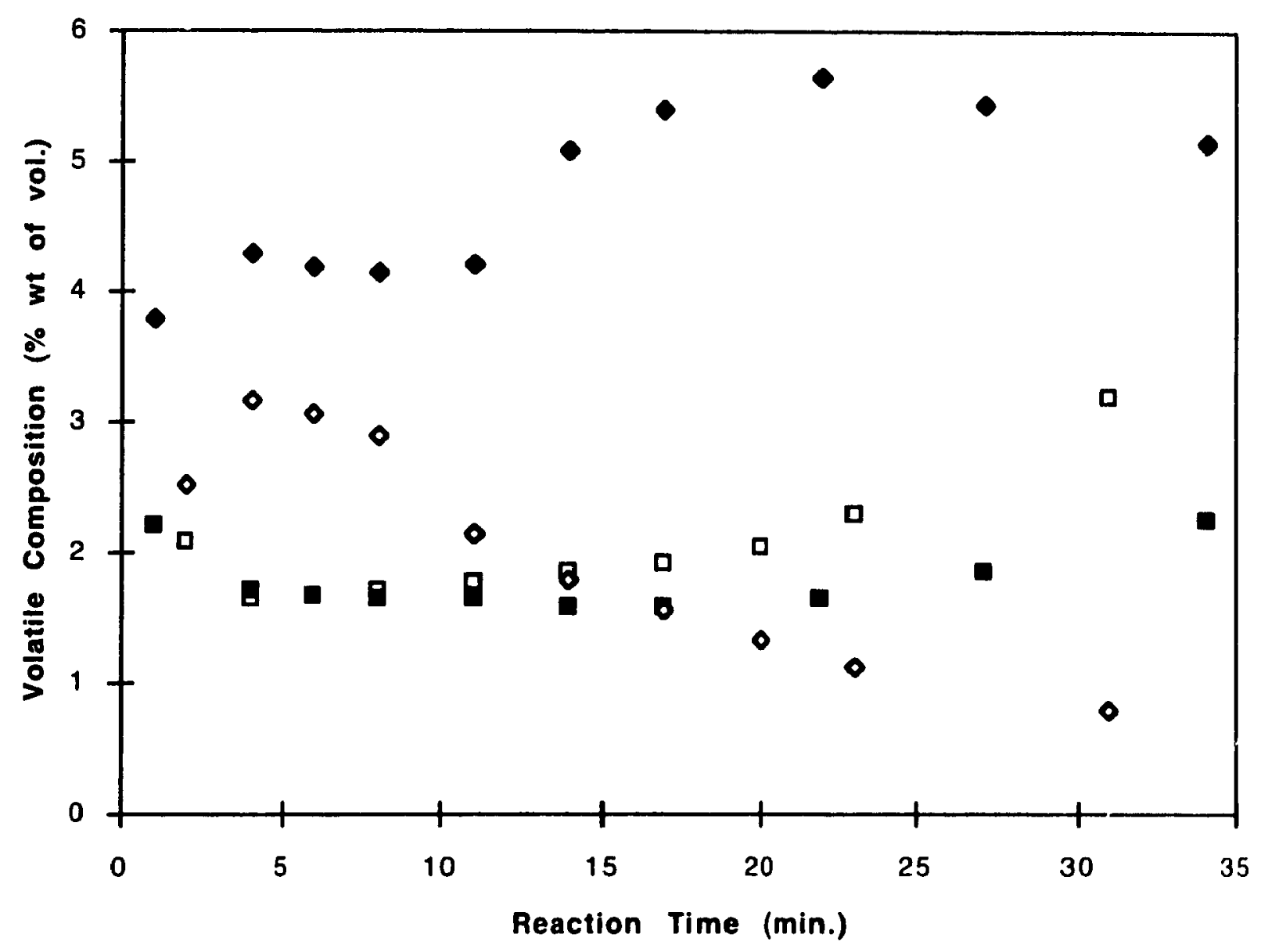

Figure 5.4, Volatile composition as a function of time at different temperatures: $\square$ Toluene at $381^{\circ} \mathrm{C}$; - Toluene at $395^{\circ} \mathrm{C}$; $\diamond$ Trimer at $381^{\circ} \mathrm{C}$; $\diamond$ Trimer at $395^{\circ} \mathrm{C}$. 


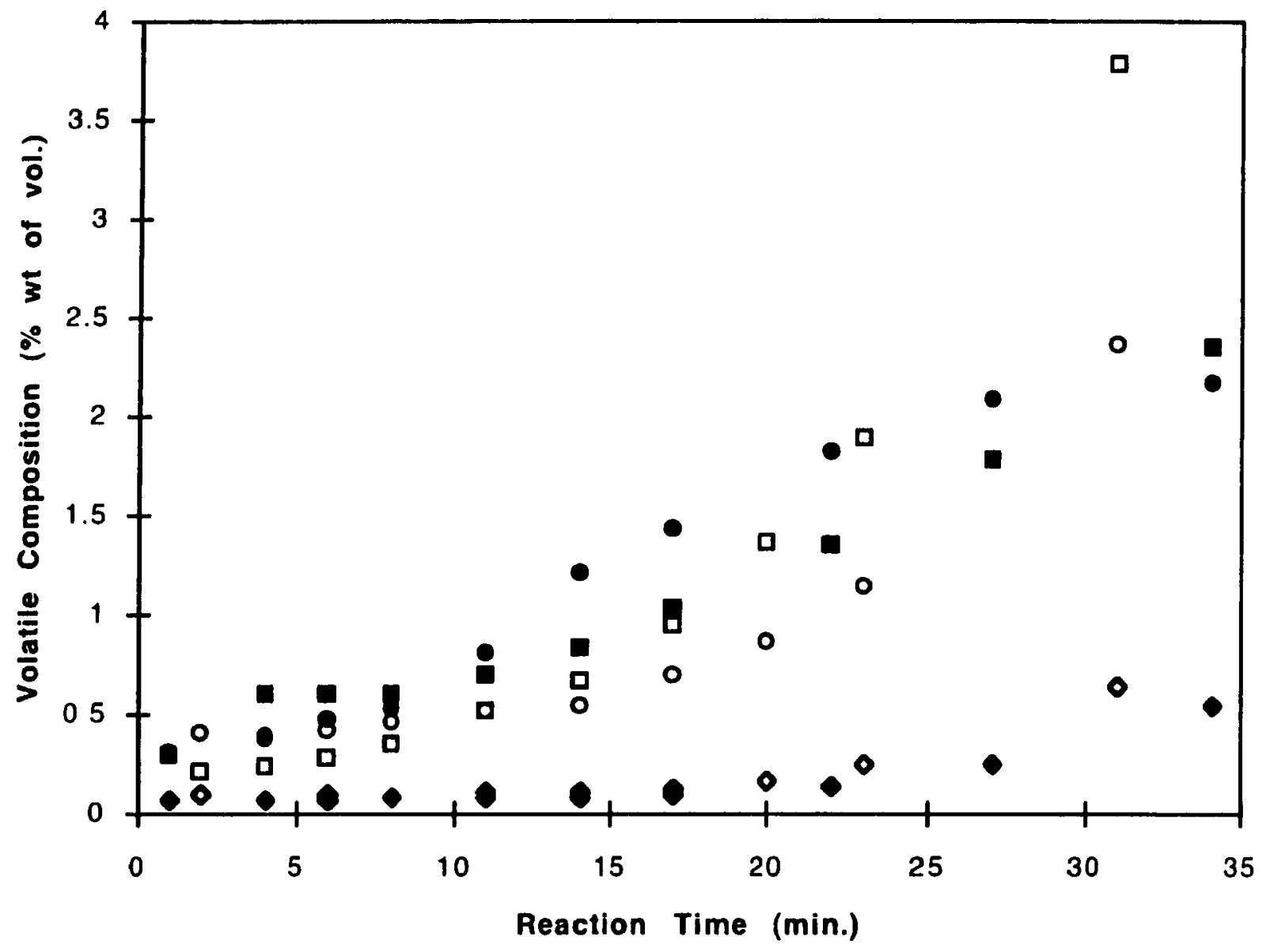

Figure 5.5, Volatile composition as a function of time at different temperatures: $\square \alpha$-Methylstyrene at $381^{\circ} \mathrm{C}$; $\alpha$-Methylstyrene at $395^{\circ} \mathrm{C}$; $\diamond$ Ethylbenzene at $381^{\circ} \mathrm{C}$; Ethylbenzene at $395^{\circ} \mathrm{C}$;

O 1,3-diphenylpropane at $381^{\circ} \mathrm{C}$; 1,3diphenylpropane at $395^{\circ} \mathrm{C}$. 
All the major components in the volatile products were identified. The cumulative concentration of each of these was plotted as a function of temperature in Figures 5.6, 5.7, 5.8 and 5.9. The compositions indicated are the fraction for each compound over the total volatile collected in a complete run. These represent the concentration of product that would have been collected if a single collection vessel was used for the entire reaction.

In Figure 5.6, there is a slight decrease in the styrene concentration when the melt or reaction temperature was increased. By increasing the temperature from $368^{\circ} \mathrm{C}$ to $395^{\circ} \mathrm{C}$, the styrene concentration decreased from $85 \% 1068 \%$ (wt styrene / wt volatile). An increase in dimer concentration, from 5\% to $15 \%$, was observed for the same $27^{\circ} \mathrm{C}$ increase in temperature. The size of the initial polystyrene charge in the reactor affected the concentration of styrene or dimer obtained in the volatile fraction. The styrene concentration was about $5 \%$ lower for the temperature range studied and the dimer concentration was $5 \%$ higher for the larger charge at the higher melt temperatures and about the same for the lower temperatures.

In Figure 5.7, it is seen that the concentrations of $\alpha$-methylstyrene and trimer were relatively small and the uncertainty is large. There was no apparent trend in the concentrations of trimer and $\alpha$-methylstyrene when the reaction temperature was changed. The size of the charge did seem to affect the trimer and $\alpha$-methylstyrene concentrations. The larger charge resulted in a lo' ',$r \alpha$ methylstyrene concentration and a higher trimer concentration.

In Figure 5.8, it is seen that the concentrations of toluene were generally higher than those of ethylbenzene. Again, for these small concentrations, there was no appaient trend in the concentrations of ethylbenzene and toluene when the reaction temperature was changed. Nor did the size of the charge affect the ethylbenzene and toluene concentrations.

Figure 5.9 shows that the size of the charge did not affect the 1,3 - 
diphenylpropane concentrations. Again, for these small concentrations, there was no apparent trend in the concentration of 1,3-diphenylpropane when the reaction temperature was changed. 


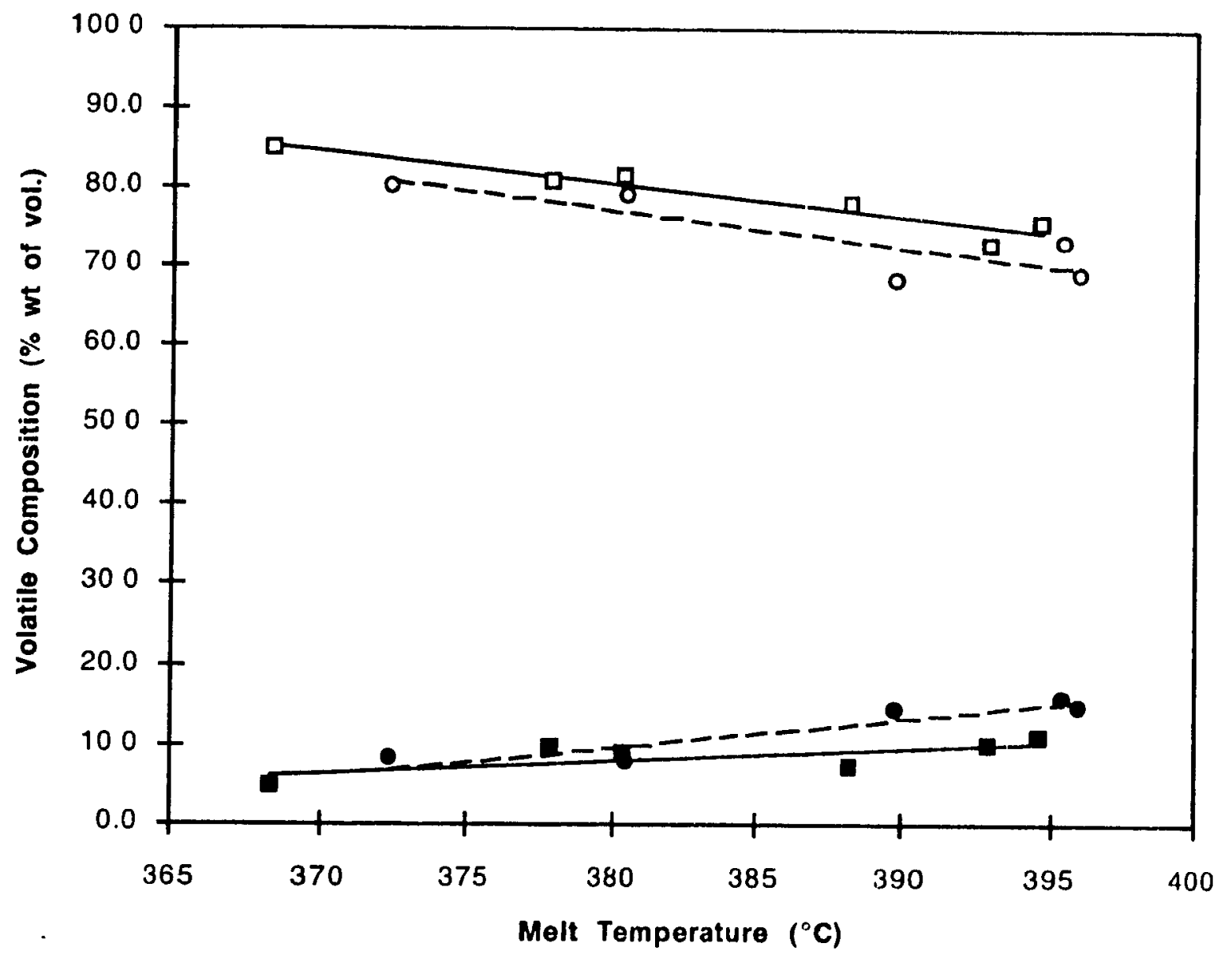

Figure 5.6, Volatile composition as a function temperature: $\square$ Styrene $120 \mathrm{~g}$; $\bigcirc$ Styrene $480 \mathrm{~g}$; - Dimer $120 \mathrm{~g}$; - Dimer $480 \mathrm{~g}$; -.- regression 120 g; - - regression $480 \mathrm{~g}$. 


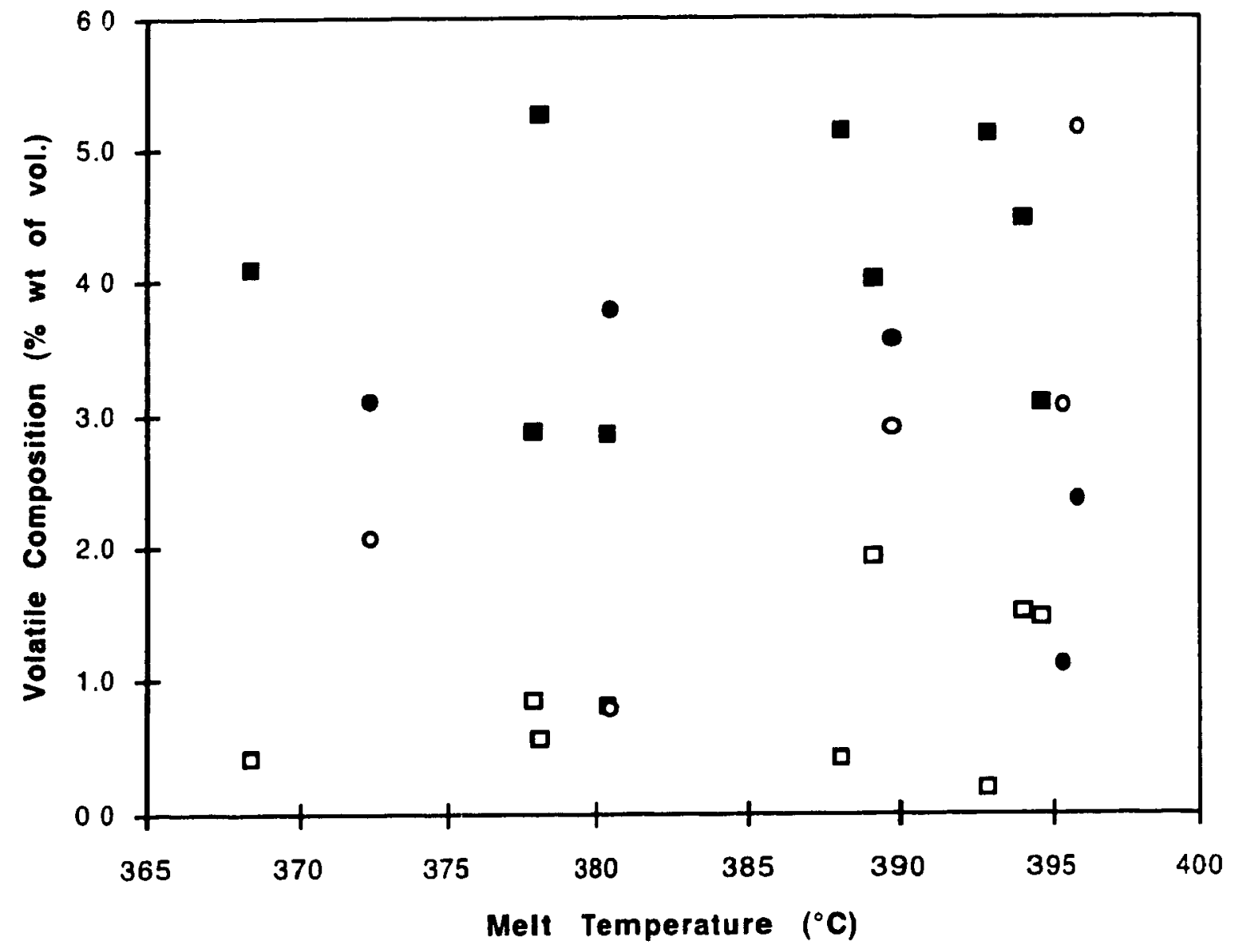

Figure 5.7, Volatile composition as a function temperature: $\square$ Trimer $120 \mathrm{~g}$; $\bigcirc$ Trimer $480 \mathrm{~g}$; $\mathbf{\alpha -}$ Methylstyrene $120 \mathrm{~g} ; \alpha$-Methylstyrene $480 \mathrm{~g}$. 


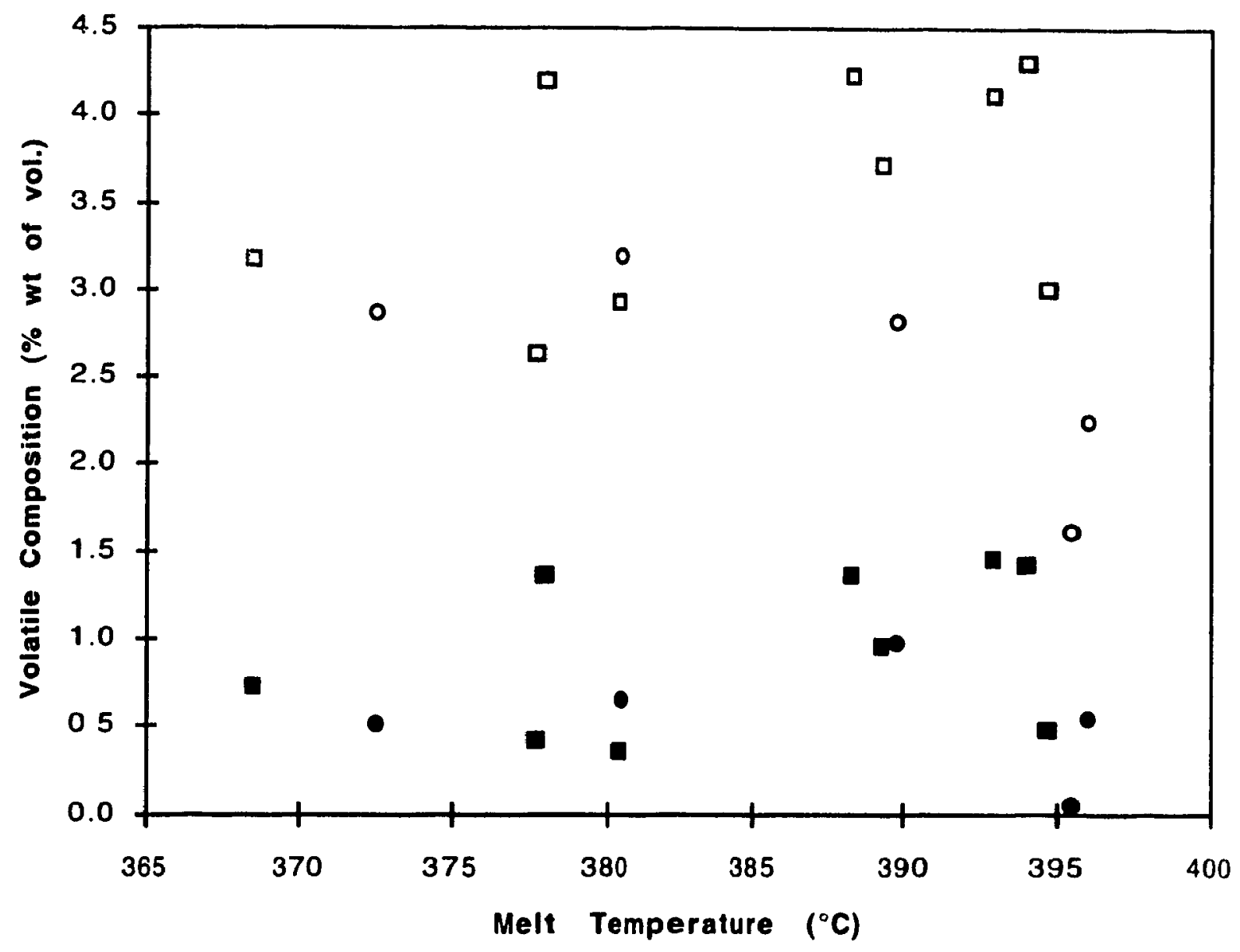

Figure 5.8, Volatile composition as a function temperature: $\square$ Toluene $120 \mathrm{~g}$; $O$ Toluene $480 \mathrm{~g}$; Ethylbenzene $120 \mathrm{~g}$; Ethylbenzene $480 \mathrm{~g}$. 


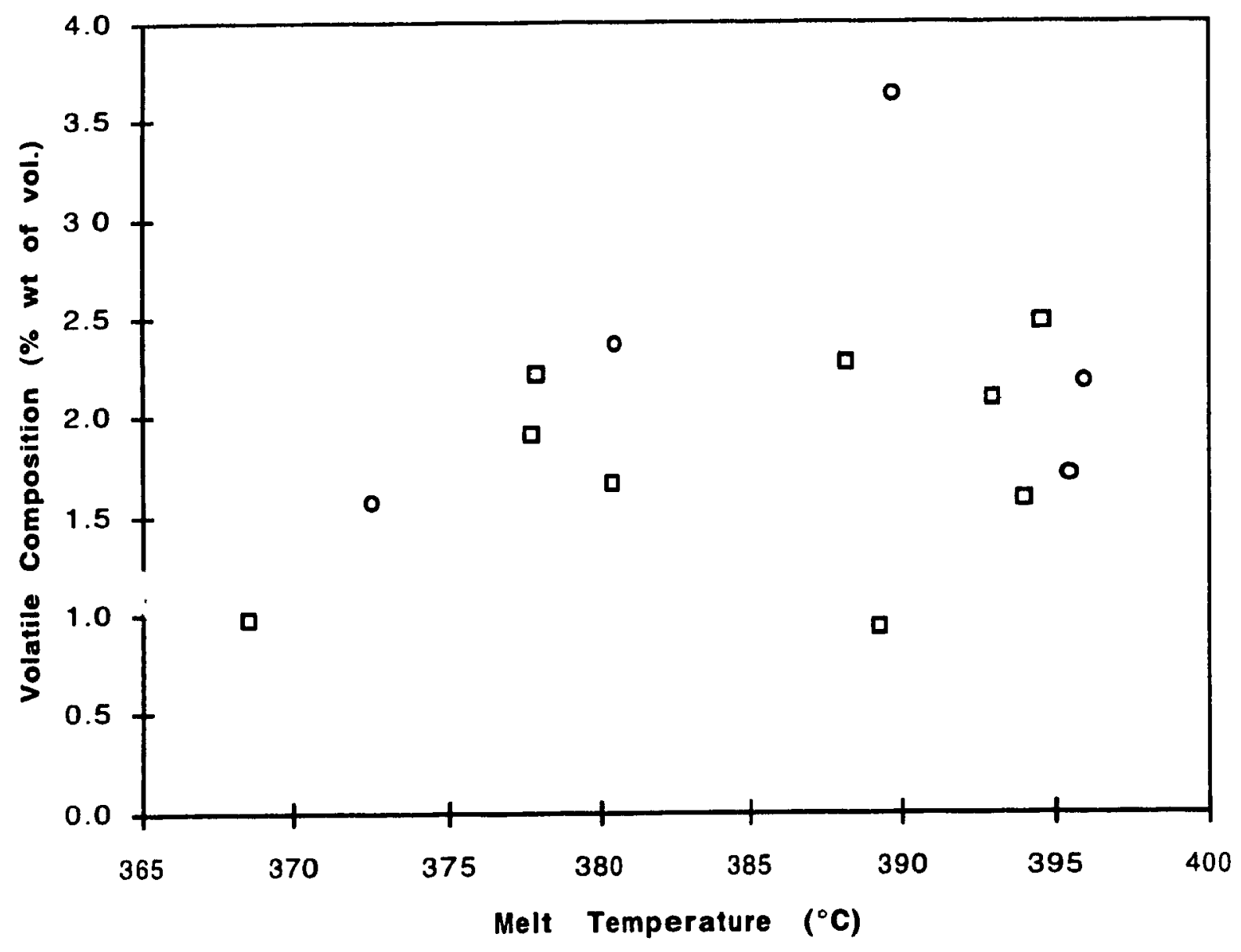

Figure 5.9, Volatile composition as a function temperature: 1,3-diphenylpropane 120 grams; $O$

1,3-diphenylpropane $480 \mathrm{~g}$. 


\subsection{Yield of Styrene}

Figure 5.10 shows the styrene collected (in grams) as a function of reaction time for different melt temperatures. Styrene collected increased as reaction time and / or mell temperature increased. This graph shows the maximum amount of styrene that can be collected with the conditions used in this work. When the initial charge is 120 grams, the maximum amount of styrene produced is about 80 grams.

Figure 5.11 shows the styrene yield (wt of styrene / wt of initial PS) as a function of reaction temperature for a reaction time of 28 to 34 minutes for different charges. The total styrene yield was found to be influenced by the size of the initial charge. The larger reactor had a lower styrene yield at low temperatures but the yield was independent of scale at higher temperatures. As seen in Figures 5.10 and 5.11, the styrene yield increased as temperature was increased but the increase was more pronounced for the larger reactor. The maximum styrene yield observed was $65 \%$ after reacting 480 grams of polystyrene for 34 minutes at $395^{\circ} \mathrm{C}$.

\subsection{Yield of Dimer}

Figure 5.12 shows the dimer collected (in grams) as a function of reaction time for different melt temperatures. The amount of dimer collected was negligible for the first 5 minutes. The amount of dimer collected increased with longer reaction time and higher melt temperature. The maximum amount of

dimer observed (11 grams) was obtained at a reaction temperature of $395^{\circ} \mathrm{C}$ after about 30 minutes.

Figure 5.13 shows the yield of dimer (wt of dimer / wt of initial PS) as a function of reaction temperature for two different initial charges. The difference in the dimer yield between the larger and smaller scales was not significant at lower temperatures but at higher temperatures more dimer was obtained from 
the larger charge. The yield of dimer increased with increasing temperature but, as observed for styrene, this trend was more pronounced with the larger reactor.

\subsection{Yield of Toluene}

Figure 5.14 shows the toluene collected as a function of reaction time for different reaction temperatures. The amount of toluene collected increased with longer reaction time and higher melt temperature. The amount of toluene collected for the first 10 minutes was under 0.5 grams. The production of toluene had not levelled off at the longest time measured.

Figure 5.15 shows the toluene yield (wt of toluene / wt of initial PS) as a function of reaction temperature for two charges. The difference in the toluene yield between the larger and smaller scale reactors is insignificant. As seen in Figures 5.14 and 5.15, the toluene yield increased slightly as temperature was increased. The increase was so small that, within the error intrinsic to the gas chromatograph measurement, the yield could be independent of melt temperature.

\subsection{Yield of Trimer}

Figure 5.16 shows the trimer collected as a function of reaction time for different melt temperatures. Trimer collected increased with increasing reaction time and increasing melt temperature. It can be seen that the production of trimer is increased greatly by increasing the melt temperature over $387^{\circ} \mathrm{C}$. The production of trimer started to levelled off at the longest time measured.

Figure 5.17 is the trimer yield (wt of trimer / wt of PS) as a function of reaction temperature for a reaction time of 28 to 34 minutes for two initial charges of different size. The difference in the trimer yield between the larger and smaller scale reactors was significant at the higher temperature. The yield of trimer was larger for the larger scale reactor. As seen in Figures 5.16 and 5.17 , the trimer yield was independent of temperature up to $390^{\circ} \mathrm{C}$ and there 
was a sudden increase in trimer yield.

\subsection{Yield of $\alpha$-Methylstyrene}

Figure 5.18 shows the $\alpha$-methylstyrene collected as a function of reaction time for different melt temperature. The amount of $\alpha$-methylstyrene collected increased with increasing reaction time and increasing melt temperature. The production of $\alpha$-methylstyrene was almost nothing for the first 10 minutes of the reaction, then there was an increase in production. There is no sign of levelling off in the $\alpha$-methylstyrene production as a function of time for any temperature studied.

Figure 5.19 is the $\alpha$-methylstyrene yield (wt of $\alpha$-methylstyrene / wt of initial PS) as a function of reaction temperature for a reaction time of 28 to 34 minutes for two different initial charges. There was no difference in the $\alpha$-methylstyrene yield between the larger and smaller scales. As seen in Figures 5.18 and 5.19, the $\alpha$-methylstyrene yield increased slightly as temperature was increased. Again the increase was so small that, within the error intrinsic to the gas chromatograph measurement, the yield could be independent of melt temperature.

\subsection{Yield of Ethylbenzene}

Figure 5.20 shows the ethylbenzene collected as a function of reaction time for different melt temperatures. The amount of ethylbenzene collected increased with increasing reaction time and increasing melt temperature. The production of ethylbenzene was nothing for the first 15 minutes of the reaction then, there was an increase. There was no sign of levelling off in the ethylbenzene production vs. time for any temperature studied.

Figure 5.21 is the ethylbenzene yield (wt of ethylbenzene / wt of initial PS) as a function of reaction temperature for a reaction time of 28 to 34 minutes for two initial charges of different size. There was no difference in the ethylbenzene 
yield between the larger and smaller scales. As seen in Figures 5.19 and 5.21, the ethylbenzene yield increased slightly as temperature was increased. The increase was so small that, within the error intrinsic to the gas chromatograph measurement, the yield could be independent of melt temperature.

\subsection{Yield of 1,3-Diphenylpropane}

Figure 5.22 shows the 1,3-diphenylpropane collected as a function of reaction time for different melt temperature. The amount of 1,3-diphenylpropane collected increased with increasing reaction time and increasing melt temperature. The production of 1,3-diphenylpropane was almost nothing for the first 5 minutes of the reaction then, there was an increase in production.

Figure 5.23 is the 1,3-diphenylpropane yield (wt of 1,3-diphenylpropane / wt of initial PS) as a function of reaction temperature for a reaction time of $\mathbf{2 8}$ to 34 minutes for two charges of different size. There was no significant difference in the 1,3-diphenylpropane yield between the larger and smaller scales. As seen in Figure 5.22 and in Figure 5.23, the 1,3-diphenylpropane yield small increased as temperature was increased. The increase was so small that, within the error intrinsic to the gas chromatograph measurement, the yield could be independent of melt temperature. 


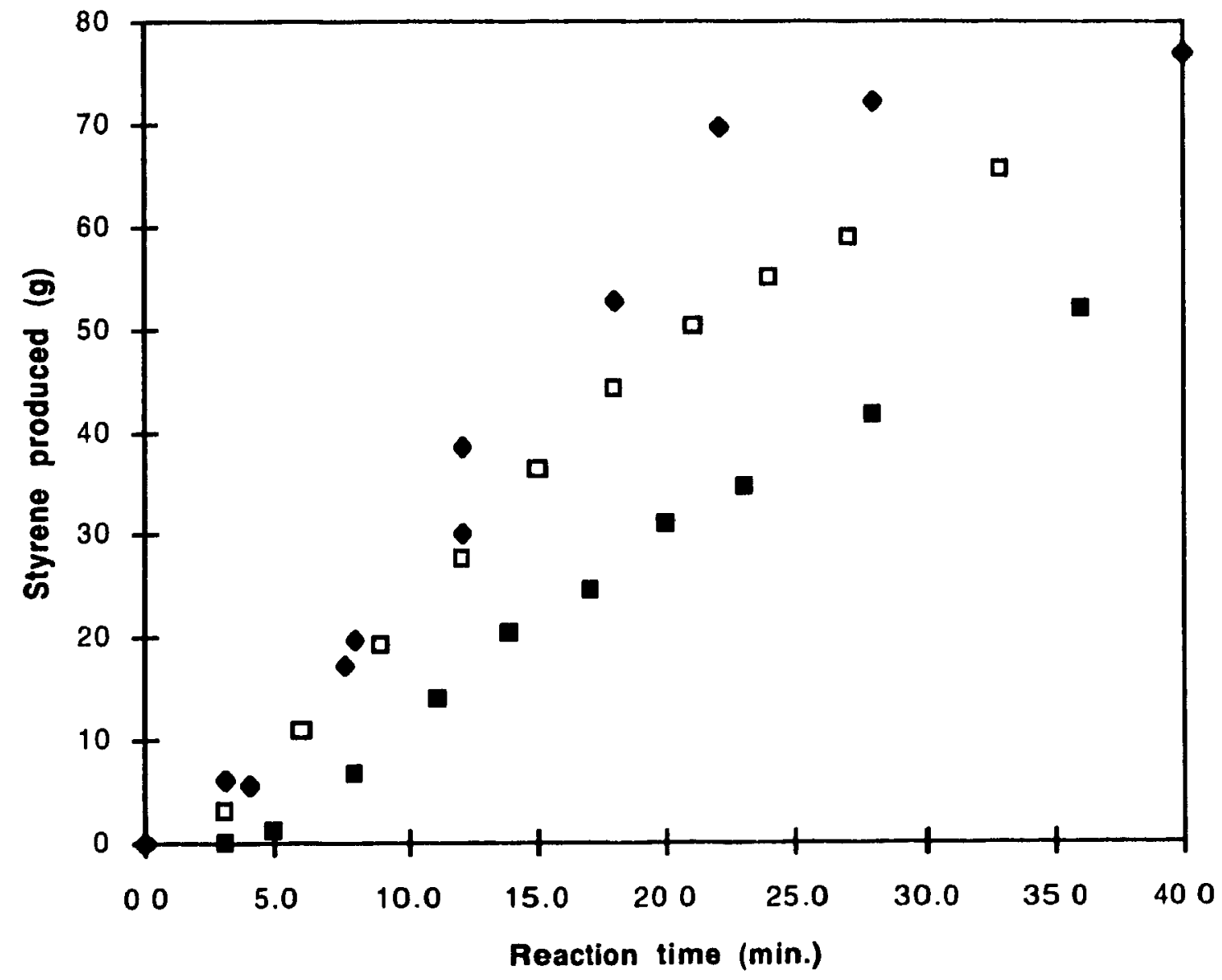

Figure 5.10, Styrene production as a function of time for different temperature: $\square 368^{\circ} \mathrm{C}$; $387^{\circ} \mathrm{C}$; $394^{\circ} \mathrm{C}$. 


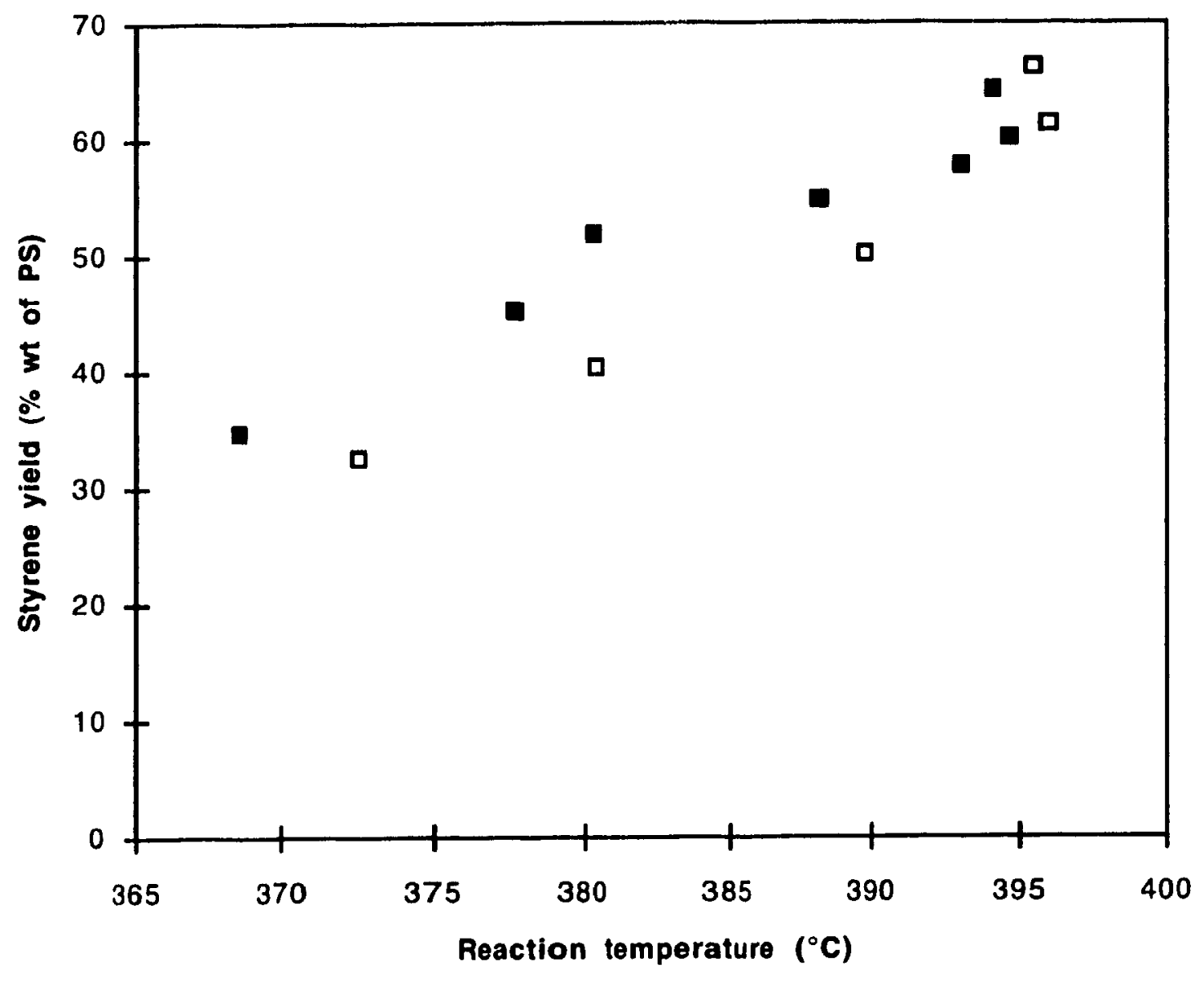

Figure 5.11, Styrene yields as a function of temperature for 30 minutes reaction and for different charges: 120 grams; $\square \mathbf{4 8 0} \mathrm{g}$. 


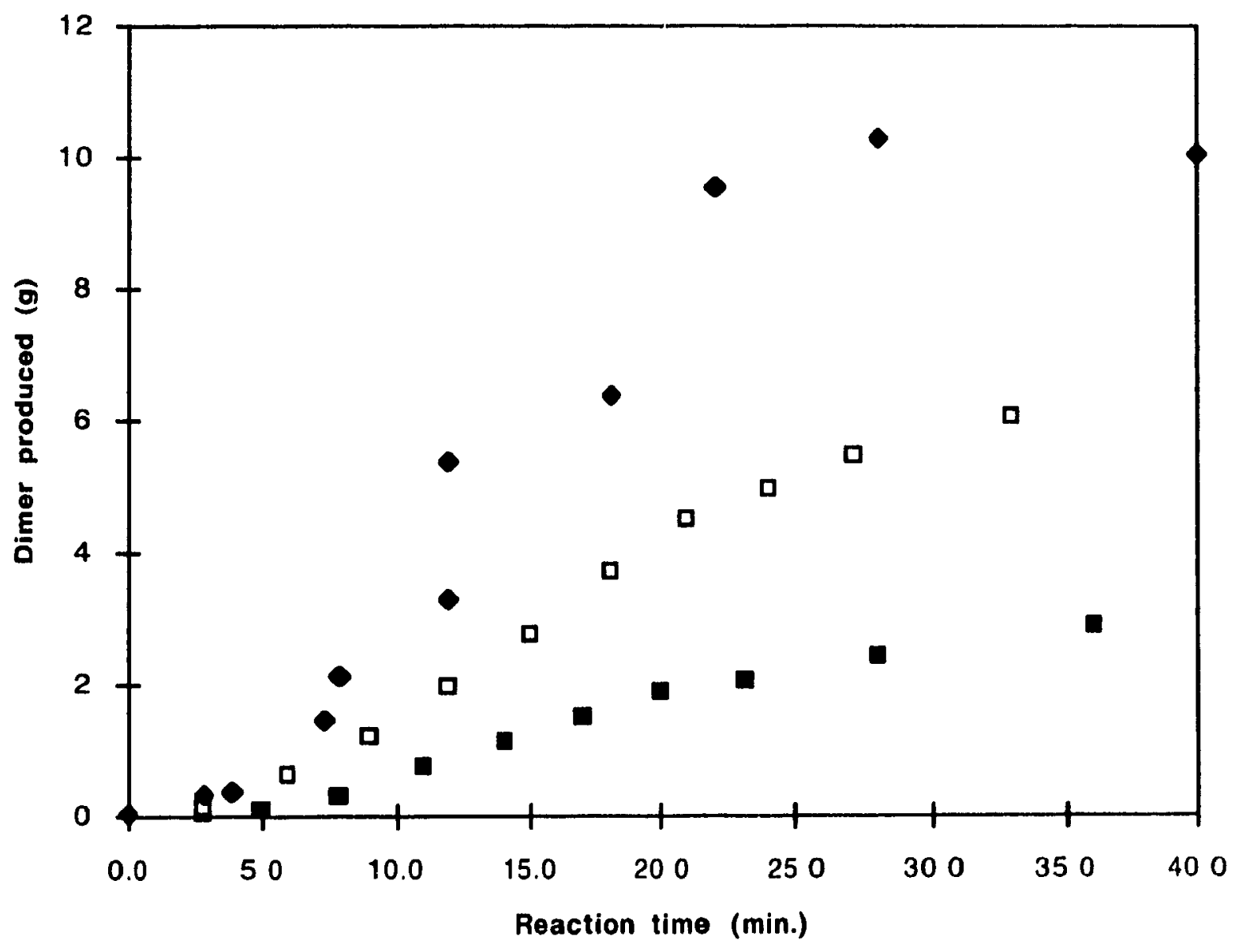

Figure 5.12, Dimer production as a function of time for different temperature: $368^{\circ} \mathrm{C}$; $387^{\circ} \mathrm{C}$; $394^{\circ} \mathrm{C}$. 


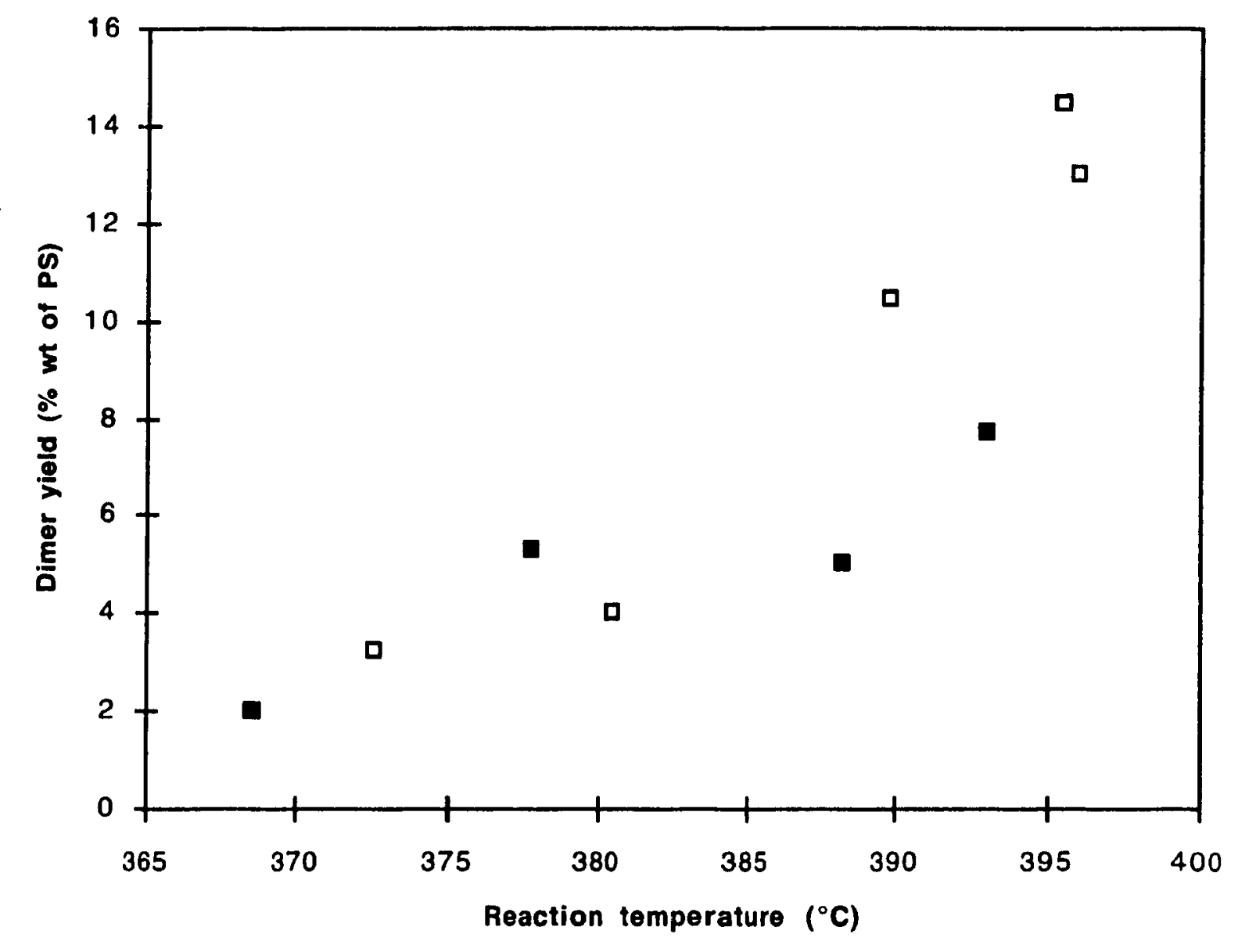

Figure 5.13, Dimer yield as a function of temperature for $\mathbf{3 0}$ minutes reaction and for different charges: 120 grams; $480 \mathrm{~g}$. 


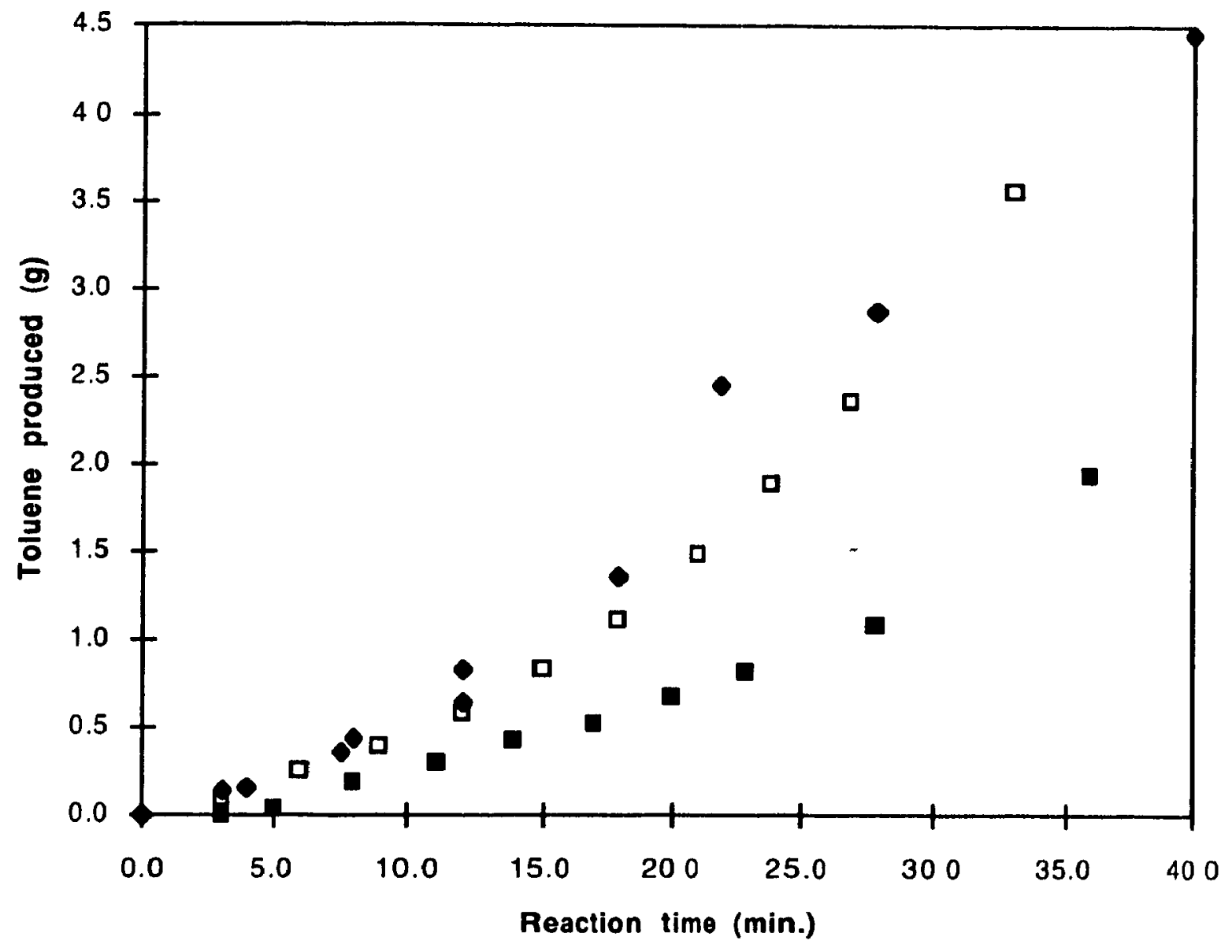

Figure 5.14, Toluene production as a function of time for different temperature: $\square 368^{\circ} \mathrm{C} ; \square 387^{\circ} \mathrm{C}$; $394^{\circ} \mathrm{C}$. 


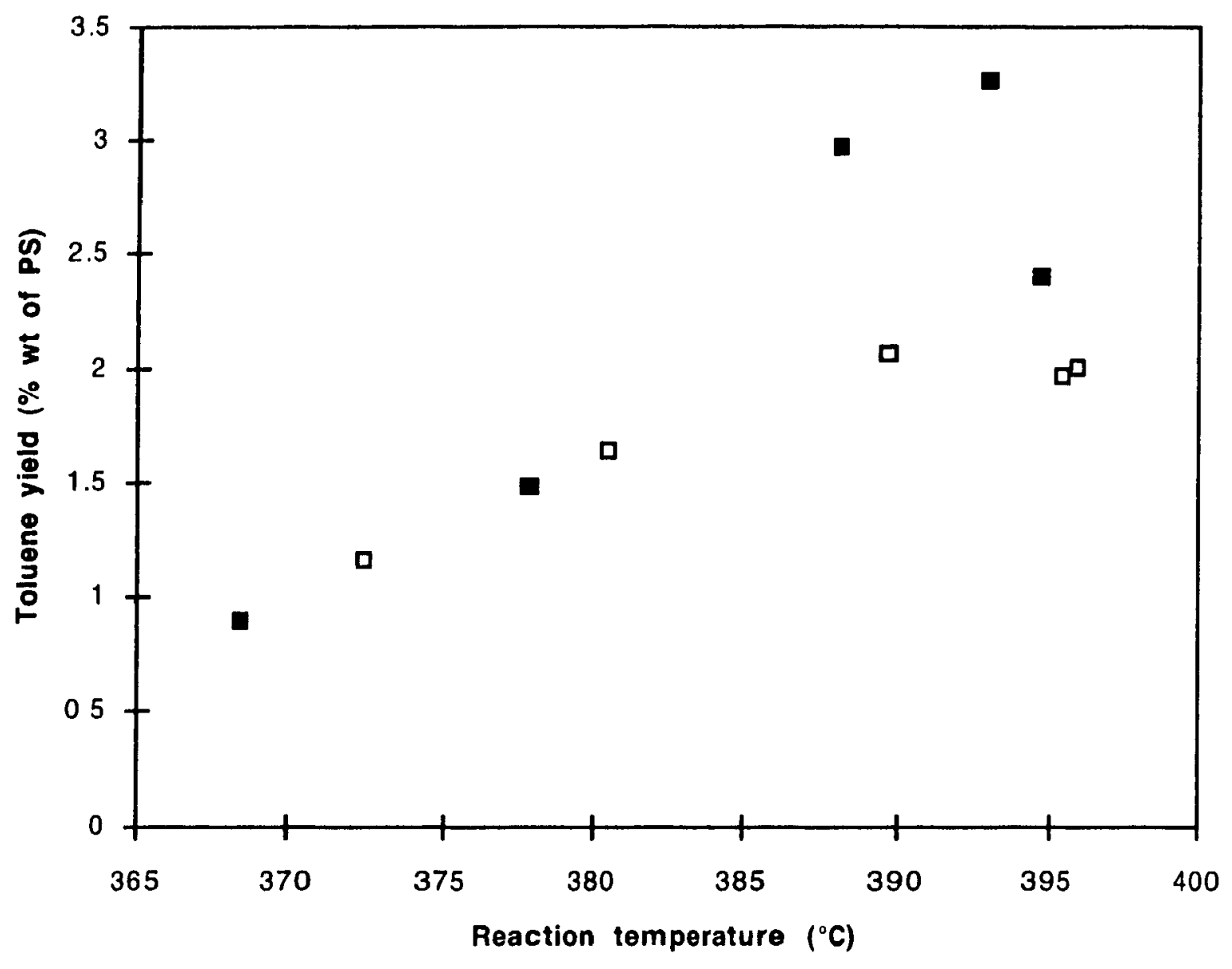

Figure 5.15, Toluene yields as a function of temperature for $\mathbf{3 0}$ minutes reaction and for different charges: 120 grams; $480 \mathrm{~g}$. 


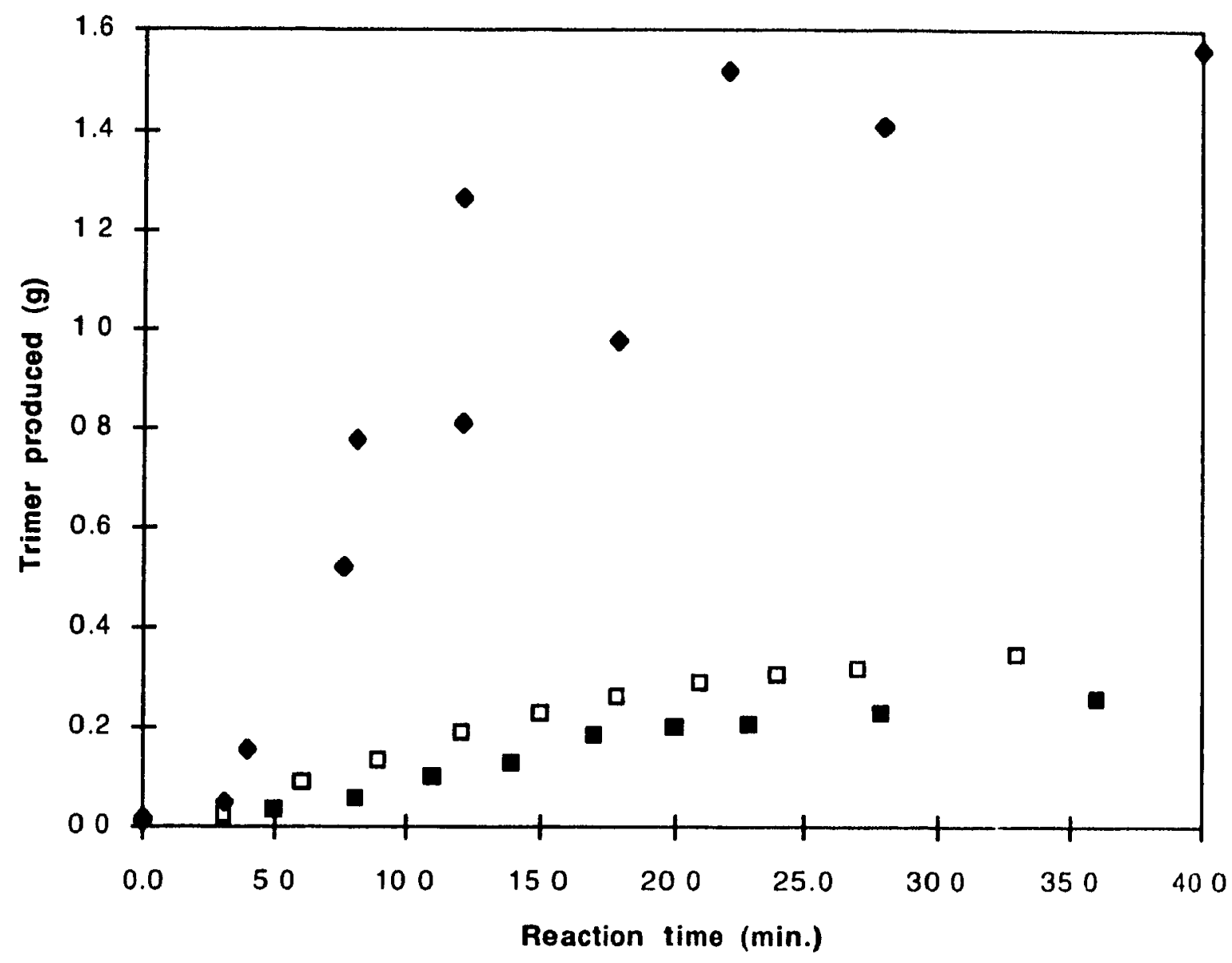

Figure 5.16, Trimer production as a function of time for different temperature: $\square 368^{\circ} \mathrm{C} ; \square 387^{\circ} \mathrm{C}$; $394^{\circ} \mathrm{C}$. 


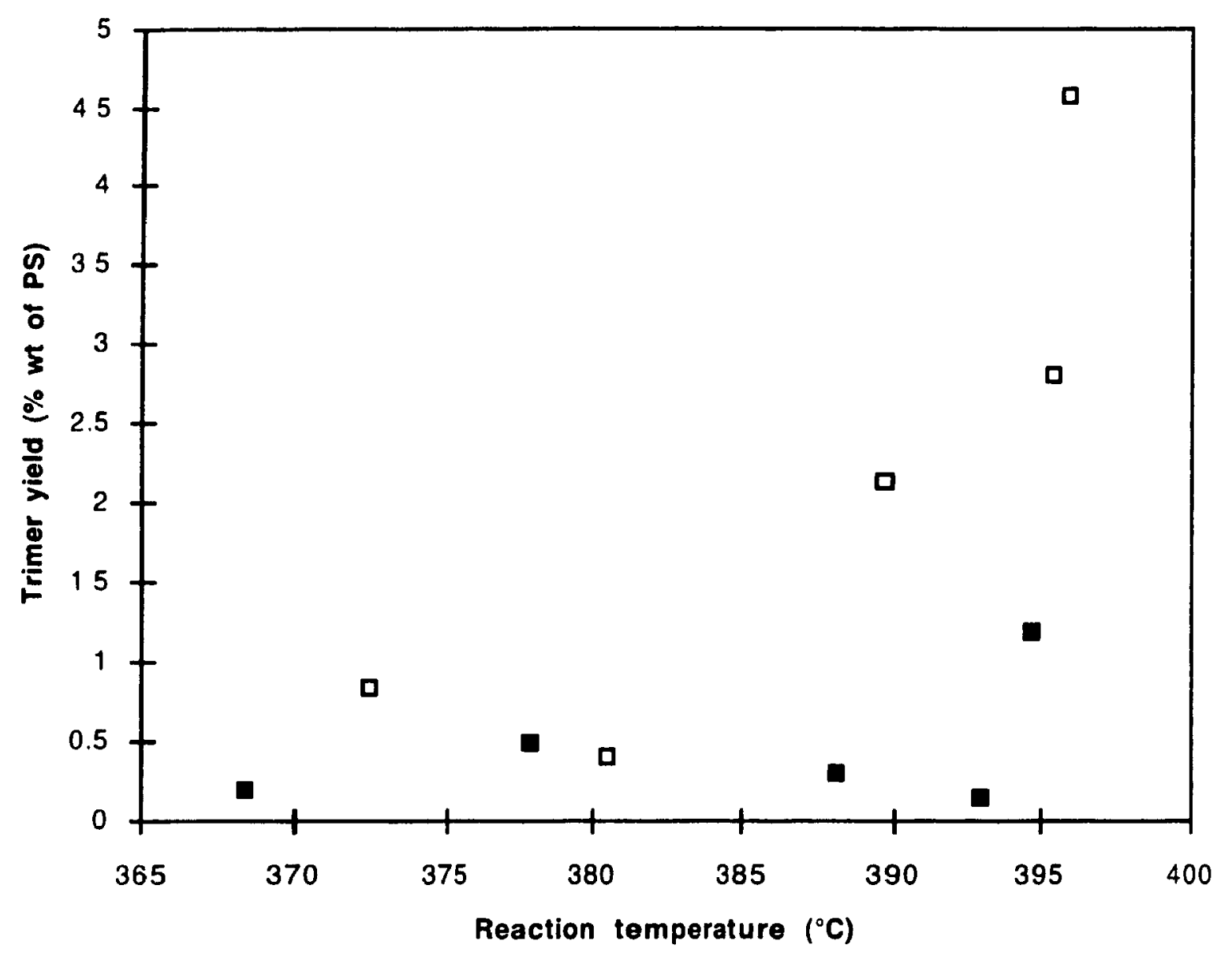

Figure 5.17, Trimer yield as a function of temperature for 30 minutes reaction and for different charges: $\square 120$ grams; $\square \mathbf{4 8 0} \mathrm{g}$. 


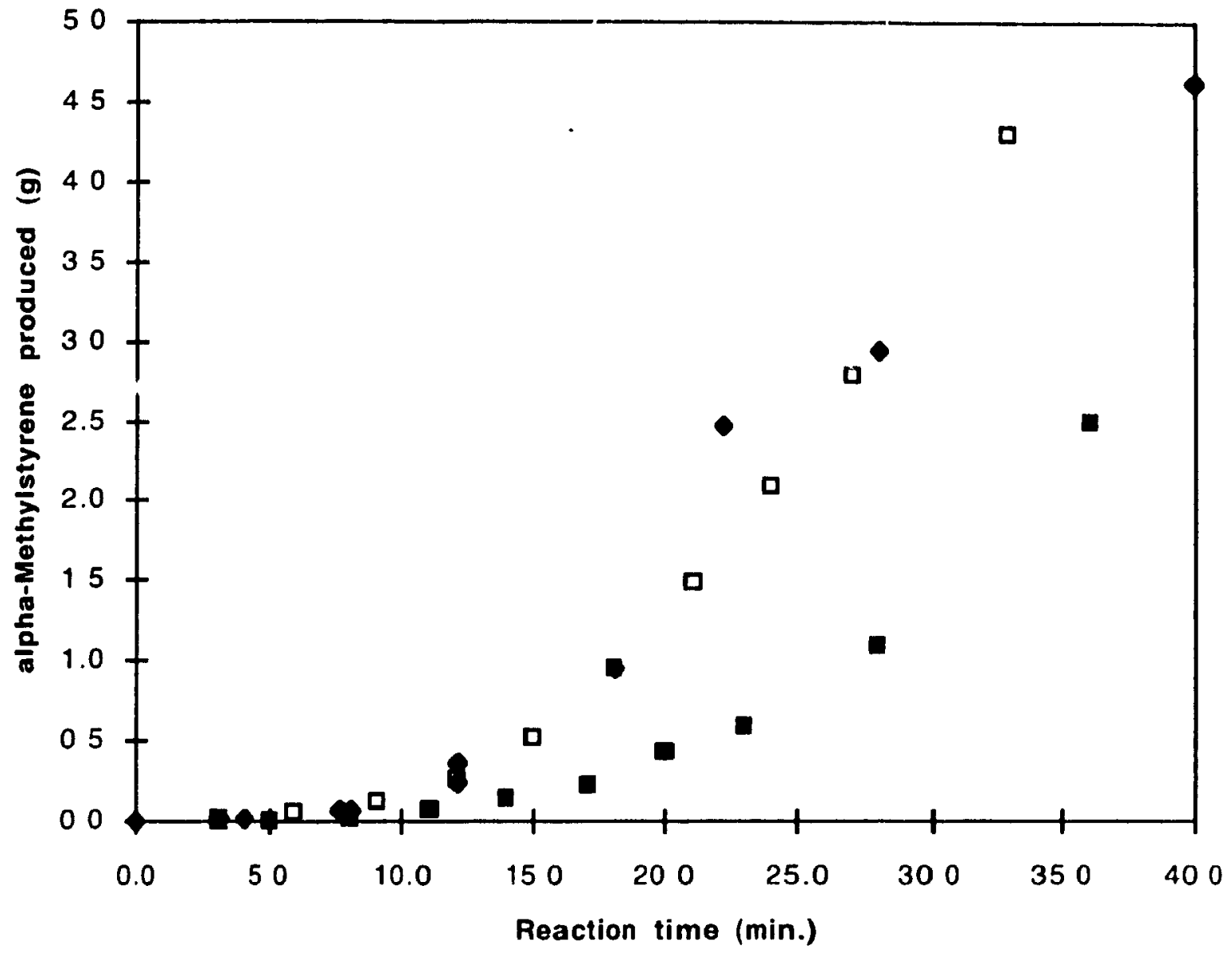

Figure 5.18, $\alpha$-Methylstyrene production as a function of time for different temperature: $\square 368^{\circ} \mathrm{C}$; a $387^{\circ} \mathrm{C} ; \bullet 394^{\circ} \mathrm{C}$. 


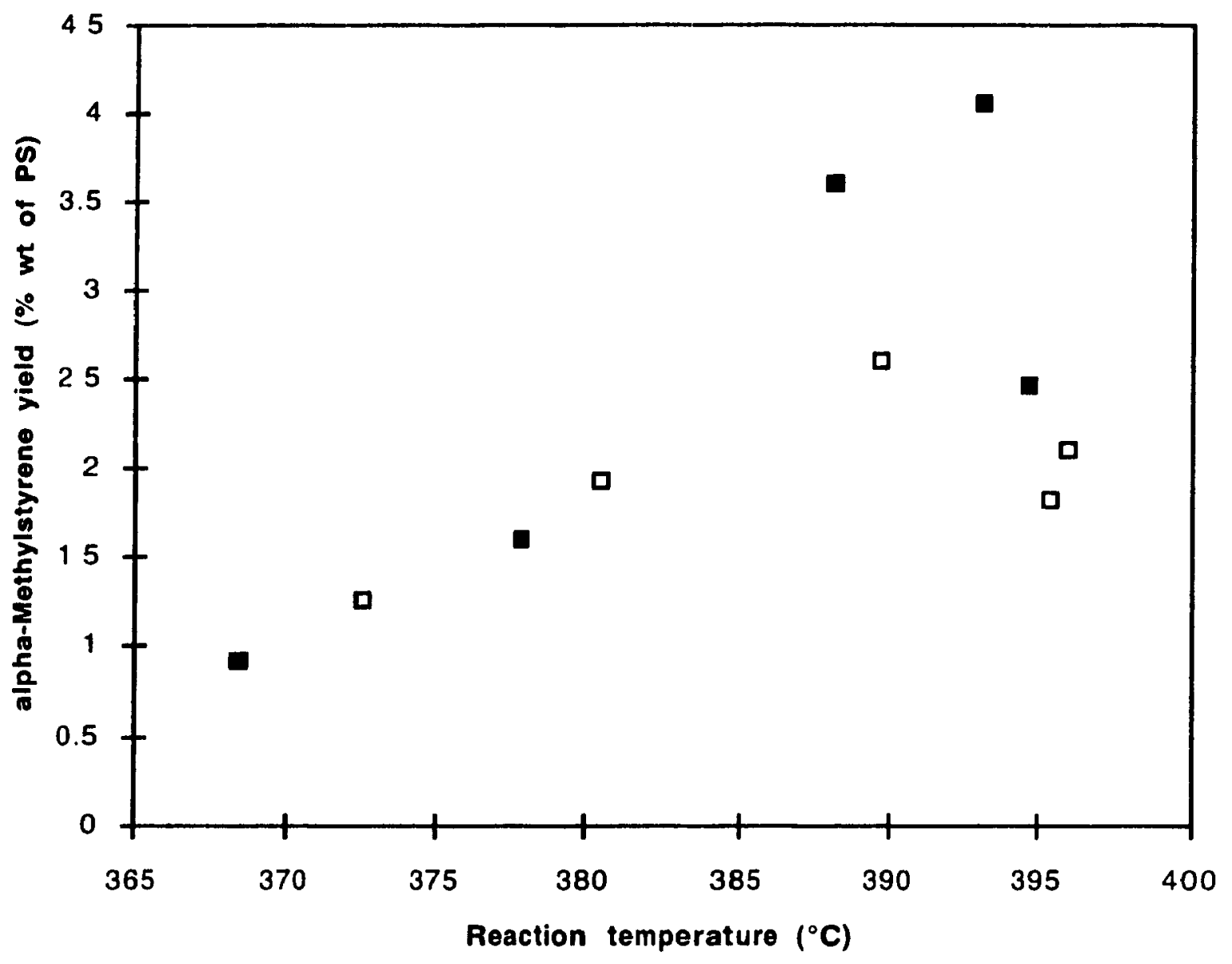

Figure 5.19, $\alpha$-Methylstyrene yield as a function of temperature for 30 minutes reaction and for different charges: $\square 120$ grams; $\square \mathbf{4 8 0} \mathrm{g}$. 


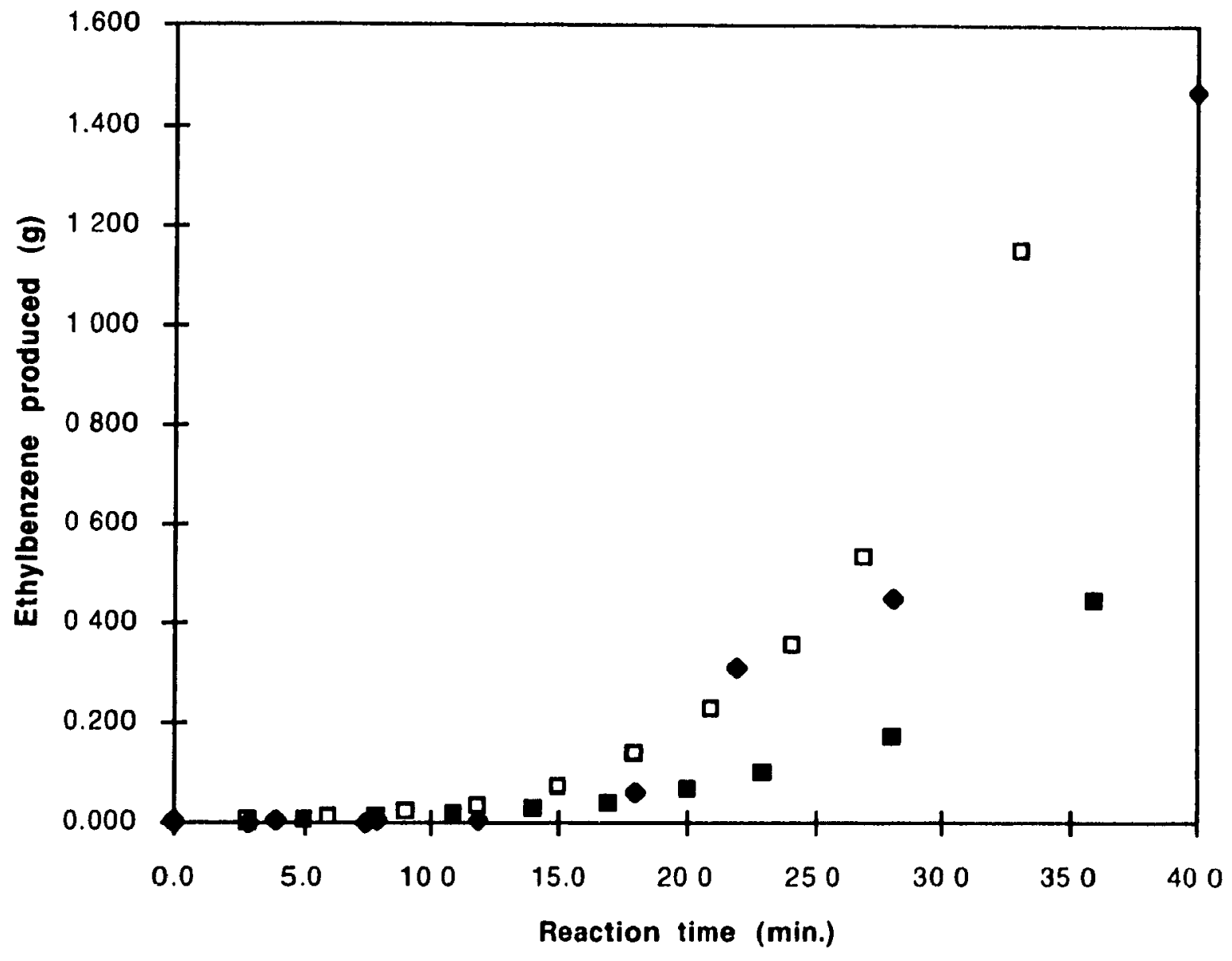

Figure 5.20, Ethylbenzene production as a function of time for different temperature: $\square 368^{\circ} \mathrm{C}$; $387^{\circ} \mathrm{C}$; $394^{\circ} \mathrm{C}$. 


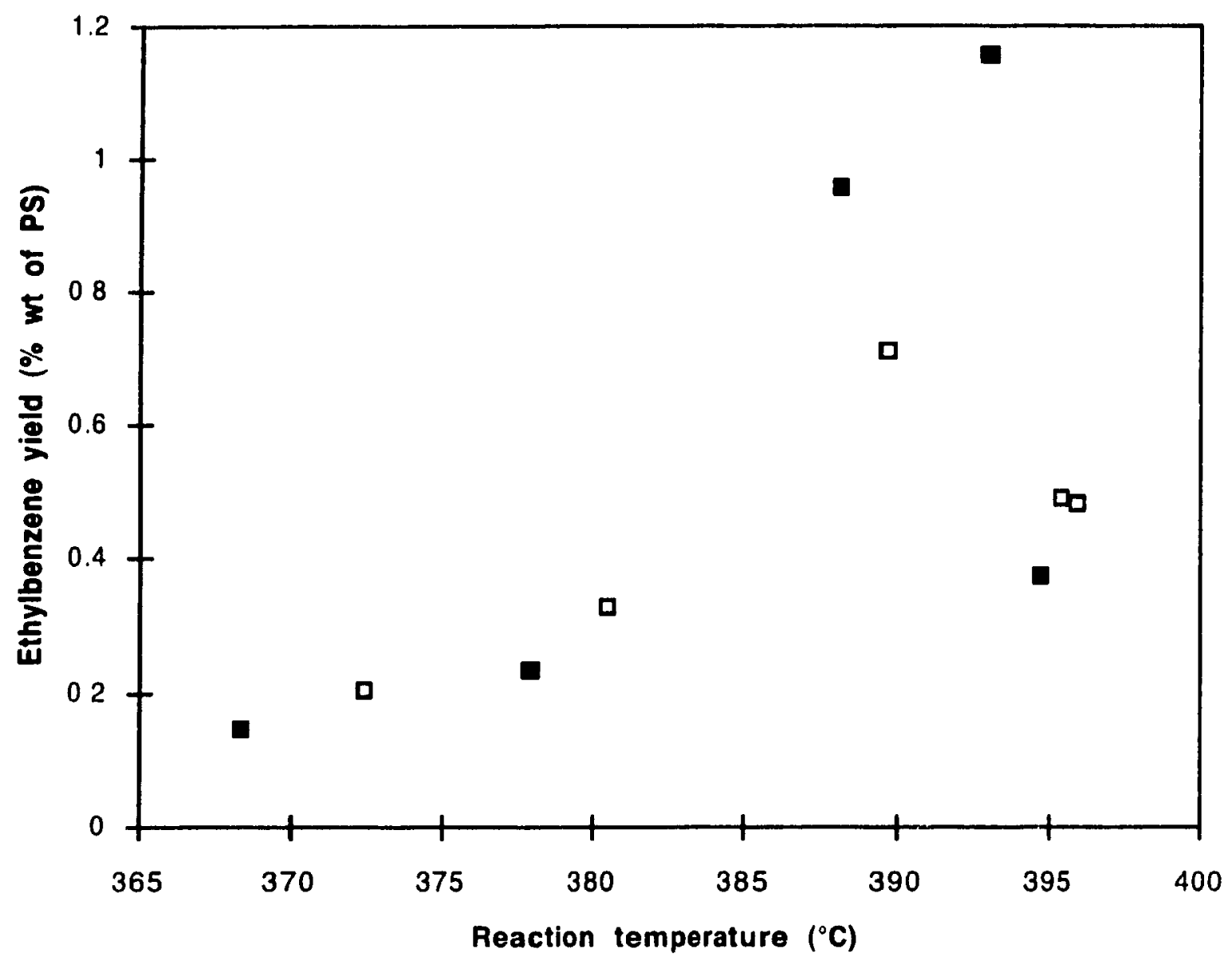

Figure 5.21, Ethylbenzene yield as a function of temperature for $\mathbf{3 0}$ minutes reaction and for different charges: 120 grams; $\square 480 \mathrm{~g}$. 


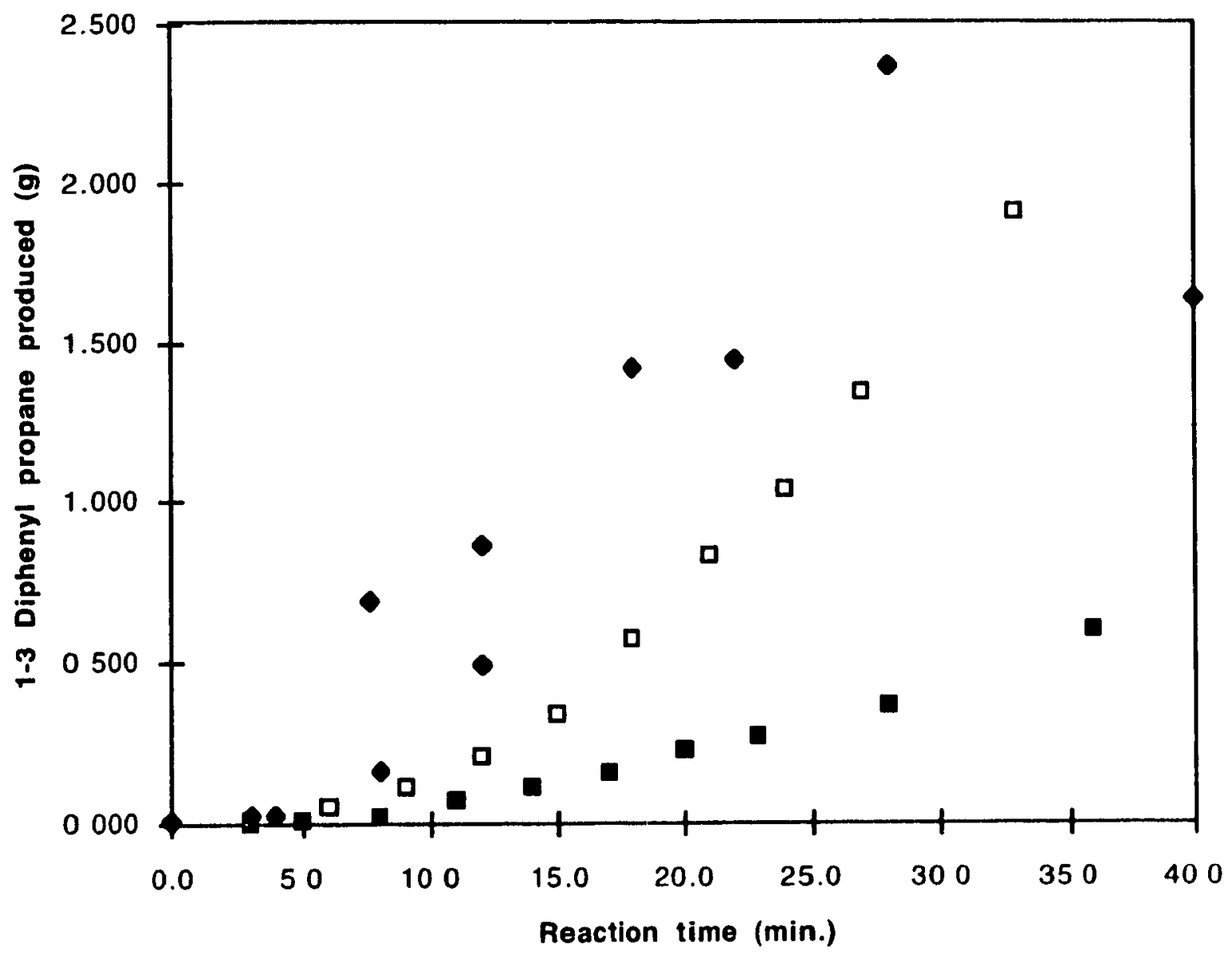

Figure 5.22, 1,3-diphenylpropane production as a function of time for different temperature: $368^{\circ} \mathrm{C}$;

ㄱ $387^{\circ} \mathrm{C}$; $394^{\circ} \mathrm{C}$. 


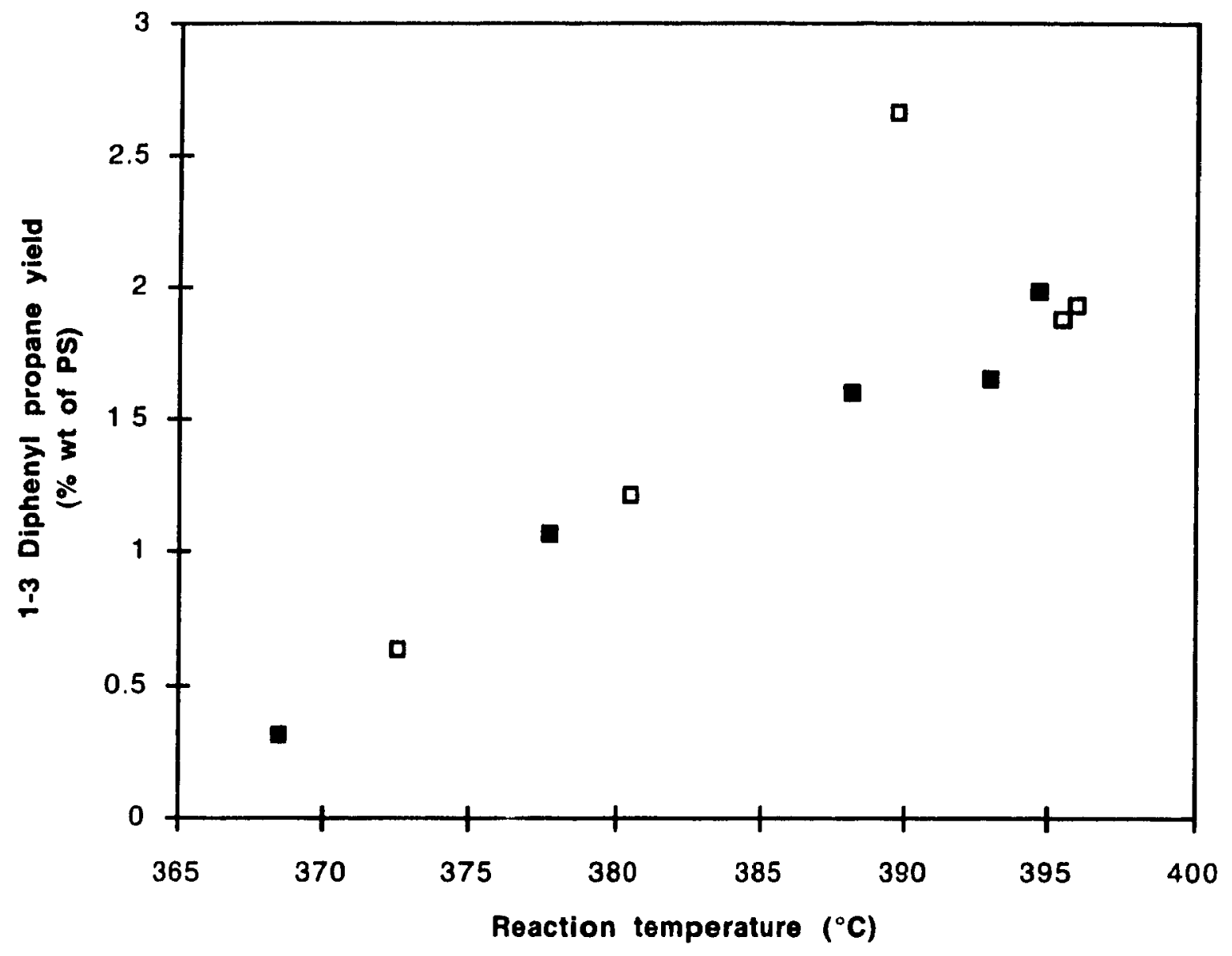

Figure 5.23, 1,3-Diphenylpropane yield as a function of temperature for $\mathbf{3 0}$ minutes reaction and for different charges: $\square 120$ grams; $\square 480 \mathrm{~g}$. 


\subsection{Amount of Residue}

The amount of residue is tabulated in Table 5.1. The residue yield (wt of residue / wt of initial PS) versus melt temperature for different times and charges is shown in Figure 5.24. As expected, the residue yield decreased as the temperature was increased. The residue yield from a reaction of 9 to 12 minutes was larger than that from a 28 to 34 minutes reaction. The initial charge in the reactor had no effect on the residue yield.

\subsection{Residue composition}

Figure 4.5 shows a NMR spectrum of polystyrene. Four broad peaks are observed in this spectrum: the peak from 1.2 to 1.7 PPM represents the methylene protons, from 1.7 to 2.2 PPM the protons on a carbon next to a phenyl group (methine), from 6.3 to 6.9 PPM the aromatic protons in the ortho position and from 6.9 to 7.5 PPM were the aromatic protons in the para and metapositions.

Figure 4.6 shows a typical NMR spectrum of the residue. This residue was obtained after 33 minutes of reaction at $370^{\circ} \mathrm{C}$. The spectrum exhibits new peaks. The methylene, methine and both aromatic peaks are still observed, but three new ranges of peak appear: 2.5 to $3.1 \mathrm{PPM}, 3.5$ to 4.2 PPM and 5.0 to 6.0 PPM. The 2.5-3.1 PPM range indicates a proton on a carbon adjacent to a terminal phenyl group (terminal methylene) and the 5.0-6.0 PPM range reflects unsaturation. The 3.5-4.2 PPM range could not be explained. One kind of unsaturation important for this work was a terminal double bond, its peak shows at 5.8 PPM. Also important to notice is that a proton on a carbon between an aromatic ring and a double bond has a quartet in the same range as a proton on an aromatic ring in ortho position with the same intensity as a terminal double bond.

Important peak intensities are shown in Table 5.2. The first three columns 
are the same as in Table 5.1. The next four are ${ }^{1} H$ NMR intensities of peaks indentified in Figures 4.5 and 4.6.

Figure 5.25 gives the molecular weight of the residue, measured by cryoscopy, as a function of the volatile yield. Clearly, there is a decrease in the molecular weight of the residue as the volatile yield increases. There is a large decrease during the first $15-20 \%$ volatilization. Subsequently, the decrease is more gradual. A curve was fitted to the data to better show the trend. 


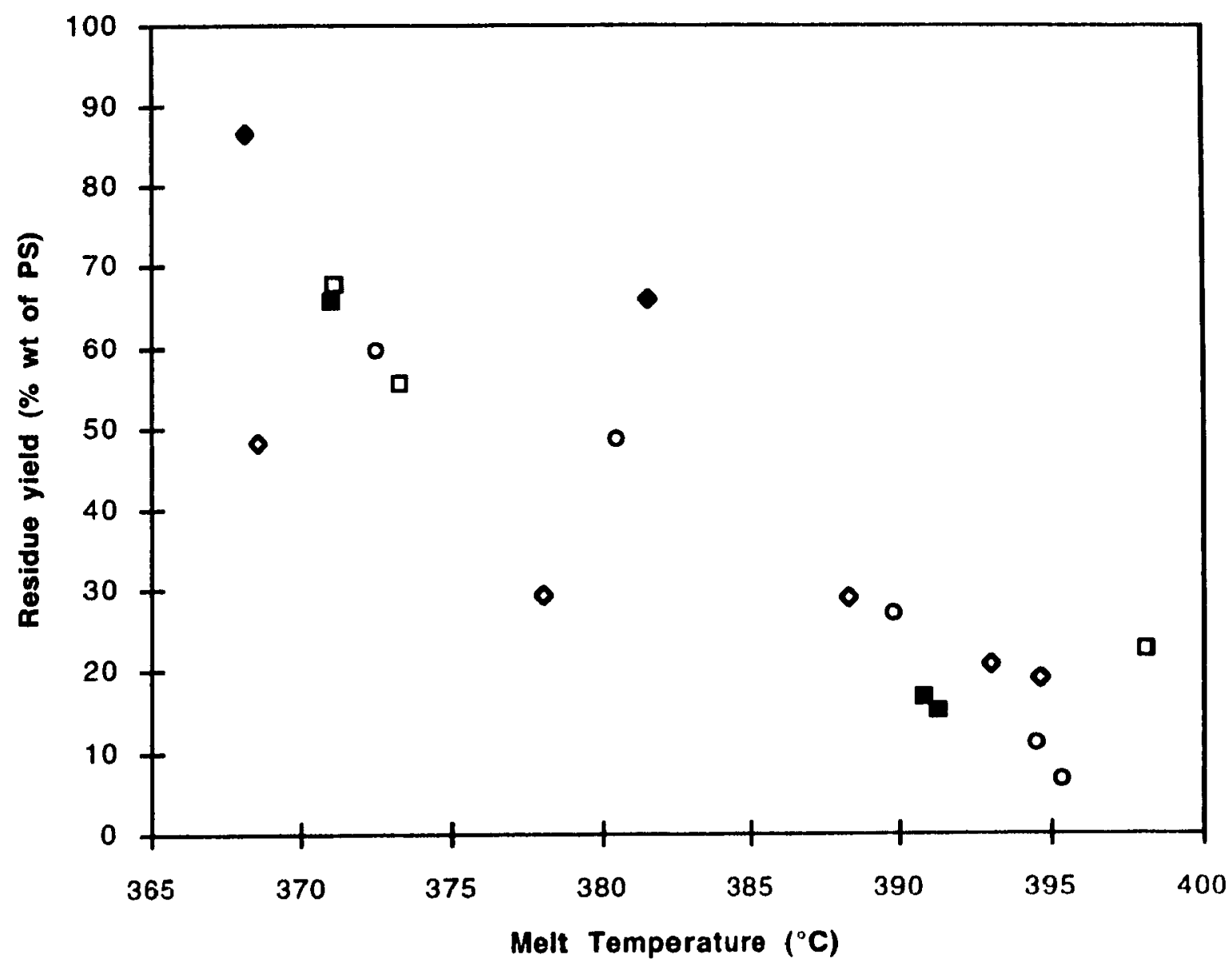

Figure 5.24, Residue yields as a function of temperature for $\mathbf{3 0}$ minutes reaction and for different charges: $\square 30$ grams; $\square 60 \mathrm{~g} ; \diamond 120 \mathrm{~g}$; $120 \mathrm{~g}$, 9-12 min; $O 480 \mathrm{~g}$. 
Table 5.2, Data of Integration of ${ }^{1} \mathrm{H}$ NMR for Experiments.

\begin{tabular}{|c|c|c|c|c|c|c|}
\hline $\begin{array}{c}\text { React. } \\
\text { time } \\
\text { (min) }\end{array}$ & $\begin{array}{c}\text { Temp. } \\
\left({ }^{\circ} \mathrm{C}\right)\end{array}$ & $\begin{array}{c}\text { Charge } \\
\text { (g) }\end{array}$ & $d, e$ & $\begin{array}{l}\text { NMR } \\
\mathbf{c , h}\end{array}$ & Intensities & $\mathbf{a}$ \\
\hline \multicolumn{3}{|c|}{ Styrene } & 95.5 & 19.7 & 19.7 & 0.0 \\
\hline \multicolumn{3}{|c|}{ Polystyrene } & 175.9 & 116.2 & 0.0 & 104.8 \\
\hline 20.0 & 381 & 30.2 & 171.0 & 6.6 & 7.1 & 10.2 \\
\hline 30.0 & 404 & 30.0 & 172.7 & 1.8 & 0.0 & $?$ \\
\hline 30.0 & 398 & 30.1 & 174.8 & 5.7 & 6.0 & 10.4 \\
\hline 30.0 & 391 & 60.0 & 168.9 & 10.1 & 2.3 & $?$ \\
\hline 16.0 & 392 & 90.0 & 173.6 & $?$ & 1.7 & $?$ \\
\hline 21.0 & 401 & 120.0 & 165.7 & 5.6 & 3.2 & 12.0 \\
\hline 22.0 & 391 & 60.1 & 174.4 & 5.2 & 1.0 & 14.6 \\
\hline 24.0 & 421 & 59.9 & 168.8 & $?$ & 0.7 & 11.3 \\
\hline 12.0 & 388 & 60.1 & 179.1 & 58.2 & 1.7 & 53.8 \\
\hline 9.0 & 382 & 120.0 & 165.6 & 73.7 & 1.0 & 65.7 \\
\hline 12.0 & 368 & 120.1 & 154.5 & 73.7 & 2.7 & 64.2 \\
\hline 34.0 & 395 & 480.6 & 167.9 & 17.2 & 4.3 & 17.9 \\
\hline 28.0 & 395 & 120.0 & 179.7 & 32.2 & 1.3 & 31.5 \\
\hline 40.0 & 394 & 120.0 & 174.3 & 8.9 & 1.2 & 12.9 \\
\hline 27.0 & 380.44 & 120.0 & 170.7 & 44.8 & 0.8 & 60.5 \\
\hline 29.5 & 377.88 & 120.0 & 168.9 & 52.5 & 1.7 & 47.1 \\
\hline 36.0 & 368.48 & 120.0 & 171.8 & 51.8 & 0.8 & 48.3 \\
\hline 33.0 & 388.19 & 120.0 & 174.9 & 37.6 & 0.4 & 39.4 \\
\hline 31.0 & 380.53 & 480.0 & 179.5 & 59.9 & 0.9 & 57.6 \\
\hline 32.0 & 389.80 & 480.0 & 174.9 & 48.3 & 0.4 & 46.2 \\
\hline 33.0 & 372.50 & 480.0 & 180.4 & 61.9 & 0.1 & 62.0 \\
\hline 34.0 & 395.92 & 480.1 & 173.0 & 34.7 & 1.3 & 33.3 \\
\hline 23.0 & 389.29 & 120.0 & 182.4 & 32.6 & 1.2 & 35.4 \\
\hline
\end{tabular}




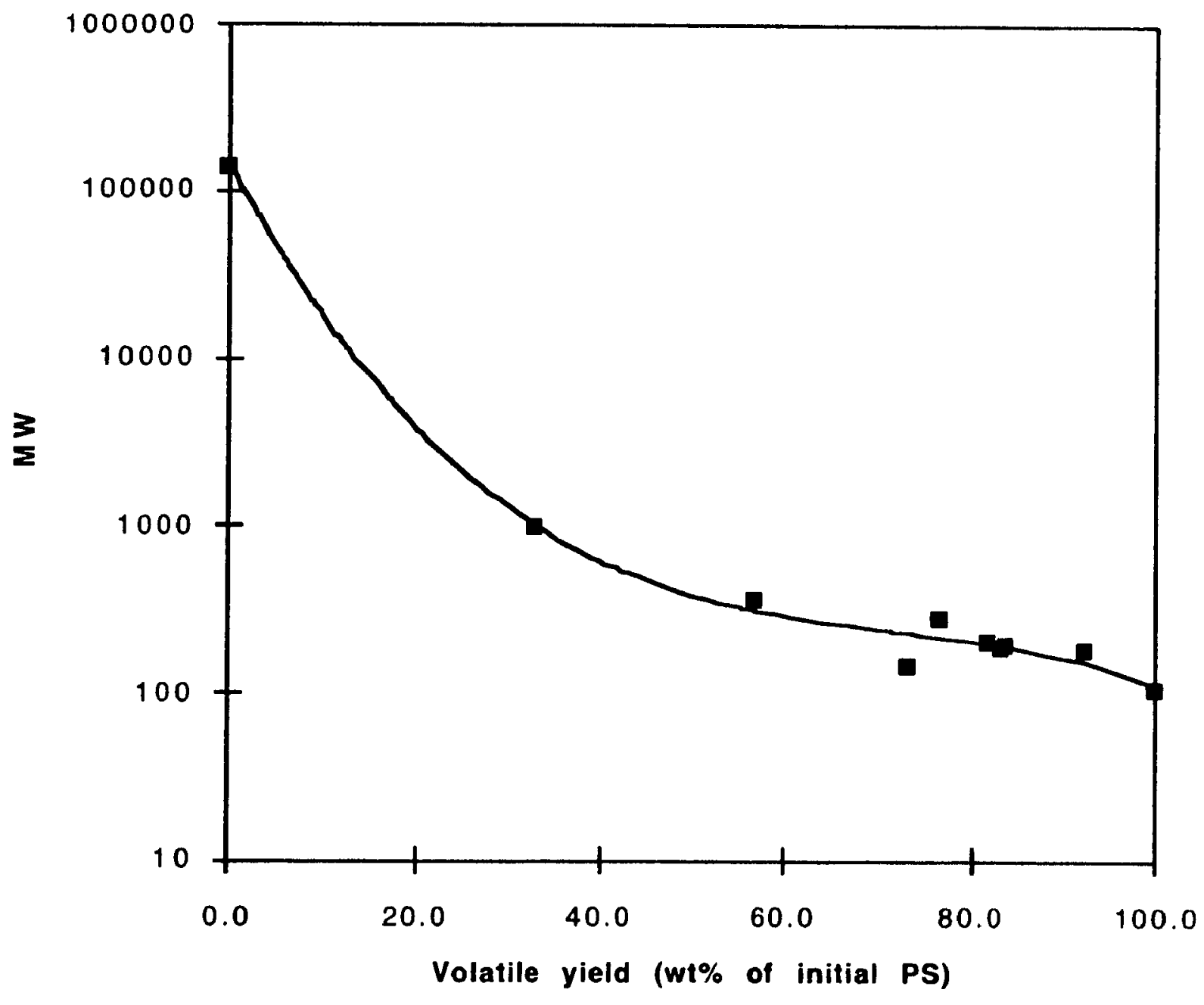

Figure 5.25, Cryoscopic molecular weight of residue as a function of volatile yield, measured, -- fitted. 


\section{DISCUSSION}

\subsection{Volatile Products}

Table 5.1 shows that the losses from the system were small. The magnitude of these losses seems to be independent of reaction charge, temperature and time, which implies that these losses are not due to the formation of non-condensible gases. These losses would be proportional to the reaction charge. These losses were due to reactor design, not all of the liquid could be recovered (e g. liquid stuck in glass tubing). Table 5.1 also shows that the experimental results were consistent and reproducible.

As expected, from previous work [22, 35, 42, 44, 46], the yield of the volatile product increased with both an increase in temperature (Figure 5.2) and with longer reaction time (Figure 5.1). The initial charge of polystyrene in the reactor did not have a significant effect on the yield of volatile products (Figure 5.2).

In order to compare the quantity of volatiles produced by thermolysis of polystyrene in the current work with results in the literature, the overall rate of volatile production as a function of temperature was used (Figure 6.1). In general, this work resulted in comparable or larger amounts of the volatile fraction per unit time. The rates obtained by Madorsky [44] appear to be higher, but they were limited to temperatures below $400^{\circ} \mathrm{C}$. Furthermore, the scale used in this work was many orders of magnitude larger because most of the literature data were based on experiments with thin films. Similar comparisons can be made if only the amount of recovered styrene is considered. The conversion rates obtained in this work are comparable or superior to values 
reported in previous work done on a smaller scale and at higher temperatures $\left(350-1200^{\circ} \mathrm{C}\right)[22,37,40,43-44,46]$.

Styrene yield appears to depend on reactor scale. This is due to the quality of the volatile product. Although overall yield is important, it is also essential to consider the quality of the condensate. In earlier studies, large amounts of dimer and trimer -- as high as $25 \%$ of each -- were obtained in a mixture with the styrene recovered in the condensed volatıle fraction $[22,30,37$, $40,44-47]$. In this work, the quality of the volatile (i.e. styrene concentration) is much better than any of the earlier reports (Figure 6.2) [22, 43-44, 46, 49]. This is true at all reaction temperatures and at all time throughout a reaction.

An obvious application for the recovered volatiles is polymerization to form polystyrene. In such a case, the dimers and trimers of styrene are useful products in the volatiles. The second largest component in the product was the dimer. If the styrene, dimer and trimer concentrations are added together, then the total would account for 85 to $95 \%$ (wt.\% of volatile) of the product (Figures 6.3 and 6.4). All this quantity is suitable for polymerisatıon.

It has been shown previously that the dimer is formed, in the reaction zone, by combination of the newly formed monomer units [34]. Therefore, a longer residence time should cause a decrease in the amount of monomer, because it is converted to dimer. This is consistent with the results in the present work. Although the cumulative concentration of styrene in the volatile product is high, there is a decrease in quality with reaction time (eg. Figure 5.3). After 35 minutes, the concentration of the side products and oligomers becomes appreciable (Figures 5.3, 5.4 and 5.5).

Figures 5.6 and 6.2 show that an increase in temperature $\left(368^{\circ} \mathrm{C}\right.$ to 
$395^{\circ} \mathrm{C}$ ) results in a significant decrease of styrene in the volatile product from $80 \%$ to $60 \%$. This decrease in styrene concentration can be explained by the relative volatilities of the various possible oligomers. When higher temperatures and/or reduced pressures are used, larger quantities of the larger, less volatile fragments are obtained in the volatile fraction. At the lower temperatures, in the current work, the less volatile dimer (Figure 5.6), trimer (Figure 5.7), etc., lend to remain in the reaction vessel and are converted to styrene monomer. Conversely, other volatile products from side reactions (i.e. toluene; $\alpha$ methylstyrene; ethylbenzene and 1,3-diphenylpropane) maintain stable concentrations over the temperature range studied (Figures 5.7, 5.8 and 5.9). They do not appear to be affected by oligomerization reactions after they are formed in the reaction vessel.

An important observation was, that although the amount of polystyrene in the initial charge did not affect the quantity of volatiles (Figure 5.2), it did affect the quality of the condensed volatile products (Figure 56 ). These results may be attributed to the higher evaporation rates in the case of the smaller charges. The net effect is that the styrene monomer produced in the reactor would experience a longer residence time in the larger reactor used in conjuction with the larger charges Thus, the formation of dimer and trimer is enhanced in the larger batches, and the quality of the condensed product is reduced. 


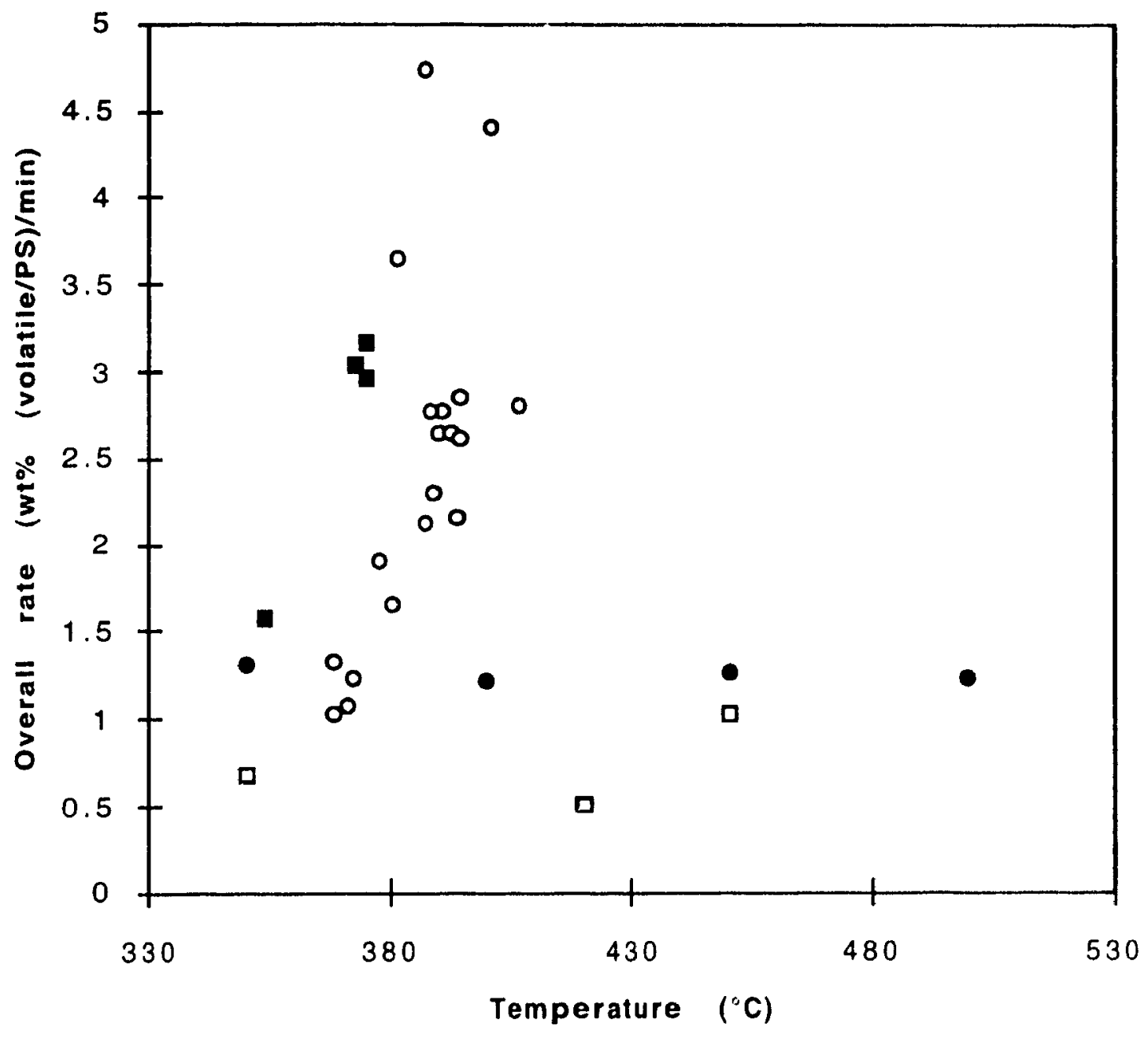

Figure 6.1, Overall rate of volatile production as a function of temperature from different sources:

Madorsky [44]; ב Ide et al [46]; O Ide et al [22]; $O$ this work. 


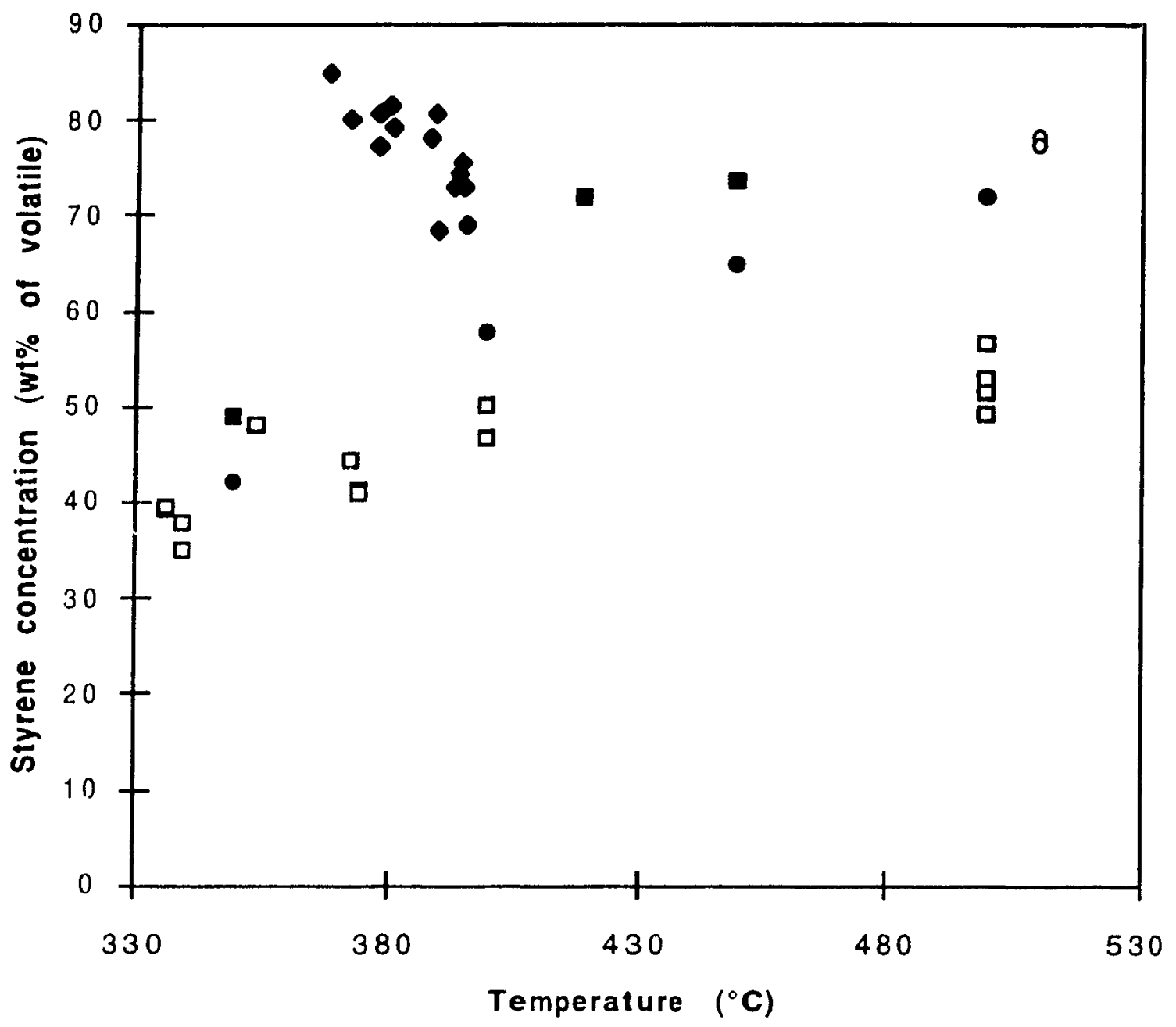

Figure 6.2, Styrene concentration as a function of temperature from different sources: $\square$ Ide et al. [46]; Jadorsky [44]; - Ide et al. [22]; O Ohtani et al. [49]; $\bullet$ this work. 


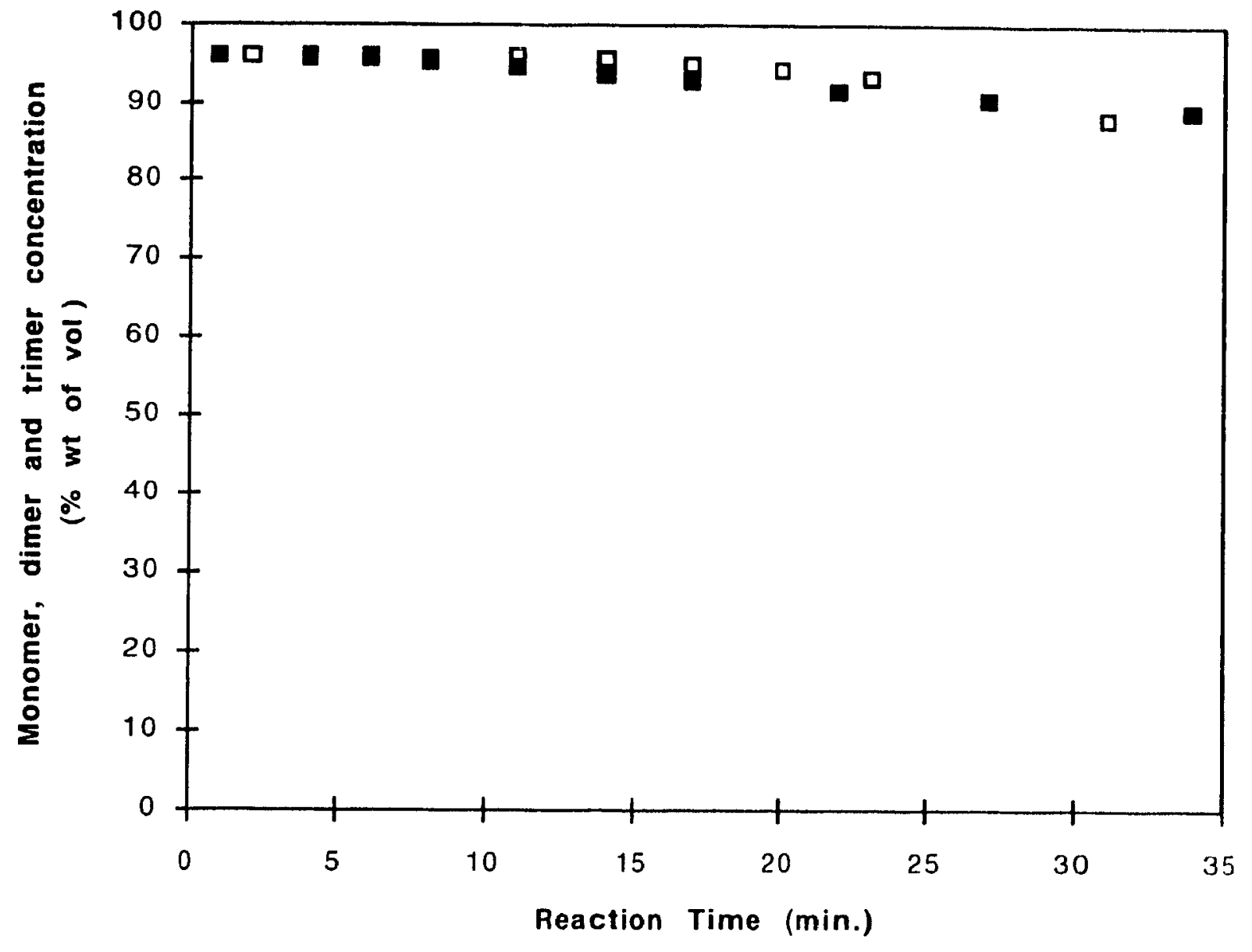

Figure 6.3, Summation of monomer, dimer and trimer concentration of styrene as a function of reaction time at different temperatures: $1395^{\circ} \mathrm{C}$ $381^{\circ} \mathrm{C}$. 


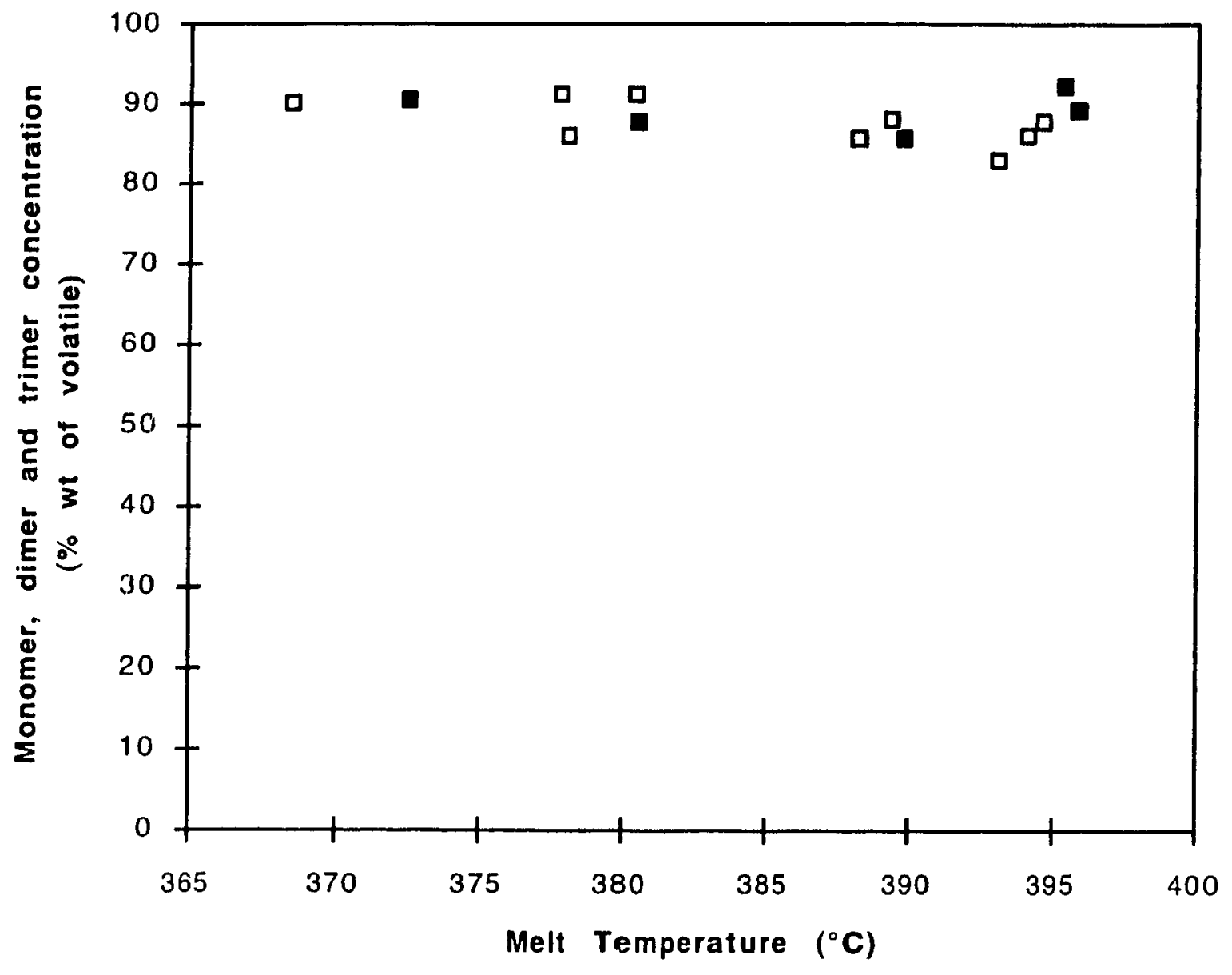

Figure 6.4, Summation of monomer, dimer and trimer concentration of styrene as a function of temperature with different initial charges: 120 grams; 480 grams. 


\subsection{Residue}

The data obtained regarding the residue fraction in this work compared very well with the results reported by other researchers $[22,35,42,44,46]$, as in the case of the volatile fraction.

The amount of residue left after treating polystyrene was small, since most of the product appeared in the volatile fraction. An increase in reaction temperature resulted in a decrease in the amount of residue (Figure 5.24). As indicated above, there was no significant variability of volatile yield with different initial charges. Consequently, the residue yield was also independent of inittal charge. Obviously, the amount of residue decreased with reaction time

Although the total amount of residue obtained was small, it is still relevant to consider its nature because a way to dispose of it and/or to reuse it has to be found.

Molecular weight is not usually determined using NMR data. Therefore, some justification and explanation of the use of this technique to determıne molecular weight is needed. ${ }^{1} \mathrm{H}$ NMR data have shown that most of the residue fraction consists of fragments of polystyrene Both the ratio of peaks attributable to terminal double conds relative to those attributable to aromatic rings and the ratio of methylene to aromatic peaks were related to the average length of residue chains. Equation (1) $(M W=104 / r)$ was develop using the terminal double bond data; where MW is the average molecular weight and $r$ is the ratio of termınal double bond to aromatıc ring peaks. Similarly, using the methylene proton data; Equation (2) (MW=104/(1-s)) was found, where $M W$ is the average molecular weight and $s$ is the ratio of methylene proton to aromatic ring peaks. 
The results from both methods were plotted in Figure 6.5 as a function of the total volatile yield, which is directly proportional to the extent of the reaction. The line in the figure represents the molecular weight measured by cryoscopy (from Figure 5.25). It can be seen that the ${ }^{1}$ H NMR data and the cryoscopic data are in reasonable agreement. Although, the cryoscopic measurement should be more reliable, it is a cumbersome measurement and very sensitive to impurities.

It is interesting that the cryoscopic data agree with the terminal double bonds to aromatic rings ratio data very well for the higher volatile yields (Figure 6.5). However, for the lower extents of reaction, the fit appears to be better with the data from the methylene to aromatic ratio (Figure 6.5).

The pattern of average molecular weight reduction obtained in this work is in good agreement with results reported by previous workers [22, 37, 40, 44-45]. The molecular weights decreased rapidly during the first $15-20 \%$ volatilization, followed by a more gradual decrease. However, the actual molecular weight reduction in this work was greater. The final molecular weight was only 180 in this work compared to 5000 by other workers $[22,37,40,44-45]$. The work of Ide ef al. [22] has shown that initiation of the depropagating chain reaction yielding monomer occurs both by random scission and at chain ends. Hence, the depolymerization reactions involve a combination of random scission and chain end scission. Therefore, the molecular weight decreases at the same tir te as monomer is being produced. Initially, the molecular weight decreases rapidly, but as the reaction proceeds, the decrease becomes more gradual because the production of unsaturated chain erids increases, and random scission becomes less important. 


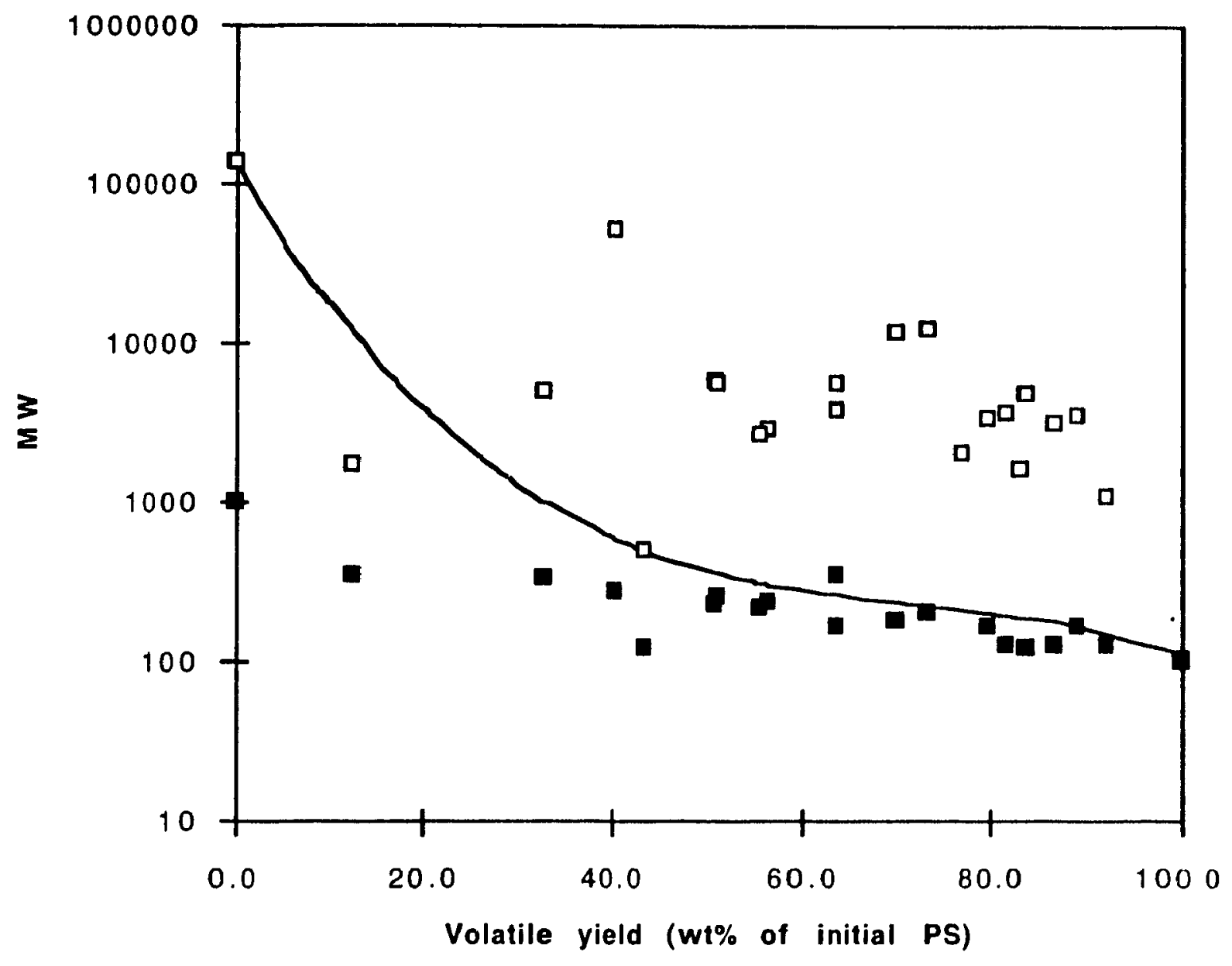

Figure 6.5, Average molecular weight of residue as a function of volatile yield: 1 calculated with terminal double bond / aromatic (Equation (1)); ' J calculated with methylene / aromatic (Equation (2));

-- measured by cryoscopy. 


\subsection{Kinetics}

Previous workers have employed zero and first order kinetics, as seen in Table 6.2, to describe the depolymerization kinetics of polystyrene. However, it was also shown that the model used did not affect the activation energy values that much [50]. Another approach was to assume that zero order was important at the beginning of the reaction and that first order was important later in the reaction. The beginning of the reaction is characterised by random scission where as $\beta$-scission predominant later in the reaction $[21,50]$. First order kinetics was used in this work because random scission was assumed to be negligible.

Figure 5.1 shows an example of volatile yield as a function of time for three reaction temperatures. These and all the other reaction data were found to fit first order kinetics. Examples of plots of $\ln (1-X)$ versus reaction time (where $X$ is the volatile yield) are shown in Figures 6.6 and 6.7. In most cases, there was evidence of a short initial anomaly which could be attributed to random scission or heatup effects. However, it is possible to ignore this early part for a first order kinetic treatement of the later data. It can be seen, that for most of the reaction time, there was an excellent fit to the first order model.

The slopes of the plots of $\ln (1-X)$ versus reaction time gave the rate constants $(k)$ for the different temperatures. The maximum slope was taken so to eliminate the heatup effect from the data treatment and to assure being in the $\beta$-scission region. The values of $k$ is reported in Table 6.1. The Arrhenius plot of In $k$ versus $1 / T$ is given in Figure 6.8, where $T$ is the absolute reaction temperature. A linear fit on all the points was done and the activation energy was found to be $166.5 \mathrm{~kJ} / \mathrm{mol}(R=0.896)$. 
The activation energy obtained in this work is comparable with previously reported values $[8,15,20,29,35,45,50-54]$ as shown in Table 6.2. Depolymerization of polystyrene activation energies varied between 138 and $243 \mathrm{~kJ} / \mathrm{mol}$. They show much variation because the values depend on a number of factors, such as, purity of initial polymer, method of preparation, molecular weight, heating rate, set up of the apparatus, conversion and mechanism applied to the polymer degradation and hence the method of treating the data.

The activation energy obtained in this work should be more reliable because of the larger initial charge used. Using a larger charge means that the volatile samples taken can be larger, therefore averaging out the concentration of each component. For the same reason it also means that the volatile products can be separated in more fractions as a function of time and still have large enough samples to be able to analyse them. 


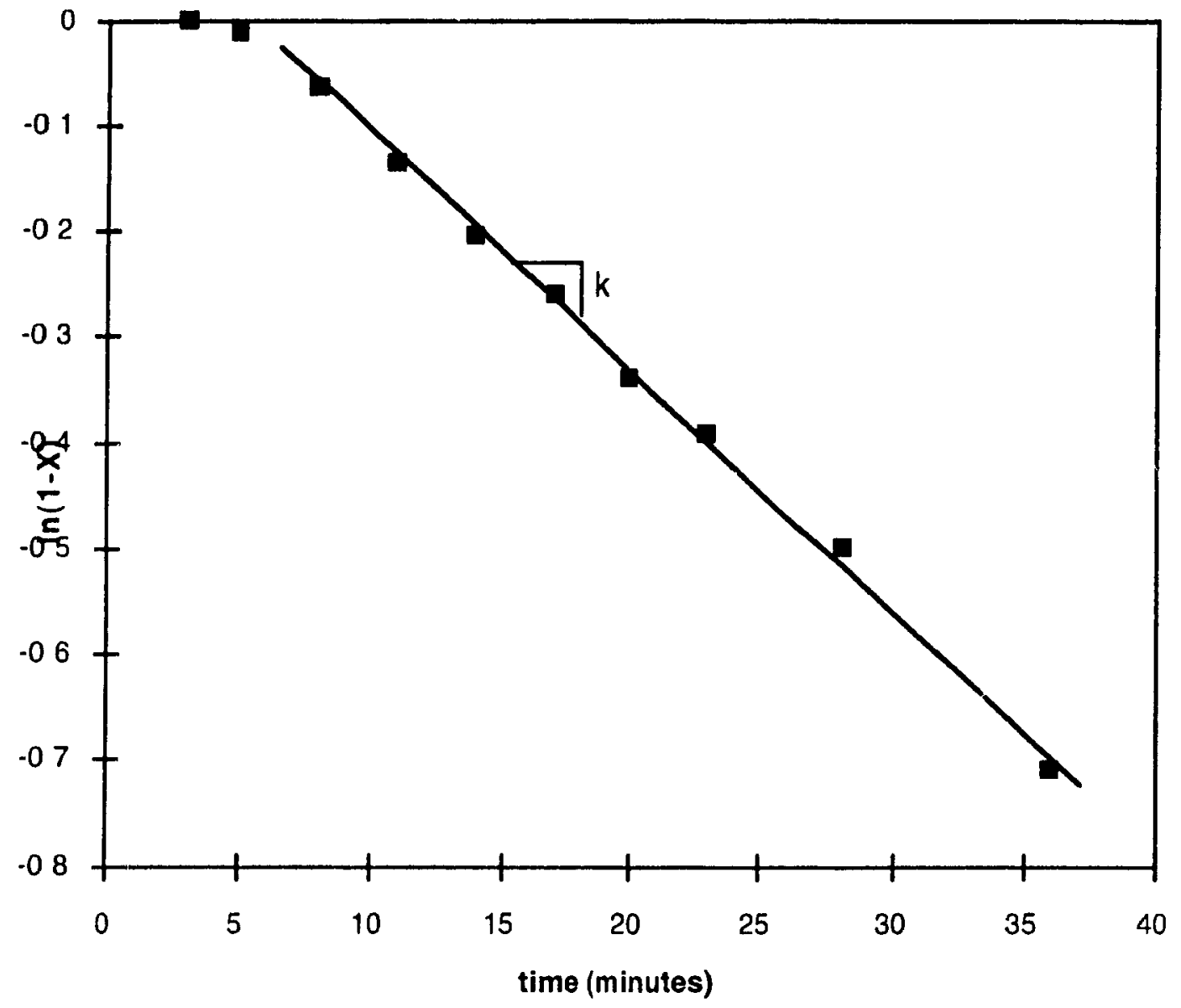

Figure 6.6, First order model, $\ln (1-X)$ versus reaction time, at $T=368^{\circ} \mathrm{C}$, initial charge of 120 grams. 


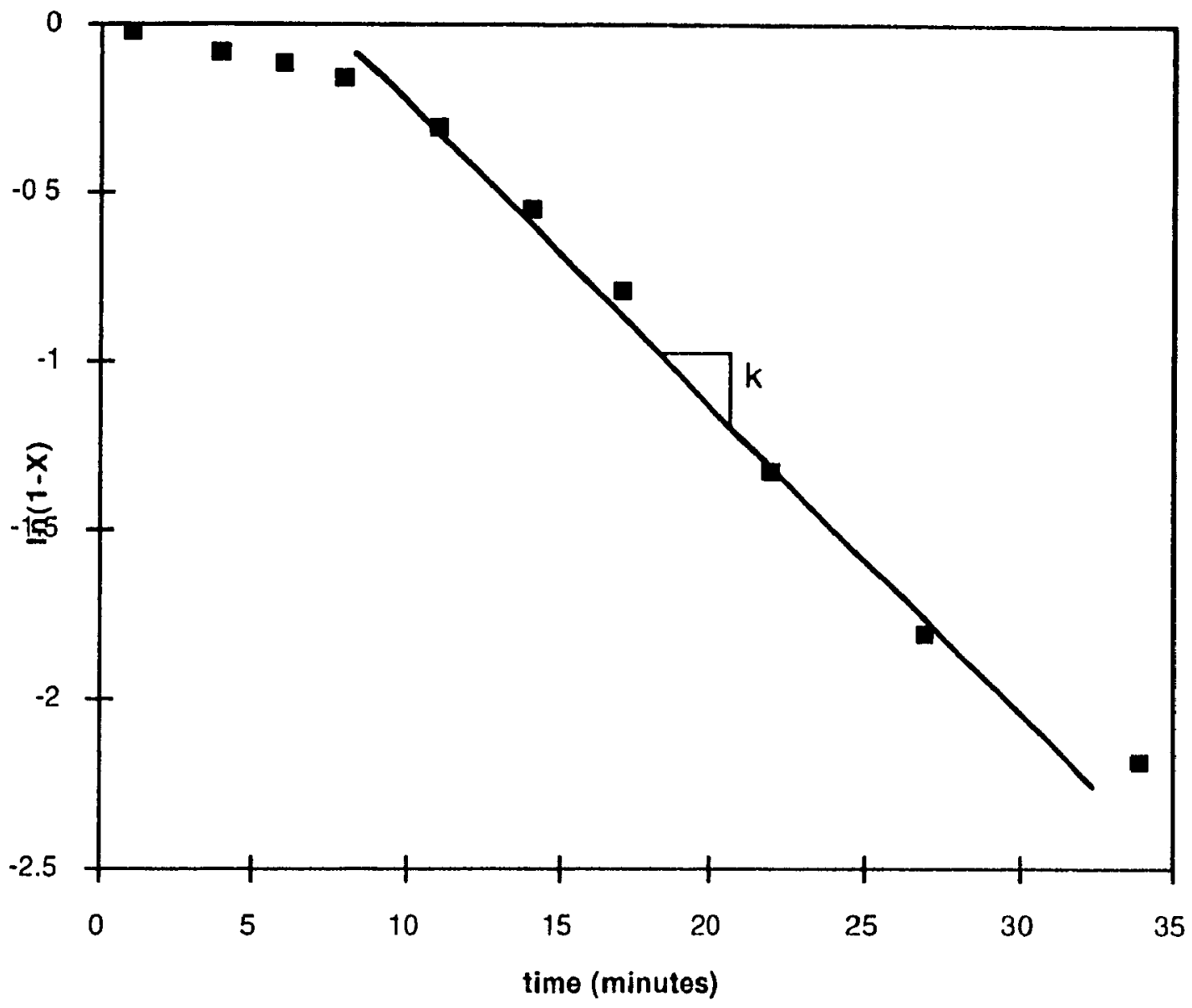

Figure 6.7, First order model, $\ln (1-X)$ versus reaction time, at $T=396^{\circ} \mathrm{C}$, initial charge of 480 grams. 
Table 6.1, Rate Constants for Experiments.

\begin{tabular}{|c|c|c|c|c|}
\hline Temp $\left({ }^{\circ} \mathrm{C}\right)$ & Charge (g) & k & $1 / T\left(K^{-1}\right)$ & $\ln k$ \\
\hline 368.5 & 120 & 0.0226 & 0.00156 & -3.79 \\
\hline 377.9 & 120 & 0.0476 & 0.00154 & -3.05 \\
\hline 380.4 & 120 & 0.0542 & 0.00153 & -2.92 \\
\hline 388.2 & 120 & 0.0424 & 0.00151 & -3.16 \\
\hline 389.3 & 120 & 0.0492 & 0.00151 & -3.01 \\
\hline .... 393 & 120 & 0.0609 & 0.00150 & -2.80 \\
\hline 394.1 & 120 & 00827 & 0.00150 & -2.49 \\
\hline 394.7 & 120 & 0.0629 & 000150 & -2.77 \\
\hline 395.9 & 480 & 00984 & 000150 & -2.32 \\
\hline 395.4 & 480 & 0.0982 & 000150 & -2.32 \\
\hline 389.8 & 480 & 0.0568 & 0.00151 & -2.87 \\
\hline 380.5 & 480 & 0.0365 & 0.00153 & -3.31 \\
\hline 372.5 & 480 & 0.10214 & 0.00155 & -3.85 \\
\hline
\end{tabular}




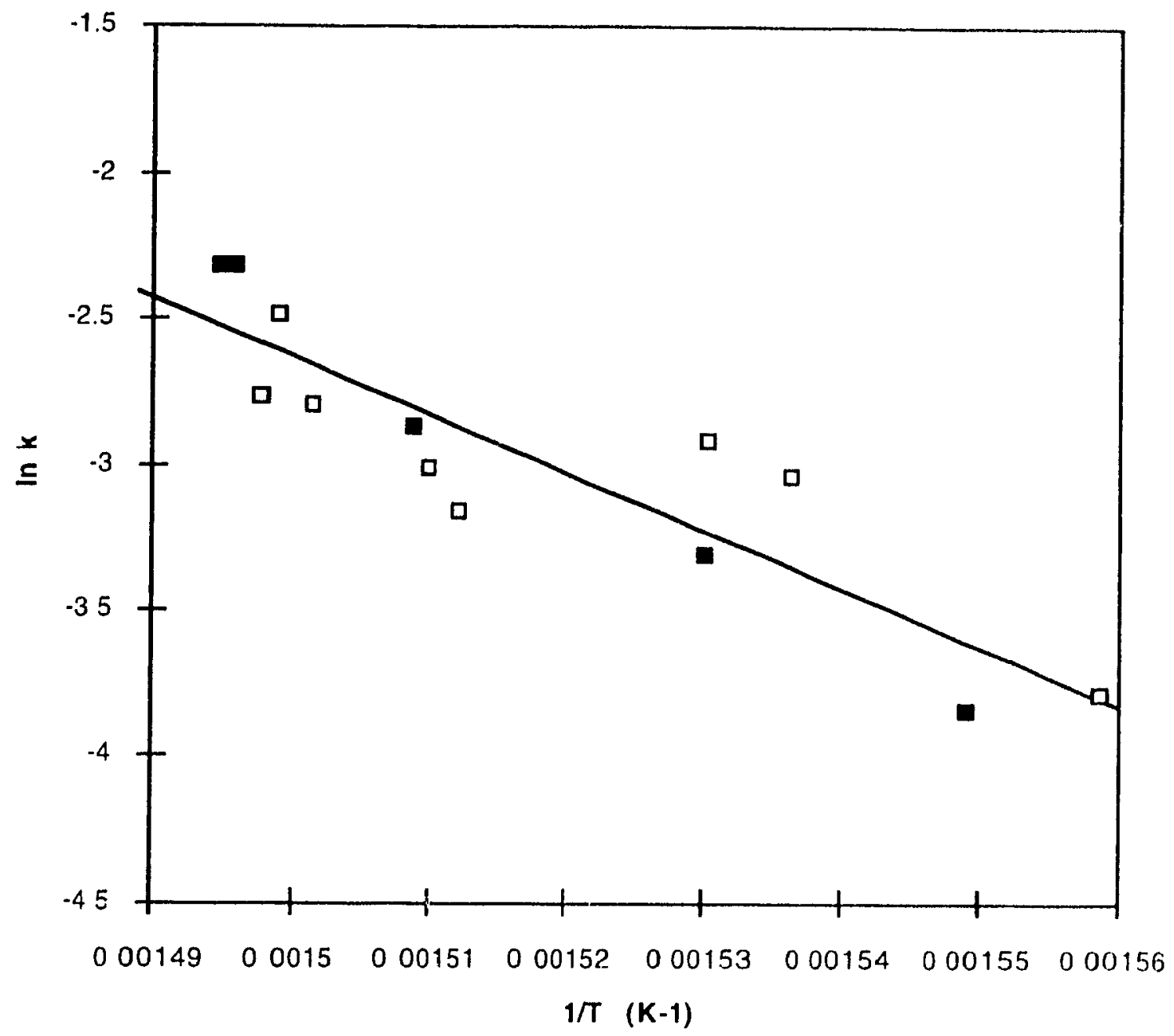

Figure 6.8, Arrhenius plot for volatile yield with melt temperatures and different charge: $\lrcorner 120$ grams; 480 grams. 
Table 6.2, Comparison of activation energies for polystyrene thermal degradation.

\begin{tabular}{|c|c|c|c|}
\hline Authors & Conditions & Charges & $\begin{array}{l}\text { Activation } \\
\text { Energles } \\
\text { (kJ/mol) }\end{array}$ \\
\hline Jellinek, 1949 [20] & $\begin{array}{l}348-398^{\circ} \mathrm{C} \\
\text { up to } 180 \mathrm{~min} \text {. } \\
\text { vacuum }\end{array}$ & $20 \mathrm{mg}$ & $\begin{array}{c}\text { munomer } \\
187 \\
\text { zero order }\end{array}$ \\
\hline $\begin{array}{l}\text { Madorsky, } 1952 \\
{[45]}\end{array}$ & $\begin{array}{l}335-365^{\circ} \mathrm{C} \\
\text { up to } 440 \mathrm{~min} \text {. } \\
\text { vacuum }\end{array}$ & $5-6 \mathrm{mg}$ & $\begin{array}{l}\text { weight iost } \\
226-243 \\
\text { zero order }\end{array}$ \\
\hline $\begin{array}{c}\text { Wall et al., } 1966 \\
{[52]}\end{array}$ & $\begin{array}{l}<350^{\circ} \mathrm{C} \\
\text { vacuum }\end{array}$ & $5-10 \mathrm{mg}$ & $\begin{array}{l}\text { weight lost } \\
205\end{array}$ \\
\hline $\begin{array}{l}\text { Richard and } \\
\text { Salter, } 1967 \text { [53] }\end{array}$ & $\begin{array}{l}260-290^{\circ} \mathrm{C} \\
\text { vacuum }\end{array}$ & $0.1 \mathrm{~g}$ & weight lost \\
\hline $\begin{array}{l}\text { Cameron and } \\
\text { Kerr, } 1968[8]\end{array}$ & $\begin{array}{l}280-320^{\circ} \mathrm{C} \\
\text { vacuum }\end{array}$ & $0.1 \mathrm{~g}$ & 205 \\
\hline $\begin{array}{c}\text { Kokia et al., } 1973 \\
{[51]}\end{array}$ & $\begin{array}{l}40^{\circ} \mathrm{C} / \mathrm{min} \\
\text { nitrogen }\end{array}$ & up to $3 \mathrm{mg}$ & $\begin{array}{c}\text { weight lost } \\
138-231 \\
\text { zero-first order }\end{array}$ \\
\hline $\begin{array}{c}\text { Dickens, } 1980 \\
{[50]}\end{array}$ & $\begin{array}{l}350-405^{\circ} \mathrm{C} \\
\text { nitrogen and } \\
\text { vacuum }\end{array}$ & up to $50 \mathrm{mg}$ & $\begin{array}{c}\text { weight lost } \\
188 \\
\text { order independent }\end{array}$ \\
\hline $\begin{array}{c}\text { Cameron et al., } \\
1984[15]\end{array}$ & $\begin{array}{l}280-300^{\circ} \mathrm{C} \\
\text { up to } 600 \mathrm{~min} . \\
\text { vacuum }\end{array}$ & Thin films & $\begin{array}{c}\text { molecular weight } \\
227-232 \\
\text { zero order }\end{array}$ \\
\hline $\begin{array}{c}\text { Carniti et al., } 1989 \\
{[54]}\end{array}$ & $\begin{array}{c}350-420^{\circ} \mathrm{C} \\
\text { up to } 8000 \mathrm{~min} \text {. } \\
\text { vacuum }\end{array}$ & $200 \mathrm{mg}$ & $\begin{array}{c}\text { free radical } \\
185 \\
\text { first order }\end{array}$ \\
\hline $\begin{array}{c}\text { Carniti et al., } 1991 \\
\text { [29] }\end{array}$ & $\begin{array}{l}360-420^{\circ} \mathrm{C} \\
\text { up to } 460 \mathrm{~min} \text {. } \\
\text { vacuum }\end{array}$ & $200 \mathrm{mg}$ & $\begin{array}{c}\text { weight losï } \\
195 \\
\text { first order }\end{array}$ \\
\hline Marc, 1992 [35] & $\begin{array}{l}330-410^{\circ} \mathrm{C} \\
\text { up to } 60 \mathrm{~min} \text {. } \\
\text { nitrogen }\end{array}$ & $3 \mathrm{~g}$ & $\begin{array}{c}\text { monomer } \\
181 \\
\text { fırst order }\end{array}$ \\
\hline This work & $\begin{array}{l}365-395^{\circ} \mathrm{C} \\
\text { up to } 40 \mathrm{~min} \text {. } \\
\text { nitrogen }\end{array}$ & $120-480 \mathrm{~g}$ & $\begin{array}{c}\text { volatile } \\
166.5 \\
\text { first order }\end{array}$ \\
\hline
\end{tabular}




\section{CONCLUSIONS}

The main conclusions of this investigation into the thermolysis of polystyrene are outlined below:

1. Under the condition empolyed in this study, polystyrene can be thermally treated in order to obtain styrene monomer, dimer, and trimer, as the main products.

2. Thermolysis was acheived using an initial charge which was several orders of magnitude larger than charges reported in the literature, but yielding comparable results.

3. High coriversions of polystyrene to styrene (up to $70 \%$ styrene yield) were obtained at moderate conditions $\left(368-395^{\circ} \mathrm{C}\right.$, nitrogen atmosphere).

4. The conditions used generated a better quality product than that reported for reactions at higher temperatures. The concentration of side products could be further reduced by using shorter reaclion times.

5. The maximum rate of thermolysis of polystyrene was found to fit a first order model. The activation energy obtained was $166.5 \mathrm{~kJ} / \mathrm{mol}$, which is in accordance with literature values.

6. A small amount of residue remained in the reactor, but it had a low molecular weight. 


\section{REFERENCES}

1. "Politique de gestion intégrée des déchets solides", Ministère de I'Environnement Quebec, 1989.

2. Facing America's Trash, Congress of the United States Office of Technology Assessment, Washington, D.C., 1989.

3. "Waste Solution", Modern Plastics, Supplement, April 1990.

4 Klemchuck, P. P., Polym. Degr. Stab., 27, 183-202,1990.

5. Chem.Eng.\& News, Dec.9, 1991, p.39.

6a. Encyclopedia of Polymer Science \& Engineering, vol.16, John Wiley \& Sons, Toronto, 1989, p1-5.

6b. Encyclopedia of Polymer Science \& Engineering, vol.16, John Wiley \& Sons, Toronto, 1989, pp.180-193.

7. Amos, J.L., Polym. Eng. Sci. ,14, 1, 1974.

8. Cameron, G.G and Kerr, G.P., Eur.Polym.J., 4, 709-717, 1968.

9. Guaita, M., Chiantore, O. and Costa, L., Polym.Deg.Stab., 12, 315, 1985.

10. McNeill, I.C., in Comprehensive Polymer Science, Pergamon Press, New York, 1989, pp.451-500.

11. Lehrle, R.S, Peakman, R.E., and Robb, J.C., Eur.Polym.J., 18, 517, 1982.

12. Cameron, G.G., Meyer, J.M. and McWalter, I.T., Macromolecules, 11, 4, 696, 1978.

13. Chiantore, O., Camino, G., Costa, L., and Grassie, N., Polym.Deg.Stab., 3, 209, 1981.

14. Cameron, G.G. and McIValter, I.T., Eur.Polym.J., 18, 1029, 1982.

15. Cameron, G.G., Bryce, W.A.J., and McWalter, I.T , Eur.Polym.J., 20, 563, 1984.

16. Grassie, N. and Kerr, W.W., Trans.Faraday Soc., 53, 234, 1957.

17. Grassie, N. and Kerr, W.W., Trans.Faraday Soc., 55, 1050, 1959.

18. Guyot, A., Polym.Deg̣.Stab., 15, 219, 1986.

19. Dean, L., Groves, S., Hancox, R., Lamb, G., and Lehrle, R.S., 
Polym.Deg.Stab., 25, 143, 1989.

20. Jellinek, H.H.G., J.Polym.Sci., 4, 13, 1949.

21. Malhotra, S.L., Hesse, J. and Blanchard, L.P., Polymer, 16, 81, 1975.

22. Ide. S., Ogawa, T., Kuroki, T. and Ikemura, T., J.Appl.Polym.Sci., 29, 2561, 1984.

23. Straus, S. a,d Madorsky, S.L., J.Research Nat'I Bur.Standards, 66A, 401, 1962.

24. Tokushige, H., Kosaki, A. and Sakai, T., Japan Steel Works, Ltd., 1974.

25. Sekiguchi,Y., Kuroki,T., Sawaguchi,T., and Ikemura,T., J.Chem.Soc.jpn., 1220, 1977.

26. Madorsky, S.L. and Straus, S., J.Research Nat'l Bur.Standards, 63A, 261, 1959.

27. Costa, L., Camino, G., Guyot, A., Clouet, G. and Brossas, J., Polym.Deg.Stab., 14, 85, 1986.

28. Scott, D.S., Czernik, S.R., Piskorz, J., and Radlein, D.St.A.G., Energy \& Fuels, 4, 407, 1990.

29. Carniti, P., Beltrame, P.L., Armada, M., Gervasini, A., and Audisio, G., Ind.Eng.Chem.Res., 30, 1624-1629, 1991.

30. Audisio, G., Bertini, F., Beltrame, P.L. and Carniti, P., Poly.Deg.Stab., 29, 191, 1990.

31. Ide, S., Ogawa, T., Kuroki, T. and Ikemura, T., Nenryo Kyokaishi, 63(3), 185194, 1984.

32. Uemichi, Y., Kashiwaya, Y., Ayama, A. and Kanoh, H., Chem.Lett., 1, 41, 1984.

33. Encyclopedia of Polymer Science \& Engineering, vol.4, John Wiley \& Sons, Toronto, 1986, p.735.

34. Ohtani, H., Yuyama, T., Tsuge, S., Plage, B. and Schulten, H.-R., Eur. Polym. J., 26, 8, 893-899, 1990.

35. Marc, K., Thermo-Chemical Recevery of Styrene from Polystyrene Waste. M.Eng. Thesis Paper, McGill University, 1992.

36. Costa, L., Camino, G., and Trossarelli, L., J. Anal. Appl. Pyr., 8, 15, 1985.

37. Madorsky, S.L. and Straus, S., J.Res.Nat.Bur.Stand. , 40, 417, 1948. 
38. Straus, S. and Madorsky, S.L., J. Res.Nat.Bur.Stand 4 50, 165, 1953.

39. Ide, S., Ogawa, T., Kuroki, T., and Ikemura, T., J. Appl. Polym. Sci., 27, 857, 1981.

40. Staudinger, H., Brunner, M., Frey, K., Garbsch, P., Singer, R., and Wherli, S., Ber._62B, 241, 1929; Ann. 468, 1, 1929.

41. Yamamoto, M., Suzuki, I., and Yamanaka, S., Nippon Kagaku Kaishi, 5, 802, 1976.

42. Lageraaeil, P.R., Thermal Degradation of Mixture of Polvethylene and Polvstyrene for Waste Value Recovery. M.Eng. Thesis Proposal, McGill University, 1992.

43. Lehmann, F.A. and Brauer, G.M., Anal.Chem., 33, 673, 1961.

44. Madorsky, S.L., Thermal Degradation of Organic Polymers, InterscienceWiley, New York, 1964.

45. Madorsky, S.L., J.Polym.Sci., 9, 133, 1952.

46. Ide, S., Nanbu, H., Kuroki, T. and Ikemura, T., J.Anal.Appl.Pyr., 6, 69, 1984.

47. McNeill, I.C., Zulficar, M., and Kousar, T., Polym.Deg.Stab., 28, 131, 1990.

48. Cowie, J.M.G., Polymers: Chemistry \& Physics of Modern materials. Chapman \& Hall, New York, $2^{\text {nd }}$ eds, 1991.

49. Ohtani, H., Tsuge, S., Matsushita, Y. and Nagasawa, M., Polym.J., 14, 6, 495-499, 1982.

50. Dickens, B., Polym Deg Stab., 2, 249-268, 1980.

51. Kokta, B.V., Valade, J.L. and Martin, W.N., J. Appl. Polym. Sci. 17, 1-19, 1973.

52. Wall, L.A., Straus, S., Flynn, J.H., Mclntyre, D. and Simha, R., J. Phys. Chem., 70, 1, 1966.

53. Richards, D.H. and Salter, D.A., Polymer, 8, 127-1.38, 1967.

54. Carnitı, P., Gervasini, A., and Beltrame, P.L., J.Polym.Sci., 27, 3865, 1989.

55. Cryette WR, Wide Range Cryoscope, MODEL \#5009, Instruction Manual. Precision Systems, Inc., Natick, 1990. 